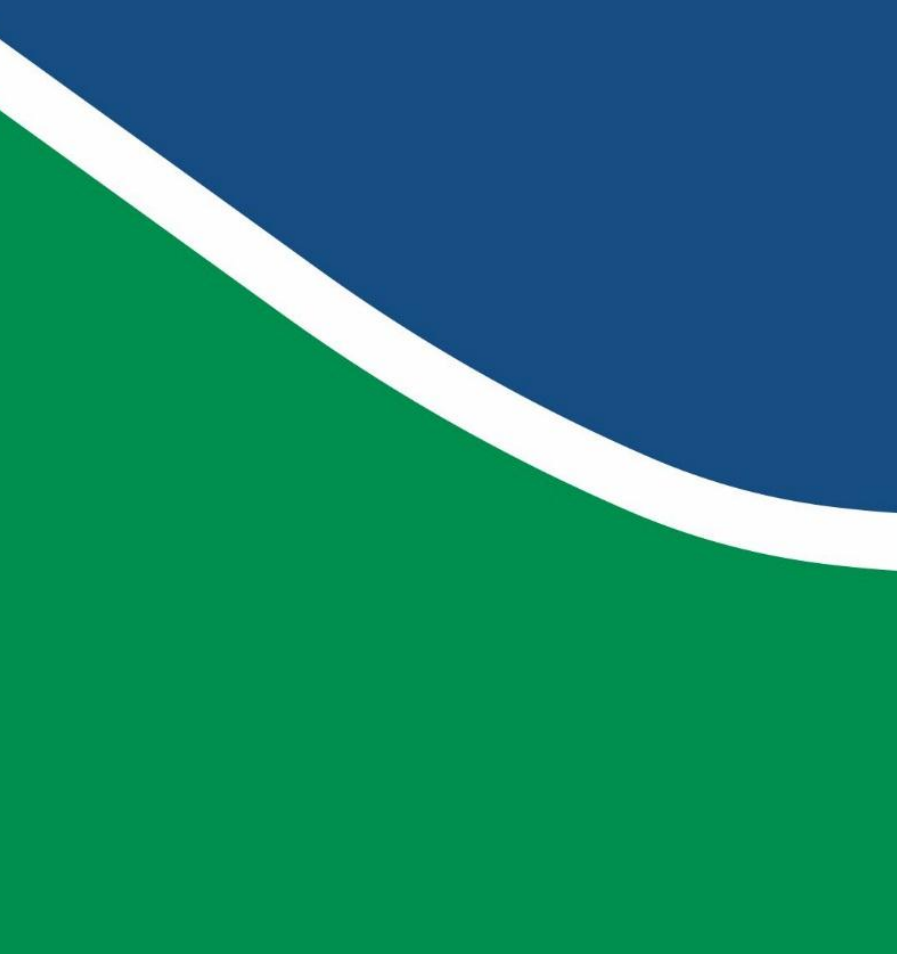

\title{
ANÁLISE DO DESEMPENHO DA PROTEÇÃO DIFERENCIAL APLICADA ÀS LINHAS DE TRANSMISSÃO DE ULTRA-ALTA TENSÃO
}

\author{
Raquel Schaeffer Batista Alves
}

DISSERTAÇÃO DE MESTRADO EM ENGENHARIA ELÉTRICA DEPARTAMENTO DE ENGENHARIA ELÉTRICA

FACULDADE DE TECNOLOGIA

UNIVERSIDADE DE BRASÍLIA 
UNIVERSIDADE DE BRASÍLIA

FACULDADE DE TECNOLOGIA

DEPARTAMENTO DE ENGENHARIA ELÉTRICA

\section{ANÁLISE DO DESEMPENHO DA PROTEÇÃO DIFERENCIAL APLICADA ÀS LINHAS DE TRANSMISSÃO DE ULTRA-ALTA TENSÃO}

RAQUEL SCHAEFFER BATISTA ALVES

ORIENTADOR: KLEBER MELO E SILVA

DISSERTAÇÃO DE MESTRADO EM ENGENHARIA ELÉTRICA

PUBLICAÇÃO: PPGEE.DM - 582/2014

BRASÍLIA/DF: DEZEMBRO - 2014 


\title{
UNIVERSIDADE DE BRASÍLIA \\ FACULDADE DE TECNOLOGIA \\ DEPARTAMENTO DE ENGENHARIA ELÉTRICA
}

\section{ANÁLISE DO DESEMPENHO DA PROTEÇÃO DIFERENCIAL APLICADA ÀS LINHAS DE TRANSMISSÃO DE ULTRA-ALTA TENSÃO}

\section{RAQUEL SCHAEFFER BATISTA}

\begin{abstract}
DISSERTAÇĀO DE MESTRADO SUBMETIDA AO DEPARTAMENTO DE ENGENHARIA ELÉTRICA DA FACULDADE DE TECNOLOGIA DA UNIVERSIDADE DE BRASÍLIA, COMO PARTE DOS REQUISITOS NECESSÁRIOS PARA A OBTENÇĀO DO GRAU DE MESTRE.
\end{abstract}

APROVADA POR:

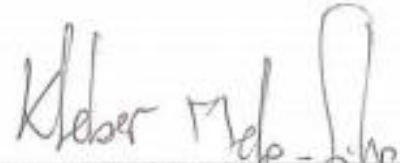

KLEBER MELO E SILVA, Dr., ENE/UNB (ORIENTADOR)

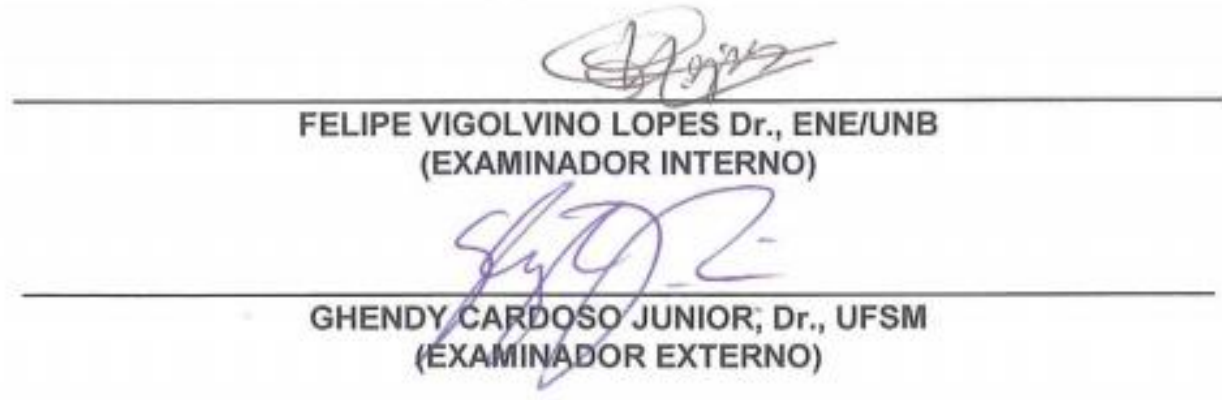




\section{FICHA CATALOGRÁFICA}

\begin{tabular}{|l|}
\hline ALVES, RAQUEL SCHAEFFER BATISTA \\
Análise do Desempenho da Proteção Diferencial Aplicada às Linhas de Transmissão de Ultra- \\
Alta Tensão [Distrito Federal] 2014. \\
xx, $81 p ., 210$ x 297 mm (ENE/FT/UnB, Mestre, Dissertação de Mestrado, 2014) \\
$\begin{array}{ll}\text { Universidade de Brasília. Faculdade de Tecnologia. Departamento de Engenharia Elétrica. } \\
\text { 1.Linhas de Transmissão } & \text { 2.Proteção Diferencial Percentual } \\
\text { 3.Corrente Capacitiva } & \text { 4.ATP } \\
\text { I. ENE/FT/UnB } & \text { II. Título (série) }\end{array}$
\end{tabular}

\section{REFERÊNCIA BIBLIOGRÁFICA}

ALVES, R. S. B. (2014). Análise do Desempenho da Proteção Diferencial Aplicada às Linhas de Transmissão de Ultra-Alta Tensão. Dissertação de Mestrado em Engenharia Elétrica, Publicação PPGEE.DM-582/2014, Departamento de Engenharia Elétrica, Universidade de Brasília, Brasília, DF, 81p.

\section{CESSÃO DE DIREITOS}

AUTOR: Raquel Schaeffer Batista Alves.

TÍTULO: Análise do Desempenho da Proteção Diferencial Aplicada às Linhas de Transmissão de Ultra-Alta Tensão.

GRAU: Mestre ANO: 2014

É concedida à Universidade de Brasília permissão para reproduzir cópias desta dissertação de mestrado e para emprestar ou vender tais cópias somente com propósitos acadêmicos e científicos. O autor reserva outros direitos de publicação e nenhuma parte desta dissertação de mestrado pode ser reproduzida sem autorização por escrito da autora.

Raquel Schaeffer Batista Alves

Universidade de Brasília-UnB

Campus Darcy Ribeiro

Faculdade de Tecnologia - FT

Departamento de Engenharia Elétrica

Brasília - DF

CEP: 70910-900 
Aos meus pais, Adílio e Sandra, ao meu irmão Henrique e ao meu esposo Fábio Ronan, DEDICO. 


\section{AGRADECIMENTOS}

Primeiramente a Deus e a Nossa Senhora Aparecida que me orientam e me guiam, abrindo todas as portas, possibilitando assim mais essa grande conquista.

À minha família, pelo apoio que sempre me foi dado. Aos meus pais, pela criação, pelo amor incondicional, pela formação do meu caráter, sendo os principais responsáveis por quem hoje sou. Ao meu irmão, pelo exemplo de profissionalismo que sempre procuro seguir. Ao meu esposo, que me incentivou, apoiou e compreendeu todos os esforços que tiveram de ser realizados, para que este objetivo fosse concluído.

Ao meu orientador, Professor Dr. Kleber Melo e Silva, pela confiança em mim depositada, pela amizade e pela orientação, não restrita somente à vida acadêmica e profissional, se expandindo também a minha vida pessoal.

Aos professores do Departamento de Engenharia Elétrica, pela disposição em transmitir os conhecimentos necessários desde o meu ingresso na graduação.

Aos amigos e colegas do LAPSE (Laboratório de Proteção de Sistemas Elétricos), por todos os momentos vividos entre estudos e confraternizações desde o início desta jornada.

Ao amigo Edgar Molas, pelo trabalho conjunto de muitos anos, pelo apoio e, principalmente, pela amizade.

Aos colegas de trabalho do ONS, pelo incentivo e apoio para a conclusão deste trabalho. 


\section{RESUMO}

Tradicionalmente, a proteção diferencial de linhas de transmissão não considera em sua formulação o efeito da corrente capacitiva da linha. Consequentemente, surge uma falsa corrente diferencial, que, quando não tratada adequadamente, pode causar a atuação indevida da proteção diferencial. Esse efeito torna-se mais preponderante à medida que o comprimento e o nível de tensão de operação da linha aumentam. Assim, para que a confiabilidade do sistema de proteção não seja afetada, deve-se compensar o efeito da corrente capacitiva. Nesse contexto, o presente trabalho tem como objetivo realizar a análise da proteção diferencial aplicada às linhas de transmissão de ultra-alta tensão (UAT), por meio da implementação de alguns algoritmos propostos na literatura para resolução da problemática do efeito da corrente capacitiva na atuação da proteção. Para tanto, um sistema de potência composto por uma LT de $1000 \mathrm{kV}$ em circuito duplo e equivalentes de Thévenin em seus terminais, é representado no software Alternative Transients Program (ATP). Esse sistema teste corresponde a uma linha de transmissão em operação no sistema elétrico interligado da China, interconectando os seus subsistemas Norte e Sul. Os desempenhos dos algoritmos implementados foram comparados mediante a análise de suas respostas transitórias para alguns casos específicos de curto-circuito e energização da linha, bem como em regime permanente de curto-circuito, por meio da análise da resposta dos algoritmos frente à variação de parâmetros como carregamento da linha, potência de curto-circuito das fontes e a localização, o tipo e a resistência de falta. A partir das constatações apresentadas neste trabalho, pode-se concluir que a proteção diferencial tal qual tem sido proposta poderá ser utilizada em linhas de transmissão de UAT, sendo capaz inclusive de eliminar adequadamente o efeito da corrente capacitiva da linha, sendo o Método das Capacitâncias Concentradas o qual se mostrou mais eficiente e estável.

PALAVRAS-CHAVE: ultra-alta tensão, linha de transmissão, proteção diferencial, corrente capacitiva. 


\section{ABSTRACT}

Traditionally, line differential protection of transmission lines does not accounts for the charging current effect in its formulation. Consequently, a false differential current appears, which may cause relay malfunction when not treated properly. This effect becomes more significant as the length and the voltage rate of the line increase, thereby jeopardizing the security and reliability of the protection scheme. To prevent harmful effects, the charging current effect should be compensated. In this regard, this study aims to conduct analysis of differential protection applied to transmission lines of ultra-high voltage (UHT), through the implementation of algorithms proposed in the literature for addressing the problem of the effect of capacitive current in action protection. Thus, a power system composed of a $1000 \mathrm{kV}$ double circuit transmission line with Thevenin equivalents at its terminals is represented in the software Alternative Transients Program (ATP). This test system simulates a transmission line operating in China interconnected power system, interconnecting its northern and southern subsystems. The performances of the implemented algorithms were compared by the analysis of their transient responses for fault and energization line cases, as well steady-state of fault, through the analysis of the algorithm response to the variation of parameters such as loading line, the short-circuit power sources and the location, type and resistance of the short circuit. From the findings presented in this paper, we can conclude that the differential protection has been proposed as such can be used in UHT transmission lines, including being able to adequately remove the effect of the capacitive current of the line and the method of capacitances Concentrated which is more efficient and stable.

INDEX TERMS: ultra-high voltage, transmission line, differential protection, charging current. 


\section{SUMÁRIO}

INTRODUÇÃO

1.1. CONTEXTUALIZAÇÃO DO TEMA

1.2. MOTIVAÇÃO 2

1.3. OBJETIVO 3

1.4. ORGANIZAÇÃO DO TEXTO 3

REVISÃO BIBLIOGRÁFICA 5

FUNDAMENTOS DA PROTEÇÃO DIFERENCIAL

3.1. PROTEÇÃO DIFERENCIAL NÃO PERCENTUAL 13

3.2. PROTEÇÃO DIFERENCIAL PERCENTUAL 15

3.3. PROTEÇÃO DIFERENCIAL EM LINHAS DE TRANSMISSÃO 18

3.3.1. Atrasos no Sistema de Comunicação 19

3.3.2. Efeito da Corrente Capacitiva 21

ALGORITMOS AVALIADOS 23

4.1. MODELO DE CAPACITÂNCIAS CONCENTRADAS 23

4.2. MÉTODO DA MEMÓRIA DE CORRENTE CAPACITIVA 25

4.3. PROTEÇÃO DIFERENCIAL UTILIZANDO EQUAÇÕES DE REGIME PERMANENTE DO MODELO $\Pi$ EQUIVALENTE DA LINHA DE TRANSMISSÃO

4.4. PROTEÇÃO DIFERENCIAL BASEADA NO MODELO DE BERGERON DA LINHA DE TRANSMISSÃO 27

APRESENTAÇÃO E ANÁLISE DOS RESULTADOS

5.1. O SISTEMA ELÉTRICO SIMULADO 31

5.2. ANÁLISE DA RESPOSTA TRANSITÓRIA DA PROTEÇÃO DIFERENCIAL

5.2.1. Sistema com falta monofásica 34

5.2.2. Falta monofásica externa a montante do terminal local 36

5.2.3. Energização do circuito 1

5.2.4. Energização do circuito 1 sob falta 41

5.3. ANÁLISES DE SENSIBILIDADE PARAMÉTRICA 43

5.3.1. Variação da Localização da Falta 43

5.3.2. Variação da Resistência de Falta

5.3.3. Variação do Carregamento do Sistema

5.3.4. Variação da Força da Fonte Local 60

5.3.5. Variação da Força da Fonte Remota 64

CONCLUSÕES E PROPOSTAS PARA TRABALHOS FUTUROS

REFERÊNCIAS BIBLIOGRÁFICAS

ENTRADA DA ROTINA LINE CONSTANTS DO ATP

$\begin{array}{ll}\text { ARQUIVO ATP } & 78\end{array}$ 


\section{LISTA DE FIGURAS}

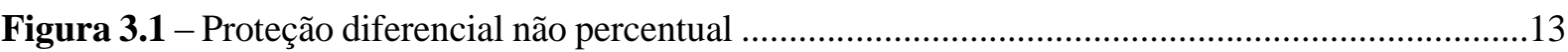

Figura 3.2 - Plano operacional do relé diferencial percentual com sua curva característica ...............16

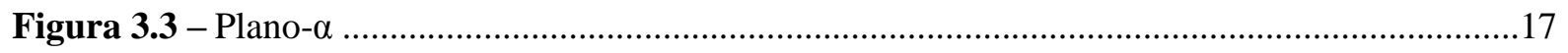

Figura 3.4 - Zonas de restrição do Plano- $\alpha$ (MOLAS, 2012 - com adaptações) ..................................18

Figura 3.5 - Esquema da proteção diferencial aplicada a linhas de transmissão (MOLAS, 2012) ......19

Figura 3.6 - Defasagem decorrente do atraso do canal de comunicação (MUNHOZ, 2011) ..............20

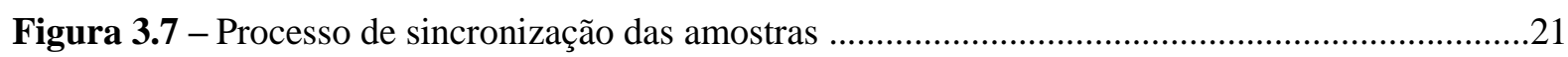

Figura 3.8 - Capacitâncias distribuídas da linha de transmissão .........................................................21

Figura 4.1 - Modelo de capacitâncias concentradas da linha ..............................................................24

Figura 4.2 - Correntes do método de proteção diferencial baseado no Modelo $\pi$ Equivalente da linha de transmissão

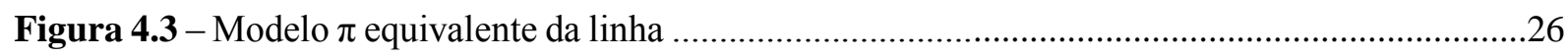

Figura 4.4 - Modelagem das perdas dividindo a linha de transmissão em duas partes iguais .27

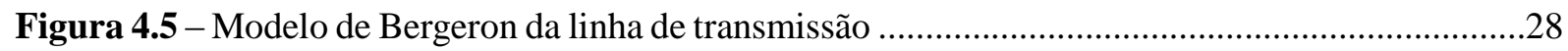

Figura 4.6 - Correntes do método de proteção diferencial baseado no modelo de Bergeron da linha ...30

Figura 5.1 - Geometria da torre de transmissão - unidades em metros (LI et al., 2012) ..........................32

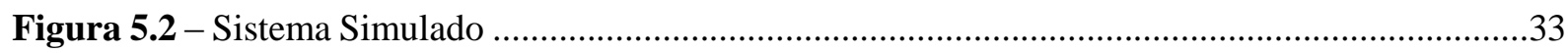

Figura 5.3 - Resposta transitória para falta monofásica na metade do circuito 1: Correntes sem compensação

Figura 5.4 - Resposta transitória para falta monofásica na metade do circuito 1: Método das Capacitâncias Concentradas .35

Figura 5.5 - Resposta transitória para falta monofásica na metade do circuito 1: Método da Memória de Corrente Capacitiva .35 
Figura 5.6 - Resposta transitória para falta monofásica na metade do circuito 1: Modelo $\pi$ Equivalente da linha .36

Figura 5.7 - Resposta transitória para falta monofásica na metade do circuito 1: Modelo de Bergeron da linha

Figura 5.8 - Resposta transitória para falta monofásica externa: Correntes sem compensação

Figura 5.9 - Resposta transitória para falta monofásica externa: Método das Capacitâncias Concentradas 37

Figura 5.10 - Resposta transitória para falta monofásica externa: Método da Memória de Corrente Capacitiva

Figura 5.11 - Resposta transitória para falta monofásica externa: Modelo $\pi$ Equivalente da linha .........38

Figura 5.12 - Resposta transitória para falta monofásica externa: Modelo de Bergeron da linha ............38

Figura 5.13 - Resposta transitória para energização do circuito 1: Correntes sem compensação .39

Figura 5.14 - Resposta transitória para energização do circuito 1: Método das Capacitâncias Concentradas

Figura 5.15 - Resposta transitória para energização do circuito 1: Método da Memória de Corrente Capacitiva .39

Figura 5.16 - Resposta transitória para energização do circuito 1: Modelo $\pi$ Equivalente da linha .40

Figura 5.17 - Resposta transitória para energização do circuito 1: Modelo de Bergeron da linha .40

Figura 5.18 - Resposta transitória para energização do circuito 1 sob falta: Correntes sem compensação

Figura 5.19 - Resposta transitória para energização do circuito 1 sob falta: Método das Capacitâncias Concentradas

Figura 5.20 - Resposta transitória para energização do circuito 1 sob falta: Método da Memória de Corrente Capacitiva .

Figura 5.21 - Resposta transitória para energização do circuito 1 sob falta: Modelo $\pi$ Equivalente da linha .42

Figura 5.22 - Resposta transitória para energização do circuito 1 sob falta: Modelo de Bergeron da linha 42 
Figura 5.23 - Falta monofásica no circuito 1 com variação da localização: Correntes Sem Compensação .44

Figura 5.24 - Falta monofásica no circuito 1 com variação da localização: Método das Capacitâncias Concentradas

Figura 5.25 - Falta monofásica no circuito 1 com variação da localização: Método da Memória de Corrente Capacitiva .45

Figura 5.26 - Falta monofásica no circuito 1 com variação da localização: Modelo $\pi$ Equivalente da linha

Figura 5.27 - Falta monofásica no circuito 1 com variação da localização: Modelo de Bergeron da linha .46

Figura 5.28 - Falta bifásica no circuito 1 com variação da localização: Correntes sem compensação

Figura 5.29 - Falta bifásica no circuito 1 com variação da localização: Método das Capacitâncias Concentradas

Figura 5.30 - Falta bifásica no circuito 1 com variação da localização: Método da Memória de Corrente Capacitiva

Figura 5.31 - Falta bifásica no circuito 1 com variação da localização: Modelo $\pi$ Equivalente da linha

Figura 5.32 - Falta bifásica no circuito 1 com variação da localização: Modelo de Bergeron da linha .48

Figura 5.33 - Falta monofásica no circuito 1 com variação da resistência de falta: Correntes sem compensação

Figura 5.34 - Falta monofásica no circuito 1 com variação da resistência de falta: Método das Capacitâncias Concentradas

Figura 5.35 - Falta monofásica no circuito 1 com variação da resistência de falta: Método da Memória de Corrente Capacitiva

Figura 5.36 - Falta monofásica no circuito 1 com variação da resistência de falta: Modelo $\pi$ Equivalente da linha .50

Figura 5.37 - Falta monofásica no circuito 1 com variação da resistência de falta: Modelo de Bergeron da linha .50 
Figura 5.38 - Falta bifásico-terra no circuito 1 com variação da resistência de falta: Correntes sem compensação

Figura 5.39 - Falta bifásico-terra no circuito 1 com variação da resistência de falta: Método das Capacitâncias Concentradas

Figura 5.40 - Falta bifásico-terra no circuito 1 com variação da resistência de falta: Método da Memória de Corrente Capacitiva .51

Figura 5.41 - Falta bifásico-terra no circuito 1 com variação da resistência de falta: Modelo $\pi$ Equivalente da linha

Figura 5.42 - Falta bifásico-terra no circuito 1 com variação da resistência de falta: Modelo de Bergeron da linha .52

Figura 5.43 - Falta monofásica no circuito 1 com variação do carregamento do sistema: Correntes sem compensação

Figura 5.44 - Falta monofásica no circuito 1 com variação do carregamento do sistema: Método das Capacitâncias Concentradas .54

Figura 5.45 - Falta monofásica no circuito 1 com variação do carregamento do sistema: Método da Memória de Corrente Capacitiva .54

Figura 5.46 - Falta monofásica no circuito 1 com variação do carregamento do sistema: Modelo $\pi$ Equivalente da linha

Figura 5.47 - Falta monofásica no circuito 1 com variação do carregamento do sistema: Modelo de Bergeron da linha .55

Figura 5.48 - Falta bifásica no circuito 1 com variação do carregamento do sistema: Correntes sem compensação .55

Figura 5.49 - Falta bifásica no circuito 1 com variação do carregamento do sistema: Método das Capacitâncias Concentradas .56

Figura 5.50 - Falta bifásica no circuito 1 com variação do carregamento do sistema: Método da Memória de Corrente Capacitiva .56

Figura 5.51 - Falta bifásica no circuito 1 com variação do carregamento do sistema: Modelo $\pi$ Equivalente da linha .56

Figura 5.52 - Falta bifásica no circuito 1 com variação do carregamento do sistema: Modelo de Bergeron da linha .57 
Figura 5.53 - Falta bifásico-terra no circuito 1 com variação do carregamento do sistema: Correntes sem compensação

Figura 5.54 - Falta bifásico-terra no circuito 1 com variação do carregamento do sistema: Método das Capacitâncias Concentradas .58

Figura 5.55 - Falta bifásico-terra no circuito 1 com variação do carregamento do sistema: Método da Memória de Corrente Capacitiva .58

Figura 5.56 - Falta bifásico-terra no circuito 1 com variação do carregamento do sistema: Modelo $\pi$ Equivalente da linha .58

Figura 5.57 - Falta bifásico-terra no circuito 1 com variação do carregamento do sistema: Modelo de Bergeron da linha

Figura 5.58 - Falta monofásica no circuito 1 com variação da força da fonte local: Correntes sem compensação

Figura 5.59 - Falta monofásica no circuito 1 com variação da força da fonte local: Método das Capacitâncias Concentradas

Figura 5.60 - Falta monofásica no circuito 1 com variação da força da fonte local: Método da Memória de Corrente Capacitiva

Figura 5.61 - Falta monofásica no circuito 1 com variação da força da fonte local: Modelo $\pi$ Equivalente da linha

Figura 5.62 - Falta monofásica no circuito 1 com variação da força da fonte local: Modelo de Bergeron da linha .61

Figura 5.63 - Falta bifásica no circuito 1 com variação da força da fonte local: Correntes sem compensação

Figura 5.64 - Falta bifásica no circuito 1 com variação da força da fonte local: Método das Capacitâncias Concentradas

Figura 5.65 - Falta bifásica no circuito 1 com variação da força da fonte local: Método da Memória de Corrente Capacitiva

Figura 5.66 - Falta bifásica no circuito 1 com variação da força da fonte local: Modelo $\pi$ Equivalente da linha

Figura 5.67 - Falta bifásica no circuito 1 com variação da força da fonte local: Modelo de Bergeron da linha 
Figura 5.68 - Falta monofásica no circuito 1 com variação da força da fonte remota: Correntes sem compensação

Figura 5.69 - Falta monofásica no circuito 1 com variação da força da fonte remota: Método das Capacitâncias Concentradas

Figura 5.70 - Falta monofásica no circuito 1 com variação da força da fonte remota: Método da Memória de Corrente Capacitiva .65

Figura 5.71 - Falta monofásica no circuito 1 com variação da força da fonte remota: Modelo $\pi$ Equivalente da linha

Figura 5.72 - Falta monofásica no circuito 1 com variação da força da fonte remota: Modelo de Bergeron da linha .65

Figura 5.73 - Falta bifásica no circuito 1 com variação da força da fonte remota: Correntes sem compensação . .66

Figura 5.74 - Falta bifásica no circuito 1 com variação da força da fonte remota: Método das Capacitâncias Concentradas .66

Figura 5.75 - Falta bifásica no circuito 1 com variação da força da fonte remota: Método da Memória de Corrente Capacitiva

Figura 5.76 - Falta bifásica no circuito 1 com variação da força da fonte remota: Modelo $\pi$ Equivalente da linha

Figura 5.77 - Falta bifásica no circuito 1 com variação da força da fonte remota: Modelo de Bergeron da linha .67 


\section{LISTA DE TABELAS}

Tabela 1.1 - Desligamentos Forçados no SIN no ano de 2012 (ONS, 2013) ...........................................02

Tabela 5.1 - Parâmetros da Linha de Transmissão....................................................................................32

Tabela 5.2 - Dados das impedâncias dos equivalentes de Thévenin .....................................................33

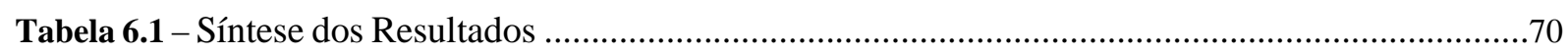




\section{LISTA DE QUADROS}

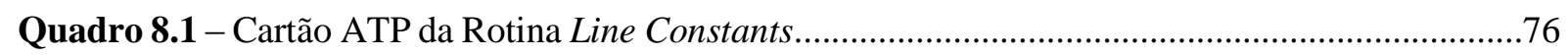

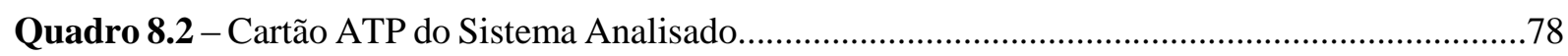




\section{LISTA DE SÍMBOLOS}

\begin{tabular}{|c|c|}
\hline$I_{o p}$ & Corrente de Operação \\
\hline$I_{\text {diff }}$ & Corrente Diferencial \\
\hline $\bar{I}_{m}$ & Fasor de corrente medido no terminal $m$ \\
\hline $\bar{I}_{n}$ & Fasor de corrente medido no terminal $n$ \\
\hline$I_{\text {pick-up }}$ & Corrente de pick-up do relé \\
\hline$I_{\text {res }}$ & Corrente de Restrição \\
\hline$K$ & Ajuste percentual da proteção diferencial (slope) \\
\hline $\bar{U}_{m}$ & Fasor de tensão medido no terminal $m$ \\
\hline $\bar{U}_{n}$ & Fasor de tensão medido no terminal $n$ \\
\hline $\bar{U}_{i}$ & Fasor de tensão medido no i-ésimo terminal da linha \\
\hline $\bar{I}_{C m}$ & Componente de corrente capacitiva do terminal $m$ \\
\hline $\bar{I}_{C n}$ & Componente de corrente capacitiva do terminal $n$ \\
\hline$\sum$ & Operador matemático que representa o somatório \\
\hline$\sqrt{ }$ & Operador matemático que representa a raiz quadrada \\
\hline $\mid$ & Operador matemático que representa o valor absoluto de um número complexo \\
\hline$\omega$ & Frequência angular fundamental do sistema \\
\hline$C_{\text {total }}$ & Capacitância total da linha de transmissão \\
\hline$C_{i}$ & Parcela da capacitância total da linha atribuída ao i-ésimo terminal da linha \\
\hline $\bar{I}_{T X}$ & Fasor de corrente compensada transmitida pelo canal de comunicação \\
\hline $\bar{I}_{R X}$ & Fasor de corrente compensada recebida do canal de comunicação \\
\hline$C_{A A}$ & Capacitância própria da fase A da linha de transmissão \\
\hline$C_{B B}$ & Capacitância própria da fase B da linha de transmissão \\
\hline$C_{C C}$ & Capacitância própria da fase $\mathrm{C}$ da linha de transmissão \\
\hline$C_{A B}$ & Capacitância mútua entre as fases A e B da linha de transmissão \\
\hline$C_{B C}$ & Capacitância mútua entre as fases B e C da linha de transmissão \\
\hline
\end{tabular}


$C_{C A} \quad$ Capacitância mútua entre as fases $\mathrm{C}$ e A da linha de transmissão

$N \quad$ Número de amostras por ciclo correspondente à taxa de amostragem empregada

$\bar{I}_{m k} \quad$ Corrente no ponto $k$ estimada a partir das grandezas do terminal $m$ utilizando o modelo $\pi$ equivalente da linha

$\bar{I}_{n k} \quad$ Corrente no ponto $k$ estimada a partir das grandezas do terminal $n$ utilizando o modelo $\pi$ equivalente da linha

$Z_{C} \quad$ Impedância característica da linha de transmissão

$\gamma \quad$ Constante de propagação da linha

$l_{n m} \quad$ Distância entre os terminais $n$ e $m$ da linha

$I_{D \phi} \quad$ Corrente diferencial da fase $\phi$ obtida utilizando o modelo $\pi$ equivalente da linha

$I_{B \phi} \quad$ Corrente de restrição da fase $\phi$ obtida utilizando o modelo $\pi$ equivalente da linha

$I_{h} \quad$ Corrente de pick-up utilizada pelo modelo $\pi$ equivalente

$k_{1}$ e $k_{2} \quad$ Diferentes inclinações da característica de restrição do relé diferencial percentual

$u_{m} \quad$ Amostra de tensão obtida no terminal $m$

$u_{n} \quad$ Amostra de tensão obtida no terminal $n$

$i_{m} \quad$ Amostra de corrente obtida no terminal $m$

$i_{n} \quad$ Amostra de corrente obtida no terminal $n$

$L_{0} \quad$ Indutância por quilômetro da linha de transmissão

$C_{0} \quad$ Capacitância por quilômetro da linha de transmissão

R Resistência total da linha de transmissão

$Z_{0} \quad$ Impedância de surto da linha de transmissão

Z Impedância equivalente da linha depois de considerar as perdas

$h \quad$ Coeficiente de reflexão de corrente

$l \quad$ Comprimento da linha

$I_{m n} e I_{n m} \quad$ Fontes de corrente fictícias representando as reflexões das ondas nos terminais da linha

$\tau \quad$ Tempo de trânsito

$i_{0} \quad$ Corrente de sequência zero depois de aplicada a Transformada de Karrenbauer

$i_{1} \quad$ Corrente de sequência positiva depois de aplicada a Transformada de Karrenbauer 
$i_{2} \quad$ Corrente de sequência negativa depois de aplicada a Transformada de Karrenbauer

$\bar{I}_{J m} \quad$ Corrente $\bar{I}_{m}$ estimada pelo terminal $n$ a partir de grandezas locais, utilizando o modelo de Bergeron da linha

$\bar{I}_{J n} \quad$ Corrente $\bar{I}_{n}$ estimada pelo terminal $m$ a partir de grandezas locais, utilizando o modelo de Bergeron da linha

$I_{\text {set }} \quad$ Corrente de pick-up utilizada pela proteção diferencial aplicando o modelo de Bergeron da linha 


\begin{tabular}{|c|c|}
\hline ANEEL & Agência Nacional de Energia Elétrica \\
\hline ATP & Alternative Transients Program \\
\hline $\mathrm{CA}$ & Corrente Alternada \\
\hline $\mathrm{CC}$ & Corrente Contínua \\
\hline EAT & Extra-Alta Tensão \\
\hline EMTP & Electromagnetic Transients Program \\
\hline EPE & Empresa de Pesquisa Energética \\
\hline GPS & Global Positioning System \\
\hline IEEE & Institute of Electrical and Electronics Engineers \\
\hline LKC & Lei de Kirchhoff das Correntes \\
\hline LT & Linha de Transmissão \\
\hline MME & Ministério de Minas e Energia \\
\hline ONS & Operador Nacional do Sistema Elétrico \\
\hline $\mathrm{P} \& \mathrm{D}$ & Pesquisa e Desenvolvimento \\
\hline SE & Subestação \\
\hline SEL & Schweitzer Engineering Laboratories \\
\hline SEP & Sistema Elétrico de Potência \\
\hline SIN & Sistema Interligado Nacional \\
\hline SIR & System Impedance Ratio \\
\hline $\mathrm{TC}$ & Transformador de Corrente \\
\hline TPC & Transformador de Potencial Capacitivo \\
\hline UAT & Ultra-Alta Tensão \\
\hline UnB & Universidade de Brasília \\
\hline
\end{tabular}




\section{CAPÍTULO 1}

\section{INTRODUÇÃO}

\subsection{CONTEXTUALIZAÇÃO DO TEMA}

A energia elétrica é de fundamental importância, pois não se concebe o mundo hoje sem ela. O avanço da tecnologia, por exemplo, estaria seriamente comprometido e poderia não se ter um mundo globalizado como hoje o é. A automatização dos processos, hoje cada vez mais crescente, acarreta em um crescimento da demanda por energia e está intimamente relacionado com o desenvolvimento econômico e o bem-estar social.

Com o intuito de atender a essa crescente demanda, são necessários constantes investimentos na expansão e na modernização das instalações elétricas do Sistema Interligado Nacional (SIN). Em contrapartida, isso acarreta o aumento da sua complexidade operacional, exigindo a utilização de modernos sistemas de proteção, a fim de garantir que faltas sejam extintas rápida e apropriadamente, pois, no caso de sistemas elétricos de potência operando de forma interligada, os distúrbios se propagam rapidamente pela rede (PAITHANKAR; BHIDE, 2007). Com uma proteção rápida, confiável, segura e seletiva, preserva-se a integridade dos equipamentos e evita-se o desencadeamento de outros defeitos, que possam culminar em interrupções no fornecimento de energia para grandes áreas do sistema.

A necessidade da expansão do sistema elétrico de potência do país torna estratégica, para o desenvolvimento, a exploração energética de plantas de geração localizadas cada vez mais distantes dos grandes centros de consumo. Com isso, muitos têm sido os estudos voltados para buscar soluções não convencionais para a transmissão de grandes blocos de energia a longas distâncias. Nesse contexto, a transmissão CA em ultra-alta tensão (UAT) surge como opção viável, no que diz respeito aos requisitos técnicos e econômicos (ANEEL, 2008).

Para que o sistema elétrico seja provido de proteção adequada, esta deve apresentar caraterísticas importantes, tais como: confiabilidade, seletividade e velocidade de atuação. Visando à manutenção da integridade dos equipamentos do SIN, a estabilidade de sua operação e a segurança das pessoas que estejam sujeitas aos riscos associados às faltas, o Operador Nacional do Sistema Elétrico (ONS), no Módulo 2.6 dos Procedimentos de Rede, limita o tempo total de eliminação de faltas para sistemas de tensões nominais iguais ou superiores a 345 kV em 100 ms (ONS, 2011). Para tanto, é 
necessário o desenvolvimento e estudo de algoritmos de proteção eficazes, capazes de detectar o defeito e atuar de forma rápida e precisa.

\subsection{MOTIVAÇÃO}

Dentre os componentes de um sistema elétrico de potência, as linhas de transmissão apresentam um alto índice de ocorrência de faltas, correspondendo a quase $70 \%$ das falhas ocorridas nos principais equipamentos de um sistema elétrico (vide Tabela 1.1). Isto ocorre devido ao comprimento, à quantidade e à exposição destas, o que as torna mais vulneráveis às intempéries climáticas e ao vandalismo. Além disso, elas são geralmente construídas em locais de difícil acesso e distantes dos centros urbanos, o que aumenta a dificuldade na realização de manutenção. Esse fato evidencia a importância da utilização de sistemas de proteção modernos que sejam capazes de atuar de forma rápida e seletiva na eliminação do defeito, garantindo a estabilidade da operação do sistema como um todo.

Tabela 1.1 - Desligamentos Forçados no SIN no ano de 2012 (ONS, 2013).

\begin{tabular}{ccc}
\hline Equipamento & Desligamentos & Porcentagem (\%) \\
\hline Linhas de Transmissão & 6490 & 69,3 \\
Transformadores & 1306 & 13,9 \\
Geradores & 873 & 9,3 \\
Barramentos & 129 & 1,4 \\
Reatores & 108 & 1,2 \\
Banco de Capacitores & 343 & 3,7 \\
Compensadores Síncronos & 59 & 0,6 \\
Compensadores Estáticos & 63 & 0,7 \\
TOTAL & & $\mathbf{1 0 0 , 0}$ \\
\hline
\end{tabular}

Dentre os diferentes tipos de proteção para linhas de transmissão, o tipo mais empregado é a proteção de distância (ZIEGLER, 2006). Porém, nas últimas décadas, o uso de sistemas de comunicação modernos juntamente com uma nova geração de relés numéricos microprocessados, tornou atrativa a aplicação da proteção diferencial, mesmo para o caso de linhas longas (ZIEGLER, 2005).

A proteção diferencial possui princípio de operação baseado na aplicação da primeira lei de Kirchhoff às correntes medidas nos diferentes terminais do elemento protegido, de modo que durante sua operação normal, a soma das correntes entrando e saindo do elemento protegido é idealmente igual a zero. Porém, a ocorrência de um curto-circuito dentro da região protegida faz com que essa soma seja consideravelmente diferente de zero, podendo ser utilizada para a detecção do defeito (ZIEGLER, 2005).

Diferentemente dos outros componentes do sistema, as linhas de transmissão apresentam, inerentemente à sua operação, uma corrente capacitiva para terra (ou corrente de descarga) que, de um modo geral, não é considerada na formulação básica da proteção diferencial, uma vez que não pode ser 
medida diretamente. Essa condição é válida para o caso de linhas curtas, visto que apresentam pequena corrente capacitiva, podendo a mesma ser desprezada. Por outro lado, à medida que o comprimento da linha aumenta e o seu nível de tensão de operação se eleva, a amplitude dessa corrente aumenta consideravelmente, podendo ser da mesma ordem de grandeza que a corrente de carga que passa pela linha (KASZTENNY et. al, 2011). Como consequência, a corrente capacitiva origina uma falsa corrente diferencial, podendo causar a atuação indevida da proteção.

Diante do exposto, evidencia-se a necessidade da eliminação do efeito da corrente capacitiva da linha no desempenho da proteção diferencial, a fim de garantir a atuação rápida, segura e seletiva da proteção da linha de transmissão.

\subsection{OBJETIVO}

O objetivo principal desta dissertação de mestrado é realizar uma análise do desempenho da proteção diferencial aplicada às linhas de transmissão de UAT. Como objetivos específicos tem-se:

- Apresentar a problemática do efeito da corrente capacitiva na atuação da proteção diferencial de linhas de UAT;

- Modelar um sistema de potência composto por uma linha de $1000 \mathrm{kV}$ no software Alternative Transients Program (ATP);

- Comparar os desempenhos de alguns algoritmos propostos na literatura para a proteção diferencial de linhas de transmissão.

\subsection{ORGANIZAÇÃO DO TEXTO}

A dissertação está organizada em seis capítulos, conforme é descrito a seguir.

No Capítulo 2, realiza-se o levantamento do estado da arte sobre a proteção diferencial de linhas de transmissão, evidenciando fatores que influenciam no seu desempenho, bem como métodos de compensação da corrente capacitiva que têm sido propostos.

No Capítulo 3, abordam-se os fundamentos da proteção diferencial percentual, dando enfoque às suas particularidades quando aplicada às linhas de transmissão.

No Capítulo 4, por sua vez, são descritos os algoritmos de compensação da corrente capacitiva que serão utilizados na análise do desempenho da proteção diferencial de linhas.

No Capítulo 5, são simulados alguns tipos de curtos-circuitos, a fim de comparar os desempenhos dos algoritmos avaliados. Para tanto, analisam-se suas respostas transitórias, bem como 
suas respostas em regime permanente de curto-circuito frente à variação de parâmetros como carregamento da linha, potência de curto-circuito das fontes e a localização, o tipo e a resistência do curto-circuito.

Por fim, no Capítulo 6, são apresentadas as conclusões obtidas com este trabalho, além da sugestão de trabalhos futuros que possam dar continuidade a este estudo. 


\section{CAPÍTULO 2}

\section{REVISÃO BIBLIOGRÁFICA}

Os primeiros trabalhos relacionados à área de proteção digital de sistemas elétricos de potência surgiram no final da década de 60, sendo o trabalho de McLaren \& Mcconnach (1965) considerado um dos primeiros artigos tratando dos algoritmos numéricos aplicados aos sistemas de proteção.

Contudo, só a partir do início da década de 70 surgiram os primeiros algoritmos de estimação de fasores, principalmente voltados para aplicações da proteção de distância de linhas de transmissão. Estes utilizam janelas de dados com poucas amostras e são, em geral, baseados no cálculo das derivadas do sinal, que é considerado perfeitamente senoidal (MANN \& MORRISON, 1971).

Sun \& Ray (1983) propuseram o uso da fibra ótica como alternativa viável para canal de comunicação de dados, substituindo o fio piloto. São apresentadas as vantagens da imunidade que a fibra ótica possui quanto às interferências realizadas por tensões parasitas. Os autores também discorreram sobre técnicas de comparação de amostras coincidentes de corrente, o que aumentava a confiabilidade do sistema de comunicação entres os relés que realizam a proteção diferencial, ampliando assim a aplicabilidade deste tipo de proteção para linhas de transmissão longas.

Bhatti (1990) apresentou os efeitos de falhas primárias e residuais, bem como do acoplamento entre as fases e de linhas de transmissão vizinhas na proteção diferencial de linhas de extra-alta tensão (EAT) e UAT (com faixa de tensão entre $345 \mathrm{kV}$ e $1500 \mathrm{kV}$ ). A análise de desempenho realizada revela que as falhas residuais e o acoplamento entre as linhas são suficientemente altos a ponto de afetarem a sensibilidade de operação da proteção diferencial e dos diversos algoritmos de proteção.

Ernst et. al (1992) propuseram um novo sistema de proteção diferencial para linhas de transmissão baseado na comparação da carga, ao invés da comparação das correntes. Os autores mostraram que essa alternativa resolve grande parte dos problemas da proteção diferencial tradicional de corrente, a saber: perda da proteção quando da falha do canal de comunicação, necessidade de um canal de comunicação com grande capacidade de transmissão e necessidade de compensação do atraso de comunicação. Os autores afirmam que esta nova técnica é adequada para linhas de transmissão de até três terminais e de todos os níveis de tensão e comprimento. 
Ward \& Erwin (1993) efetuaram uma análise do desempenho da proteção diferencial de corrente e da proteção diferencial por comparação de carga utilizando-se as mesmas condições do sistema para ambos tipos de proteção. Entre os fatores que os autores avaliaram estão: tempo de atuação, sensibilidade, confiabilidade e segurança. Foram analisados diversos cenários, considerando erros decorrentes da saturação dos transformadores de corrente (TCs), diversas condições de carga, efeito do atraso e da assimetria do canal de comunicação. Por fim, os autores apresentaram conclusões que auxiliam nas considerações de ajuste dos relés de proteção.

Adamiak et. al (1998) discorreram sobre uma nova abordagem para proteção diferencial numérica de linhas de transmissão a qual oferece melhor desempenho em relação à abordagem de proteção diferencial percentual convencional. O algoritmo diferencial utiliza um novo método de cálculo de fasores na frequência fundamental denominado de phaselets, em substituição à abordagem tradicional utilizando os algoritmos de Fourier de um e meio ciclo, a qual utiliza janela fixa. Esta abordagem também facilita o cálculo do nível de confiança para as correntes medidas. Isto permite que a proteção diferencial adapte as suas características de operação baseada na qualidade dos valores de corrente medidos. Outras abordagens adaptativas para comunicações piloto entre os terminais de linha também são discutidas. Elas permitem que a proteção diferencial se ajuste dinamicamente às alterações nos tempos de transmissão entre os terminais, fornecendo redundância no caso de perda parcial do sistema de comunicação.

Hall et. al (2003) apresentaram um relé de proteção diferencial comercial que realiza a sincronização de tempo de amostragem entre duas ou mais subestações usando a informação de tempo via GPS. Este relé é capaz de manter o sincronismo mesmo quando há assimetria de canal e possui também um eficiente sistema de back-up, o qual permite que o desempenho seja mantido, mesmo no caso de o sinal GPS ser interrompido, assumindo a tarefa de sincronização neste caso.

Bhalja \& Maheshwari (2006) apresentaram um esquema de proteção diferencial baseado na transformada Wavelet. Neste esquema é feita a decomposição dos sinais medidos em cada relé local, usando a Wavelet mãe Daubechies 4, e os coeficientes de aproximação no terceiro nível de resolução são reconstruídos e utilizados para gerar as correntes de restrição e operação, sendo a corrente de operação o valor absoluto da diferença de sinal reconstruído para cada fase e a corrente de restrição um terço do valor absoluto da soma do sinal também reconstruído para cada fase. Os coeficientes de detalhe são utilizados para extrair as características de detalhe (ou de alta frequência), as quais são sensíveis à falta de alta resistência, além de proporcionarem uma discriminação adequada entre as faltas internas e externas. 
Xu et. al (2007) propuseram uma nova forma de aplicar o princípio da proteção diferencial levando em consideração a natureza distribuída dos parâmetros da linha. Na metodologia proposta, ao invés de comparar as correntes medidas em ambos os terminais da linha de transmissão, faz-se a escolha de um ponto comum para comparação e então são calculadas as correntes neste ponto utilizando-se o modelo $\pi$ equivalente da linha. Por fim, estas correntes são comparadas na forma tradicional da proteção diferencial percentual. Vale ressaltar que, como estão sendo comparadas correntes em um mesmo ponto, estas não sofrem influência do efeito capacitivo da linha.

Pires \& Guerreiro (2008) apresentaram uma nova abordagem para a proteção diferencial de linhas de transmissão. Os autores utilizam a transformação de Park (ou transformação $A B C-d q 0$ ) para converter um sistema trifásico equilibrado em três componentes de corrente contínua e implementam a proteção diferencial percentual convencional utilizando as correntes transformadas. Com isso, aumentase a imunidade para problemas de atraso de canal. No artigo, vários resultados de simulações são apresentados, de modo a demonstrar a eficácia da abordagem proposta. Além disso, os autores afirmam que a análise diferencial aplicada apenas a componente de eixo direto apresenta os melhores resultados.

Ren et. al (2008) propuseram um tipo de proteção centralizada que fornece proteção às múltiplas usinas e subestações. Neste artigo é descrito um esquema de proteção diferencial integrado no qual os relés são instalados em cada subestação de uma rede e são responsáveis pela proteção de todas as seções de linha de transmissão conectadas ao barramento da subestação. Os algoritmos diferenciais de corrente com várias configurações são implementados no relé para cobrir todas as seções da linha protegida e o sistema é suportado por uma rede de comunicação. Estudos mostram que o novo relé oferece mais funções de proteção e vantagens econômicas significativas sobre os relés diferenciais de corrente convencionais.

Sezi et. al (2008) apresentaram os aspectos práticos do uso de relés digitais para a proteção de linhas de transmissão e introduzem um novo princípio de comparação de corrente diferencial, cuja a característica de restrição é adaptativa. Os autores discorrem sobre os diversos aspectos que devem ser considerados e as dificuldades encontradas ao ajustar o relé diferencial de linhas, tais como: precisão e saturação de TCs, sincronização de tempo das amostras utilizadas, instabilidade no tempo de transferência da informação (delay), corrente de carga capacitiva e desvio de frequência do sistema. Dentre os diversos aspectos estudados, os autores se dedicam de forma mais criteriosa aos aspectos relacionados à comunicação entre os dispositivos, abordando inclusive os tipos de fibra e topologia da comunicação. No texto é destacado também o aspecto multifuncional dos relés digitais, capazes de combinar proteção diferencial de linha e proteção de distância no mesmo hardware, tornando a proteção de linha segura e confiável. 
Dambhare et. al (2009) apresentaram uma nova metodologia de controle adaptativo da região de restrição em um plano de corrente diferencial. Em seu artigo, os autores desenvolvem um modelo baseado no conceito de fasor dinâmico de uma linha de transmissão e realizam uma análise de erro da proteção diferencial que faz uso do conceito convencional de fasor. Em sua metodologia é realizado o controle adaptativo da região de restrição em função do carregamento do sistema, de forma que para um carregamento baixo, a área de restrição é mantida pequena, aumentando a sensibilidade do relé. Já a medida que se aumenta o carregamento, a área de restrição cresce proporcionalmente à corrente, aumentando a segurança do relé sem comprometer sua sensibilidade. Os autores também estendem a metodologia para a proteção de linhas com compensação série e avaliam o conflito entre a velocidade e a precisão da proteção, mostrando que esta metodologia é confiável mesmo para esse caso.

Bin et. al (2009) também propuseram uma nova forma de aplicar o princípio da proteção diferencial levando em consideração a natureza distribuída dos parâmetros da linha de transmissão. Neste método, as amostras de tensão e corrente obtidas em um terminal são utilizadas para calcular essas mesmas grandezas no lado oposto da linha, utilizando-se do modelo de Bergeron da linha. Em seguida, cada terminal calcula a corrente diferencial, a partir do fasor obtido localmente e do fasor de corrente enviado pelo terminal oposto. Ambos são fasores locais, não sendo afetados pela corrente capacitiva. A proteção diferencial percentual é aplicada de forma semelhante à tradicional. Contudo, a corrente diferencial é calculada através da diferença entre o fasor local e o fasor recebido do terminal remoto, pois ambos os fasores, por representarem a mesma corrente, possuem a mesma direção.

Gajic et. al (2010) apresentaram um método de compensação da corrente capacitiva, o qual obtém o valor da corrente capacitiva ao longo do tempo e subtrai-o do valor mais recente de corrente diferencial. Este método é denominado nessa dissertação de método da Memória da Corrente Capacitiva. Nele estima-se a corrente capacitiva da linha como a média das correntes diferenciais armazenadas nos três últimos ciclos e a subtrai do valor atual de corrente diferencial, resultando em uma corrente de operação confiável. O processo de remoção é aplicado a todas as fases do sistema eliminando praticamente toda a corrente capacitiva durante regime permanente. Durante a ocorrência de falta não são atualizados os valores de corrente capacitiva. Nesses momentos, aplica-se o último valor de corrente capacitiva calculado no regime permanente. Este método não considera a diminuição da tensão na fase defeituosa durante o curto-circuito, superestimando a corrente capacitiva para esta fase, o que pode comprometer a confiabilidade da proteção.

Uma nova técnica de transformação da corrente instantânea da linha de transmissão que faz uso do conceito de janela móvel foi proposta por Dambhare et. al (2010). Os autores demonstram que, se o intervalo de tempo de janela em movimento é igual ao tempo de um ciclo, o valor CC da corrente 
transformada é zero, considerando que esta corrente é originalmente um sinal periódico composto de frequência fundamental e suas harmônicas. Por outro lado, distorções do sinal fazem a componente CC das correntes transformadas se desviarem do valor nominal zero, permitindo o desenvolvimento de um esquema sensível, seguro, rápido e simples de proteção diferencial. Através dos resultados apresentados no trabalho, é evidenciado pelos autores que o método proposto é de duas a três vezes mais sensível se comparado à proteção diferencial de corrente tradicional.

Miller et. al (2010) propuseram um método de compensação da corrente capacitiva, denominado nesta dissertação como Método das Capacitâncias Concentradas. Este método calcula a contribuição individual dos terminais da linha para a corrente capacitiva, como se houvesse um capacitor concentrado em cada um deles. Com isso, cada terminal possui uma parcela da corrente de descarga, não havendo a necessidade de enviar amostras de tensão adicionais pelo canal de comunicação. Cada relé envia sua corrente já compensada, a qual corresponde à diferença entre a corrente medida no terminal e a contribuição da corrente capacitiva calculada. Por fim, a corrente diferencial é calculada da forma tradicional utilizando às correntes compensadas. Este é um método de fácil implementação, contudo necessita dos sinais de corrente e de tensão dos terminais da linha, o que acarreta na necessidade de instalação de transformadores de potencial.

Sanaye-Pasand \& Jafarian (2011) apresentam um algoritmo baseado em diagrama de estados para linhas de transmissão de circuito duplo, usando as informações obtidas do relé do barramento local. Uma nova técnica de proteção diferencial cruzada é proposta, a qual compara as correntes nas fases correspondentes dos circuitos paralelos. Um algoritmo baseado em impedância é utilizado em conjunto para cobrir os defeitos em faltas evolutivas e algumas condições em que a técnica diferencial cruzada não consegue identificar as faltas internas sozinha. O efeito da impedância mútua entre os circuitos paralelos sobre as impedâncias medidas é compensado adaptativamente de acordo com o estado das correntes dos circuitos paralelos. Por fim, o algoritmo com base no diagrama de estado proposto combina as saídas das técnicas diferencial cruzada e impedância, para fornecer uma resposta confiável em todos os estados de funcionamento dos circuitos paralelos. A partir das simulações mostradas, os autores concluem que o novo algoritmo é capaz de distinguir as fases defeituosas das fases sãs e funciona bem inclusive para faltas evolutivas.

Rebizant \& Solak (2011) apresentam um novo esquema de proteção diferencial de linhas de transmissão com a aplicação de lógica Fuzzy. Com a aplicação deste esquema é obtida melhor estabilização da proteção diferencial para classificação adequada das faltas externas com saturação dos TCs. O esquema funciona bem também para detecção de faltas internas, com atuação tão rápida quanto das soluções tradicionais. 
Também em 2011, um tutorial das características de operação dos relés diferenciais de linha de transmissão (87L) da Schweitzer Engineering Laboratories (SEL) foi apresentado em Kasztenny et. $a l$, 2011. Entre os diversos aspectos da proteção diferencial de linhas, os autores discorrem sobre o problema da compensação da corrente capacitiva e apresentam três alternativas para mitigar o impacto da corrente capacitiva na proteção diferencial. A primeira delas é a definição do o valor da corrente de pick-up acima do valor da corrente de carga, limitando assim a sensibilidade do relé, principalmente para linhas de transmissão longas. Esta solução melhora o desempenho se aplicada para relés de sequência, pois nestes a corrente de pick-up só precisa ser definida com relação ao pequeno desbalanço do sistema. A segunda alternativa apresentada é o método da memória de corrente capacitiva, já mencionado neste capítulo (GAJIC et. al, 2010). Esta solução não pode ser usada durante a energização da linha, pois neste caso a memória de corrente é igual a zero. Por fim, eles apresentam como alternativa mais viável o método das capacitâncias concentradas, também já descrito anteriormente (MILLER et. $a l, 2010)$. Este método é bastante preciso, mesmo em condições desequilibradas e de transitórios elevados. Contudo, este método requer a informação da tensão nos terminais da linha de transmissão.

Dahane \& Dambhare (2012) propõem um algoritmo de proteção diferencial de corrente para a proteção de linhas de transmissão de extra-alta tensão não transpostas. Tal algoritmo é baseado no Modelo $\pi$ Equivalente da linha de transmissão. O relé diferencial proposto realiza o cálculo da diferença das correntes do ramo série da linha, as quais são calculadas a partir do modelo $\pi$ equivalente da linha. Este relé utiliza um sincronizador das medições, garantindo que estão sendo comparadas correntes correspondente ao mesmo instante de tempo. Desta forma, o desempenho do relé é imune a corrente de carga da linha, aumentando, assim, a sensibilidade, a segurança e a confiabilidade da proteção. 


\section{CAPÍTULO 3}

\section{FUNDAMENTOS DA PROTEÇÃO DIFERENCIAL}

Define-se como sistema de proteção o conjunto de relés, sensores, transformadores para instrumento, disjuntores, equipamentos de teleproteção, circuitos de alimentação, circuitos de comando e sinalização, que tem por finalidade prover a proteção de algum componente ou parte do sistema elétrico de potência contra faltas, garantindo a integridade dos equipamentos e a segurança das pessoas (SILVA, 2009).

Dentre algumas consequências de faltas, podem-se citar: danos em equipamentos causando destruição e fogo; explosões em equipamentos contendo isolamento a óleo; sobreaquecimento, subtensões e sobretensões na vizinhança da falta; interrupção do fluxo de potência; redução das margens de estabilidade; operações incorretas devido ao desbalanço do sistema; e queda do sistema por perda de sincronismo (FLACK, 2008).

Dessa forma, a principal função do sistema de proteção é detectar defeitos no sistema elétrico e atuar de forma rápida e seletiva, eliminando o rastro do defeito, preservando a integridade dos equipamentos e garantindo a estabilidade do sistema e a continuidade do fornecimento de energia ao maior número de usuários possível. Visando à manutenção da integridade dos equipamentos do SIN, a estabilidade de sua operação e a segurança das pessoas que estejam sujeitas aos riscos associados às faltas, o Operador Nacional do Sistema Elétrico (ONS), no Submódulo 2.6 dos Procedimentos de Rede, limita o tempo total de eliminação de faltas para sistemas de tensões nominais iguais ou superiores a 345 kV em 100 ms (ONS, 2011).

Neste contexto, podem ser identificados alguns requisitos básicos de um sistema de proteção (ANDERSON, 1999):

- Sensibilidade: capacidade do sistema de proteção em detectar as faltas para as quais ele foi projetado.

- Confiabilidade: habilidade de atuar corretamente quando necessário.

- Segurança: habilidade de evitar operação indevida, impedindo assim a interrupção do serviço de fornecimento de energia desnecessariamente.

- Seletividade: capacidade de isolar uma falta realizando o mínimo de desconexões, de forma a possibilitar a máxima continuidade de serviço. 
- Coordenação: determinação dos ajustes apropriados do sistema de proteção, a fim de se obter seletividade em sua operação.

- Velocidade: atuar o mais rapidamente possível, reduzindo o tempo de duração da falta e os danos causados ao sistema protegido.

- Simplicidade: utilização mínima de equipamentos e circuitos na execução da proteção, tornando-a mais econômica e prática.

Também no Submódulo 2.6 dos Procedimentos de Rede, o ONS estabelece os requisitos mínimos para os sistemas de proteção e de telecomunicações para as linhas de transmissão e equipamentos associados que fazem parte da rede básica do SIN: todo componente, excetuando-se os barramentos, deve ser protegido por dois sistemas de proteção completamente independentes, chamados de proteção principal e proteção alternada. Essas proteções devem ser realizadas por equipamentos distintos, incluindo equipamentos de teleproteção e relés, e possuindo fontes de alimentação auxiliar independentes.

Existem basicamente três tipos de relés de proteção: eletromecânicos, estáticos e digitais. Os relés eletromecânicos têm sua operação baseada na interação eletromagnética entre correntes e fluxos. Eles possuem algumas desvantagens, tais como: inércia dos elementos móveis e consumo elevado.

Os relés estáticos são constituídos de circuitos integrados que podem implementar todas as funções de proteção existentes nos relés eletromecânicos. A principal desvantagem deste tipo de relé é a sensibilidade às altas temperaturas e umidade, além de sensibilidade a sobrecorrentes e sobretensões, o que pode ocasionar atuações indevidas.

Com o desenvolvimento da tecnologia de redes de comunicação de dados e processamento digital de sinais, sugiram os relés numéricos microprocessados, também chamados de relés digitais. Com eles, é possível aplicar lógicas de proteção, monitoramento e controle em tempo real de sistemas de potência em um único relé.

Algumas características dos relés de proteção numéricos microprocessados merecem ser destacadas: a auto-supervisão, que corresponde a capacidade de programação em monitorar-se diversas partes de hardware e software simultaneamente; a integração aos sistemas digitais, o que permitiu uma grande evolução aos sistemas de automação; e a flexibilidade funcional, que permite aos dispositivos de proteção modernos serem condicionados a diferentes circunstâncias operacionais (SANTOS, 2006).

O uso da proteção digital oferece algumas vantagens em relação ao emprego de relés eletromecânicos, tais como: redução de custo, maior precisão nos ajustes, flexibilidade para realizar 
funções adicionais como medição e controle, confiabilidade e possibilidade de implementação de novos algoritmos e o uso de técnicas de inteligência artificial (GONÇALVES, 2012).

Os relés eletromecânicos foram por várias décadas os componentes mais empregados na proteção dos sistemas de potência. Contudo, após o desenvolvimento dos relés numéricos microprocessados, estes equipamentos vêm sendo substituídos gradativamente nas subestações existentes. Os projetos de novas subestações de energia elétrica empregam exclusivamente relés de proteção digitais (GONÇALVES, 2012).

Dentre os diferentes tipos de proteção para linhas de transmissão convencionais, o tipo mais empregado é a proteção de distância (ZIEGLER,2006). Porém, nas últimas décadas, o uso de sistemas de comunicação modernos juntamente com uma nova geração de relés numéricos microprocessados, tornou atrativa a aplicação da proteção diferencial, mesmo para o caso de linhas longas.

\subsection{PROTEÇÃO DIFERENCIAL NÃO PERCENTUAL}

A proteção diferencial de sobrecorrente se baseia na aplicação da Lei de Kirchhoff das Correntes (LKC) ao sistema protegido. Durante uma falha ocorrida dentro da região protegida (linha de transmissão, barramento, transformador, etc.) cria-se um novo caminho para a corrente, de forma que a quantidade que entra nessa região passa a ser diferente da que sai. Assim, pode-se efetuar a detecção de uma falta através da corrente de operação $\left(I_{o p}\right)$, definida pela soma das correntes que entram e saem da região protegida. Caso $I_{o p}$, também conhecida como corrente diferencial $\left(I_{d i f f}\right)$, ultrapasse uma corrente de pick-up pré-determinada do relé, o mesmo será sensibilizado (PAITHANKAR; BHIDE, 2007).

A região protegida pelo sistema de proteção de um determinado equipamento é denominada zona de proteção. Na proteção diferencial, os limites da zona de proteção são estabelecidos pelos TCs, que servem de entrada para os relés de proteção.

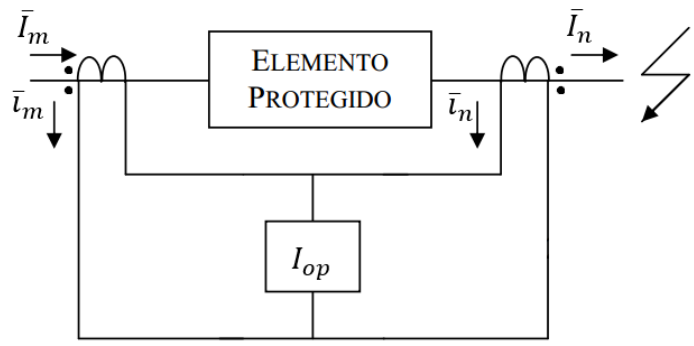

(a)

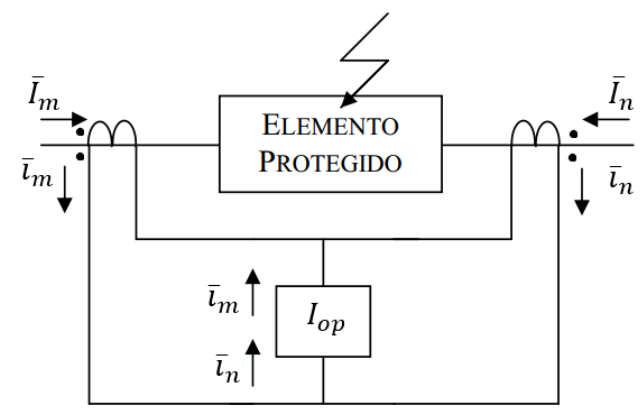

(b)

Figura 3.1 - Proteção Diferencial Não Percentual: (a) Falta Externa (b) Falta Interna 
Observando-se a Figura 3.1 percebe-se que, idealmente, para o caso de falta externa a região protegida ou funcionamento normal do sistema, as correntes $\bar{I}_{m}$ e $\bar{I}_{n}$ possuem o mesmo módulo e sentidos opostos, acarretando em uma corrente diferencial nula (Figura 3.1 a) e, para o caso de falta interna, a soma de $\bar{I}_{m}$ e $\bar{I}_{n}$ resulta em uma imagem da corrente de curto (Figura 3.1 b). Se esta corrente for superior a corrente de pick-up, ocorrerá a atuação do relé. Considerando-se a polaridade dos TCs de acordo com a direção das correntes de curto-circuito entrando na região protegida, define-se $I_{o p}$ segundo (3.1) e o critério de atuação da proteção diferencial de sobrecorrente segundo (3.2).

$$
\begin{aligned}
& I_{o p}=\left|\bar{I}_{m}+\bar{I}_{n}\right| \\
& I_{o p}>I_{\text {pick-up }}
\end{aligned}
$$

sendo $\bar{I}_{m}$ e $\bar{I}_{n}$ os fasores de corrente medidos nos terminais $m$ e $n$ do elemento protegido.

Pode-se afirmar que a proteção diferencial é o tipo de proteção que melhor preenche o requisito de seletividade, pois esta constitui uma proteção unitária e intrinsecamente restrita, o que a torna mais rápida, uma vez que não necessita de temporização. Uma proteção rápida ajuda a garantir a estabilidade do sistema, o qual a cada dia opera mais próximo de seu limite de transmissão.

Outra vantagem do uso da proteção diferencial é que quando implementada com segregação de fase, esta é intrinsecamente adequada à seleção de fase. Isto a torna bastante adequada para aplicação em linhas aéreas dotadas de religamento automático. Entretanto, existem erros impostos pelo próprio sistema elétrico, como erros intrínsecos aos TCs, ao componente protegido e à transmissão do sinal, os quais contribuem para erro no cálculo da corrente diferencial, podendo ocasionar a má operação da proteção. O erro intrínseco aos TCs está relacionado com sua classe de exatidão. Os erros impostos pelo sistema elétrico decorrem principalmente dos parâmetros shunt da linha de transmissão. Já os erros na transmissão do sinal são basicamente ocasionados pela assimetria e atraso dos canais e dos dispositivos de telecomunicações, o que acarreta em desalinhamento das informações de cada terminal com relação ao tempo.

Quando o sistema protegido é submetido a curto-circuito externo de corrente elevada, a proteção diferencial pode acabar atuando indevidamente. Essa possibilidade existe devido aos erros de medição das correntes pelos TCs, pois os mesmos são suscetíveis à saturação e apresentam diferenças construtivas que impedem que as correntes dos terminais sejam iguais para o caso de faltas externas (MOLAS \& SILVA, 2012). Os TCs podem saturar em virtude da magnitude da corrente em seu primário e do fluxo magnético remanescente em seu núcleo no momento da ocorrência do curto-circuito. Cabe 
ressaltar que o comportamento na saturação do TC depende também do seu tipo e da impedância conectada em seu enrolamento secundário (SEZI et. al, 2008).

A fim de mitigar as consequências dos erros intrínsecos ou impostos pelo sistema elétrico, a proteção diferencial pode ser implementada de diversas formas (NAVARRO et. al, 2003):

- Relé de sobrecorrente ligado como diferencial: inadequado para permitir, concomitantemente, a perspectiva de fraco desempenho dos TCs para faltas externas e a sensibilidade adequada para faltas internas;

- Inclusão de resistor estabilizador no ramo diferencial: com isso, a proteção torna-se mais flexível com relação à solução anterior, mas não o suficiente para tornar-se uma solução genérica;

- Relé de alta impedância: permite grande sensibilidade para faltas internas e é seletivo para faltas externas com TC saturado, mas necessita da conexão dos secundários dos TCs em paralelo fisicamente, o que inviabiliza sua aplicação no caso de linhas de transmissão;

- Relé diferencial percentual: solução mais viável, podendo ser implementada por qualquer tecnologia (eletromecânica, estática ou digital).

\subsection{PROTEÇÃO DIFERENCIAL PERCENTUAL}

A proteção diferencial percentual surge como alternativa à proteção diferencial convencional, sendo menos suscetível a erros que levem à má operação para faltas fora da região protegida (PAITHANKAR; BHIDE, 2007). Para isso, utiliza-se uma corrente de restrição $\left(I_{\text {res }}\right)$, proporcional às correntes nos terminais do elemento protegido. A atuação da proteção diferencial ocorrerá caso a razão entre $I_{o p}$ e $I_{r e s}$ seja maior que o ajuste percentual $K$ determinado previamente, isto é, quando a corrente de operação alcançar uma porcentagem definida da corrente de restrição.

Considerando-se a polaridade dos TCs positiva para correntes entrando na região protegida, define-se $I_{o p}$ segundo (3.3) como o módulo da soma das correntes. Por sua vez, $I_{\text {res }}$ pode ser definida de diversas maneiras, conforme descrito por Tziouvaras et al. (2004). Contudo, neste trabalho será utilizada a forma mostrada em (3.4) para todos os métodos que não definirem a corrente de restrição explicitamente, por ser a formulação mais comumente utilizada pelos fabricantes de relés.

$$
\begin{gathered}
I_{o p}=\left|\bar{I}_{m}+\bar{I}_{n}\right| \\
I_{\text {res }}=\left|\bar{I}_{m}\right|+\left|\bar{I}_{n}\right|
\end{gathered}
$$

sendo $\bar{I}_{m}$ e $\bar{I}_{n}$ os fasores de corrente medidos nos terminais $m$ e $n$ do elemento protegido. 
O critério de atuação da proteção diferencial pode ser escrito de acordo com (3.5), que representa a equação de uma reta crescente que passa pela origem. Esta reta é chamada de característica de operação do relé diferencial percentual, e sua inclinação define a sensibilidade do mesmo. É possível que sejam usados dois valores para $K$, a fim de se satisfazer diferentes condições do sistema como, por exemplo, no caso de problemas de saturação dos TCs. Para lidar com fatores como erros de regime permanente dos TCs, além de outros erros decorrentes da operação de cada tipo de equipamento protegido (THOMPSON, 2011), uma corrente mínima de pick-up $K_{0}$ deve ser definida adicionando uma segunda condição, descrita em (3.6).

$$
\begin{gathered}
I_{o p}>K \cdot I_{\text {res }} \\
I_{o p}>K_{0}
\end{gathered}
$$

Os valores de $K$ são definidos principalmente em função dos estudos de curtos-circuitos no sistema a ser protegido e apresentam valores típicos de 10, 20 e 40\% (THOMPSON, 2011). Dessa forma, quanto menor a inclinação da característica, mais sensível será o relé.

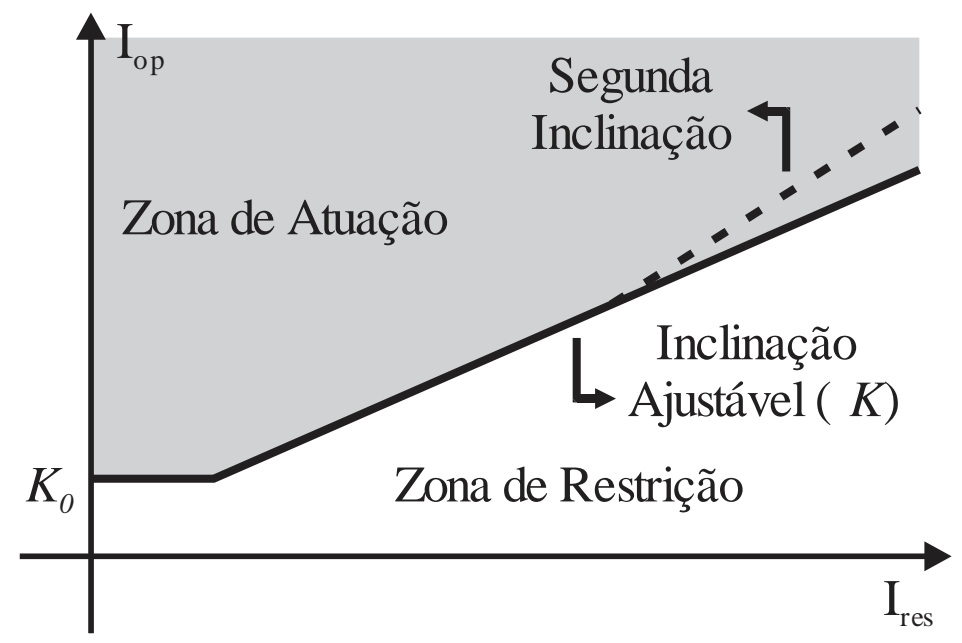

Figura 3.2 - Plano operacional do relé diferencial percentual com sua curva característica.

Como pode ser visto na Figura 3.2, o funcionamento da proteção diferencial percentual pode ser apresentado graficamente através do plano operacional, que representa a corrente de operação versus a corrente de restrição. Nela estão indicadas as regiões de atuação e restrição do relé, bem como uma característica de restrição que utiliza duas inclinações diferentes para lidar com problemas de saturação de TCs (ZIEGLER, 2005). 
Outra maneira de visualizar a atuação da proteção diferencial é o chamado plano- $\alpha$, ilustrado na Figura 3.3. Este representa as partes real e imaginária da razão das correntes dos terminais da linha e é definido através das equações (3.7) a (3.9) (WARRINGTON, 1962).

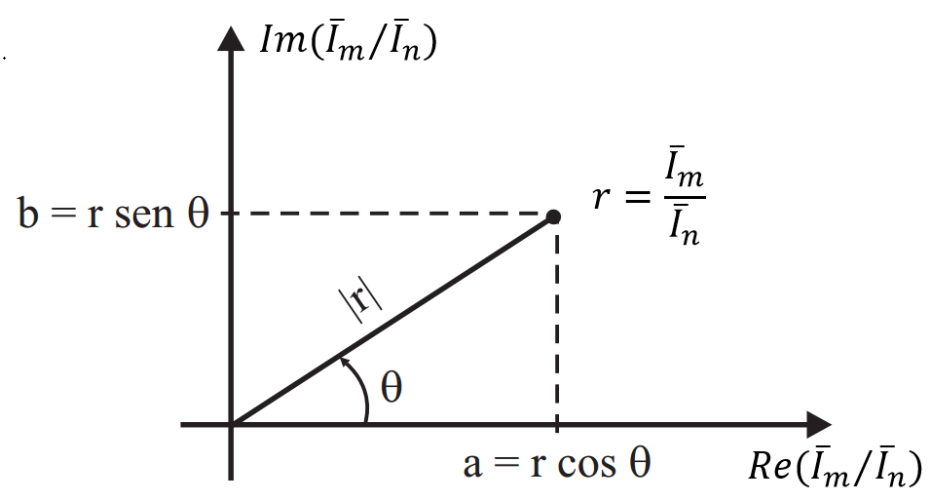

Figura 3.3 - Plano- $\alpha$.

$$
\begin{gathered}
\frac{\bar{I}_{m}}{\bar{I}_{n}}=a+j b=r=|r| e^{j \theta} \\
|r|=\frac{\left|\bar{I}_{m}\right|}{\left|\bar{I}_{n}\right|}=\sqrt{a^{2}+b^{2}}, \theta=\arctan \left(\frac{b}{a}\right) \\
a=|r| \cos \theta, b=|r| \operatorname{sen} \theta
\end{gathered}
$$

Pode-se realizar o mapeamento do plano operacional para o plano- $\alpha$, partindo-se das equações (3.5) e (3.6), substituindo nessas equações a definição realizada em (3.7) e realizando a manipulação matemática apresentada nas equações (3.10) a (3.17) (MOLAS, 2012). Por simplicidade definiu-se aqui a corrente de restrição como a diferença entre $\bar{I}_{m}$ e $\bar{I}_{n}$.

$$
\begin{gathered}
\left|\bar{I}_{m}+\bar{I}_{n}\right|=K\left|\bar{I}_{m}-\bar{I}_{n}\right| \\
\left|\frac{\bar{I}_{m}}{\bar{I}_{n}}+1\right|=K\left|1-\frac{\bar{I}_{m}}{\bar{I}_{n}}\right| \\
|a+j b+1|=K|-a-j b+1| \\
\sqrt{(a+1)^{2}+b^{2}}=K \sqrt{(1-a)^{2}+b^{2}} \\
a^{2}\left(1-K^{2}\right)+b^{2}\left(1-K^{2}\right)+2 a\left(1+K^{2}\right)+1-K^{2}=0 \\
a^{2}+b^{2}+2 a \frac{\left(1+K^{2}\right)}{\left(1-K^{2}\right)}+1=0
\end{gathered}
$$


completando-se quadrados para $a$ obtém-se:

$$
\left(a+\frac{1+K^{2}}{1-K^{2}}\right)^{2}+b^{2}=\left(\frac{1+K^{2}}{1-K^{2}}\right)^{2}-1
$$

que representa uma circunferência cujo centro e raio são:

$$
\text { CENTRO: }\left(-\frac{1+K^{2}}{1-K^{2}}, 0\right) ; \quad \text { RAIO: } \frac{2 K}{1-K^{2}}
$$

A circunferência formada, ilustrada na Figura 3.4, representa o limiar de operação do relé, sendo sua região interna a zona de restrição e a região externa a zona de atuação.

Vale ressaltar que este mapeamento dependerá de como é definida a corrente de restrição do relé diferencial. No caso do mapeamento das equações (3.3) e (3.4), considerando a operação definida por (3.5), a característica de restrição no plano- $\alpha$ será não-circular e, a depender do valor escolhido para o slope, poderá assumir a forma de uma cardioide (MOLAS, 2012).

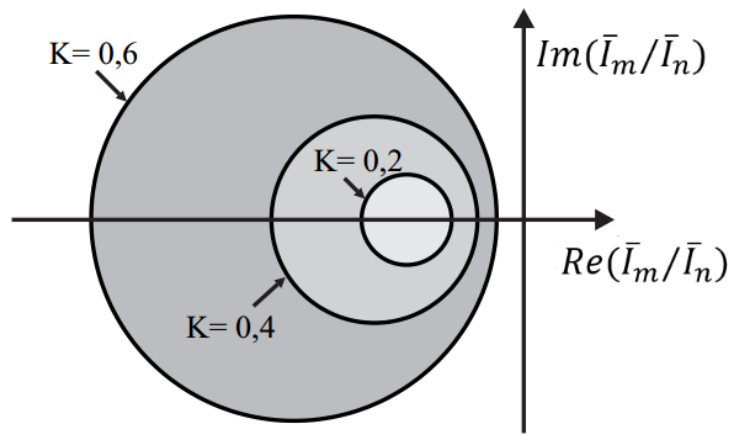

Figura 3.4 - Zonas de Restrição do Plano- $\alpha$ (MOLAS, 2012 - com adaptações).

\subsection{PROTEÇÃO DIFERENCIAL EM LINHAS DE TRANSMISSÃO}

Historicamente, a aplicação da proteção diferencial a linhas de transmissão restringia-se a linhas curtas, cuja distância entre os terminais viabilizava a troca de informações medidas por meio de fio piloto ou, quando houvesse disponibilidade, de canais de micro-ondas, cujos custos eram mais elevados. Com o advento das fibras ópticas, os meios de comunicação tornaram-se mais adequados para aplicação da função diferencial na proteção de linhas de transmissão, passando a ser empregada mesmo em linhas de comprimentos mais significativos com uso de fibras monomodo e mesmo a linhas bastante longas com o uso de repetidores ou amplificadores óticos. Graças à tecnologia digital, a função diferencial percentual começa a figurar dentre as funções integradas nas mais recentes proteções de linhas (NAVARRO et. al, 2003). 
Quando se aplica a proteção diferencial a linhas de transmissão, além dos problemas típicos relacionados e este tipo de proteção, como erros de medição e saturação de TCs, outros aspectos merecem ser destacados. Em se tratando de linhas, os terminais do sistema protegido se localizam a dezenas ou centenas de quilômetros de distância um do outro. Com isso, faz-se necessário utilizar um relé em cada terminal da linha para garantir a sua correta atuação. Desta forma, é preciso fazer uso de tecnologias de comunicação que garantam rapidez e segurança para a troca de informações entre eles. Além disso, diferentemente dos outros componentes do sistema, as linhas de transmissão apresentam corrente capacitiva (ou corrente de descarga) que não é considerada pela proteção diferencial, uma vez que não pode ser medida diretamente. Esta corrente pode gerar correntes diferenciais espúrias, levando a má atuação da proteção diferencial. Estes aspectos serão detalhados a seguir.

\subsubsection{Atrasos no Sistema de Comunicação}

Conforme mencionado anteriormente, os dispositivos de proteção localizados nos terminais da linha de transmissão estão separados por dezenas ou centenas de quilômetros necessitando, assim, da utilização de tecnologias de comunicação para realizar a troca de informações entre os relés. A Figura 3.5 apresenta o esquema de proteção diferencial aplicado a linhas, considerando o sistema de comunicação.

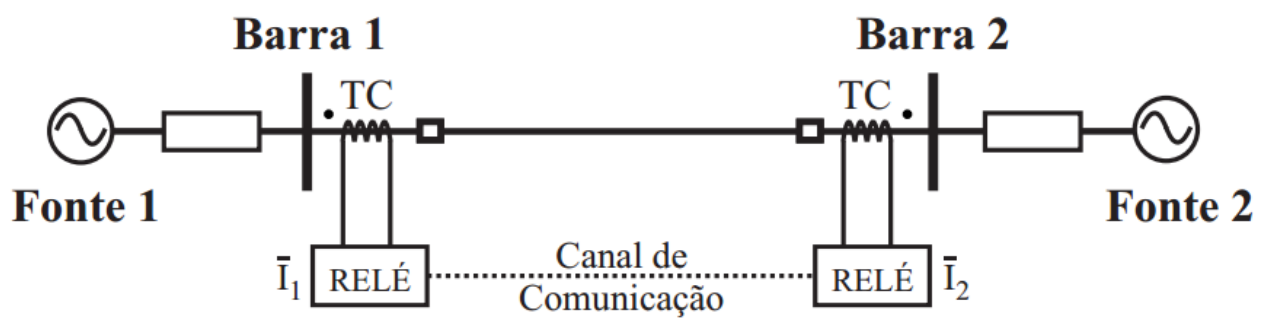

Figura 3.5 - Esquema da proteção diferencial aplicada a linhas de transmissão (MOLAS, 2012).

A troca de informações entre os dispositivos de proteção vem acompanhada de atrasos que afetam o desempenho da proteção, que são ocasionados pelo tempo de latência do canal de comunicação. Esses atrasos geram uma defasagem aparente entre os sinais adquiridos das correntes (Figura 3.6), o que requer compensação específica para se garantir o funcionamento adequado da proteção.

Com o intuito de exemplificar a magnitude do atraso de comunicação, supõe-se um atraso de $3 \mathrm{~ms}$ em um sistema de potência que opera a $60 \mathrm{~Hz}$ :

$$
\frac{T}{360^{\circ}}=\frac{3 \cdot 10^{-3}}{\theta} \Rightarrow \theta=\frac{\left(3 \cdot 10^{-3}\right) 360^{\circ}}{1 / 60}=64,8^{\circ}
$$


no qual o período T corresponde ao inverso da frequência fundamental do sistema.

Como pode ser visto na equação (3.18) um atraso de $3 \mathrm{~ms}$ corresponde a uma defasagem angular entre as amostras de aproximadamente $65^{\circ}$, o que pode ocasionar uma corrente diferencial espúria, provocando a atuação indevida da proteção diferencial.

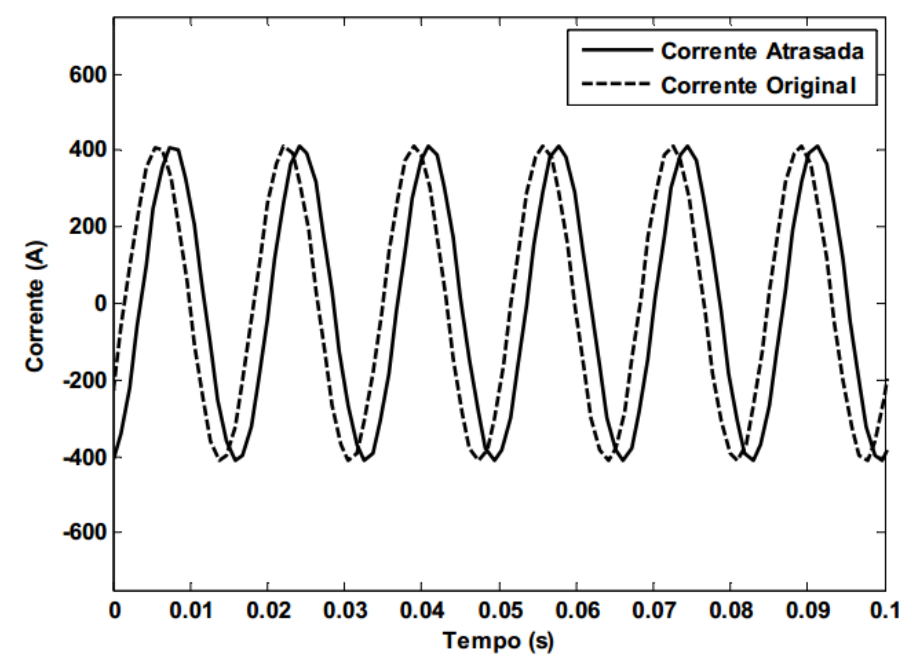

Figura 3.6 - Defasagem decorrente do atraso do canal de comunicação (MUNHOZ, 2011)

Dentre as técnicas de compensação do atraso de comunicação, a técnica denominada pingpong é a mais tradicional. Esta calcula o tempo de latência do canal como sendo a metade do tempo decorrido ida e volta de uma mensagem teste, sendo bastante efetiva em canais simétricos e que tenham variações pequenas no atraso ao longo do tempo. Havendo assimetria do canal, o que depende da arquitetura do sistema de telecomunicações, podem surgir atrasos não compensáveis inferiores a $2 \mathrm{~ms}$ (NAVARRO et. al, 2003).

A mais nova técnica de sincronização aplicada consiste na sincronização externa dos clocks dos relés de proteção utilizando o GPS (Global Positioning System), o qual marca cada amostra com o instante de tempo em que ela foi medida (SEZI et. al, 2008).

Outra forma de se compensar o atraso decorrente do canal de comunicação consiste em uma variação da técnica ping-pong. Nesta técnica o canal de comunicação é utilizado para realizar a sincronização entre os relés e, então envia-se os sinais de corrente com tags contendo o instante de tempo em que o sinal de corrente foi amostrado.

Ao tomar conhecimento do instante em que sinal de corrente recebido foi amostrado - por exemplo através de uma tag colocada no sinal transmitido - o relé receptor irá realizar o cálculo diferencial com a amostra coletada por ele no instante correspondente, mitigando, assim, o efeito do 
atraso de comunicação na proteção diferencial. A Figura 3.7 mostra como é feita a sincronização das amostras de corrente pelos relés diferenciais.

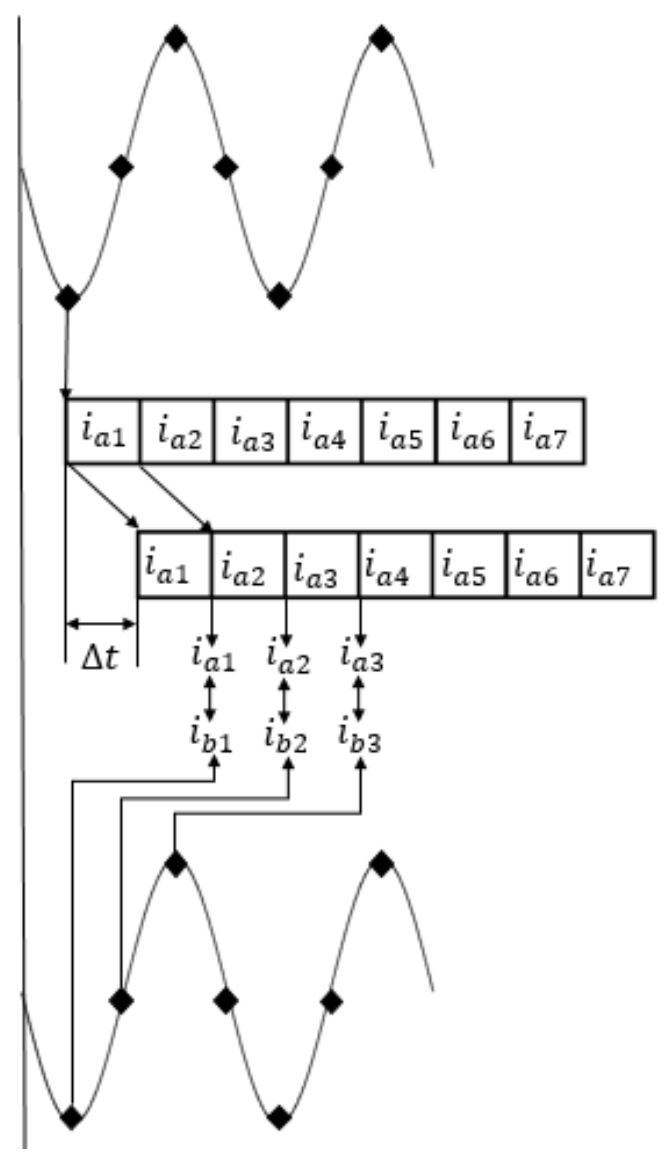

Figura 3.7 - Processo de sincronização das amostras

\subsubsection{Efeito da Corrente Capacitiva}

Conforme ilustrado na Figura 3.8, uma linha de transmissão possui capacitâncias distribuídas ao longo de sua extensão. Essas drenam a chamada corrente capacitiva da linha, ou corrente de descarga, responsável pelo efeito Ferranti na linha, além de interferir o desempenho dos diversos esquemas proteção aplicados às linhas. A distribuição desta corrente depende, essencialmente, do perfil de tensão da linha e de seus segmentos.

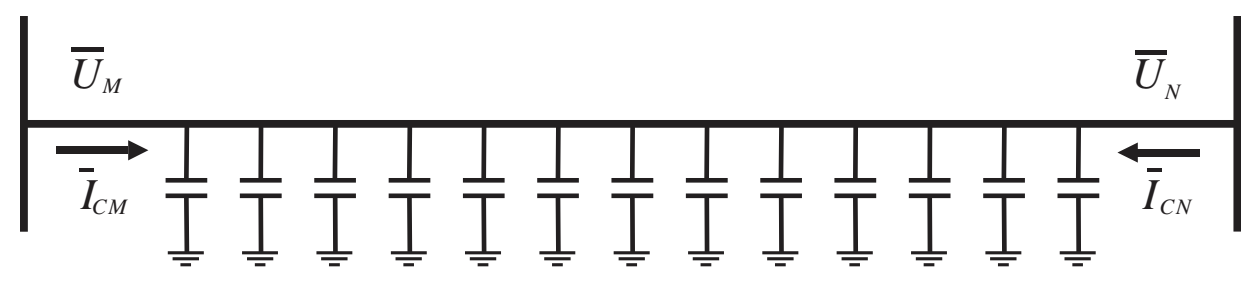

Figura 3.8 - Capacitâncias distribuídas da linha de transmissão.

Por não poder ser medida diretamente, a corrente capacitiva não é considerada pela formulação básica da proteção diferencial. Em linhas curtas, é razoável desprezar sua influência, uma vez que estas 
apresentam pouca corrente capacitiva. Entretanto, à medida que o comprimento e o nível de tensão da linha aumentam, a corrente capacitiva passa a alterar sobremaneira o comportamento esperado do sistema de proteção, afetando diretamente sua sensibilidade e confiabilidade (BI et al., 2005).

Em linhas de transmissão longas, tanto durante seu funcionamento normal, quanto durante uma falta externa, a corrente capacitiva atua como falsa corrente diferencial, podendo ocasionar a atuação indevida da proteção diferencial. No caso de linhas longas e com nível de tensão elevado a corrente capacitiva total pode chegar a centenas de ampères (MILLER et al., 2010). A corrente de pick$u p$ - termo $K_{0}$ da equação (3.6) - deve ser determinada levando em conta esta situação adicional.

O caso de maior magnitude de corrente capacitiva é o momento de energização da linha, sendo este o pior cenário para proteção, pois a corrente capacitiva surge alimentada apenas por um terminal, não existindo outra corrente que possa ser utilizada para a realização da restrição da mesma. Com isso, deve-se ajustar uma corrente de pick-up elevada para garantir a não atuação da proteção para este caso, o que acarreta em perda de sensibilidade da proteção. Outro fator complicador no que tange à influência da corrente capacitiva no momento da energização é que esta possui uma parcela transitória, com valores de pico muito superiores aos encontrados em regime permanente, prejudicando ainda mais o bom funcionamento da proteção (KASZTENNY et. al, 2011).

Como os sistemas de transmissão em UAT têm como principal objetivo a transmissão de grandes blocos de energia a longas distâncias, estes requerem máxima segurança e confiabilidade, visto que o desligamento deste tipo de sistema ocasiona a interrupção de grande número de consumidores industriais e residenciais. Além disso, para minimizar as perdas nas linhas, maximizando assim sua eficiência, sistemas de UAT utilizam condutores dispostos com uma geometria tal que resultam em elevados valores de capacitância shunt para o sistema de transmissão. Isso faz com que este tipo de linha tenha uma corrente de descarga ainda maior, tornando-se de suma importância sua compensação. A solução mais adequada é a aplicação de um algoritmo de remoção da corrente capacitiva, ou de lógicas diferenciais que a levem em consideração. 


\section{CAPÍTULO 4}

\section{ALGORITMOS AVALIADOS}

Como foi dito anteriormente, diferentemente dos outros componentes do sistema, as linhas de transmissão apresentam corrente capacitiva, que, a princípio, não é considerada pela proteção diferencial convencional, uma vez que não pode ser medida diretamente. Contudo, a não consideração dela pode levar a uma má atuação da proteção. Portanto, essa corrente deve ser compensada pelo algoritmo da proteção diferencial, a fim de viabilizar sua aplicação em linhas de transmissão.

Tradicionalmente, os métodos de compensação definem a capacitância shunt da LT como um elemento a parâmetros concentrados, o que, via de regra, não é recomendado para a proteção diferencial de linhas de UAT, visto que esta consideração não garante a sensibilidade, confiabilidade e segurança requeridas para esse tipo de linha, já que estas possuem elevados valores de capacitância shunt.(MOLAS et al., 2014). No estado da arte acerca deste assunto existem diferentes algoritmos de compensação da corrente capacitiva, sendo que em alguns deles a própria corrente é estimada e subtraída das correntes medidas, enquanto que em outros o seu valor não é estimado, mas levado em consideração indiretamente na formulação empregada. A seguir serão definidos alguns destes algoritmos, os quais farão parte da análise da proteção diferencial realizada nesta dissertação.

\subsection{MODELO DE CAPACITÂNCIAS CONCENTRADAS}

Neste método, descrito em Miller et al. (2010), o cálculo da corrente capacitiva é feito utilizando a média da tensão na linha e sua capacitância total (4.2). Isso pode ser realizado calculandose a contribuição individual dos terminais da linha para a corrente capacitiva como se houvesse um capacitor concentrado em cada um deles, conforme representado na Figura 4.1. Uma vez que $\bar{U}_{\text {média }}=$ $\sum_{i=1}^{n} \bar{U}_{i} / n$, sendo $n$ o número de terminais da linha protegida, cada terminal irá drenar a corrente capacitiva $\bar{I}_{C, i}$ descrita em (4.3) no domínio da frequência.

$$
\begin{gathered}
\bar{I}_{C, \text { total }}=j \omega C_{\text {total }} \cdot \bar{U}_{\text {média }} \\
\bar{I}_{C, i}=\frac{1}{n} \cdot j \omega C_{\text {total }} \cdot \bar{U}_{i}
\end{gathered}
$$


na qual $\bar{U}_{i}$ é a tensão medida no $i$-ésimo terminal da linha, e $\omega$ é a frequência angular fundamental do sistema.

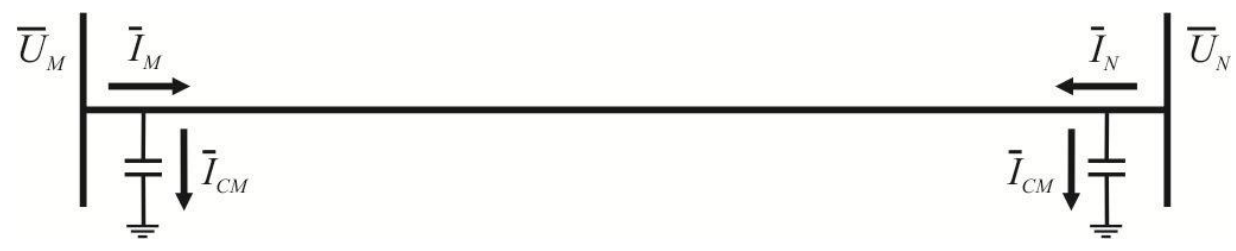

Figura 4.1 - Modelo de Capacitâncias Concentradas da linha.

Com isso, cada terminal possui uma parcela da corrente de descarga, não havendo a necessidade de enviar amostras de tensão adicionais pelo canal de comunicação. Cada relé envia uma corrente compensada $\bar{I}_{T X}$, como indicado em (4.4).

$$
\bar{I}_{T X}=\bar{I}_{i}-\bar{I}_{C, i}
$$

na qual $\bar{I}_{i}$ é a medição de corrente obtida no $i$-ésimo terminal da linha e $\bar{I}_{T X}$ é a corrente compensada que será transmitida pelo canal de comunicação.

A compensação ocorre de maneira automática quando o relé local calcula a corrente diferencial do sistema utilizando os valores compensados recebidos, como apresentado em (4.5) e (4.6).

$$
\begin{gathered}
I_{\text {Dif,comp }}=\left|\bar{I}_{T X}+\sum_{i=1}^{n-1} \bar{I}_{R X}\right|=\left|\sum_{i=1}^{n-1} \bar{I}_{i}-\sum_{i=1}^{n-1} \bar{I}_{C, i}\right| \\
I_{\text {Dif,comp }}=\left|\bar{I}_{D i f}-\bar{I}_{C, \text { total }}\right|
\end{gathered}
$$

na qual $\bar{I}_{T X}$ é a corrente compensada que será transmitida pelo terminal que está calculando a corrente diferencial e $\bar{I}_{R X}$ são as correntes compensadas recebidas dos outros terminais da linha.

Em sistemas trifásicos, de forma geral, aplica-se (4.7) para calcular a corrente capacitiva das três fases em cada terminal. Os elementos da diagonal principal representam as capacitâncias próprias de cada fase enquanto o restante dos elementos são capacitâncias mútuas entre fases, as quais podem ser obtidas a partir das susceptâncias de sequência positiva e zero da linha de transmissão.

$$
\left[\begin{array}{l}
\bar{I}_{A} \\
\bar{I}_{B} \\
\bar{I}_{C}
\end{array}\right]_{C a p}=\left[\begin{array}{lll}
C_{A A} & C_{A B} & C_{A C} \\
C_{B A} & C_{B B} & C_{B C} \\
C_{C A} & C_{C B} & C_{C C}
\end{array}\right] \cdot j \omega\left[\begin{array}{l}
\bar{U}_{A} \\
\bar{U}_{B} \\
\bar{U}_{C}
\end{array}\right]
$$


Neste ponto cabe ressaltar que este algoritmo faz uso tanto dos sinais de corrente quanto dos sinais de tensão dos terminais da linha, o que acarreta a necessidade de instalação de transformadores de potencial (TPCs), agregando erros de medição inerentes a este equipamento.

\subsection{MÉTODO DA MEMÓRIA DE CORRENTE CAPACITIVA}

Gajié et al. (2010) propuseram um método que obtém o valor da corrente capacitiva ao longo do tempo e subtrai este do valor mais recente de corrente diferencial calculado. Tal método não depende da tensão e pode ser aplicado para configurações com mais de dois terminais.

Inicialmente, armazena-se a amplitude dos valores calculados de corrente diferencial a partir dos fasores dos últimos cinco ciclos de regime permanente. Em seguida, estima-se a corrente capacitiva das linhas como a média dos três últimos ciclos armazenados, conforme descrito em (4.1). Por fim, subtrai-se a corrente capacitiva calculada do valor atual de corrente diferencial, resultando em uma corrente de operação confiável. O processo de remoção é aplicado a todas as fases do sistema, eliminando praticamente toda a corrente capacitiva durante o regime permanente.

$$
I_{c}(k)=\frac{1}{3 N} \sum_{n=1}^{3 N} I_{o p}(k-3 N+n)
$$

na qual $N$ corresponde ao número de amostras por ciclo correspondente à taxa de amostragem empregada aos sinais.

Segundo Gajié et al. (2010), essa compensação deve ser feita apenas durante o funcionamento normal do sistema. Na ocorrência de falta, ou durante outros distúrbios, não são atualizados os valores de corrente capacitiva. Nesses momentos, aplica-se o último valor de corrente capacitiva calculado no regime permanente. Esta característica requer o uso de um detector de faltas, uma unidade direcional e considera que o perfil de tensão permanece inalterado durante um distúrbio do sistema.

Cinco ciclos após o retorno do sistema para a condição normal de carga, reinicia-se o cálculo dos valores de corrente capacitiva.

\subsection{PROTEÇÃO DIFERENCIAL UTILIZANDO EQUAÇÕES DE REGIME PERMANENTE DO MODELO $\Pi$ EQUIVALENTE DA LINHA DE TRANSMISSÃO}

Xu et al. (2007) propuseram uma nova forma de aplicar o princípio diferencial levando em consideração a natureza distribuída dos parâmetros da linha de transmissão. Ao invés de comparar as correntes medidas em ambos os terminais da linha (aqui denotados por $m$ e $n$ ), escolhe-se um ponto $k$ 
comum para comparação (Figura 4.2). Utilizando-se o modelo $\pi$ equivalente da linha, calculam-se as correntes neste ponto e então estas são comparadas da forma tradicional. A representação da linha a partir do modelo $\pi$ equivalente é apresentada na Figura 4.3.

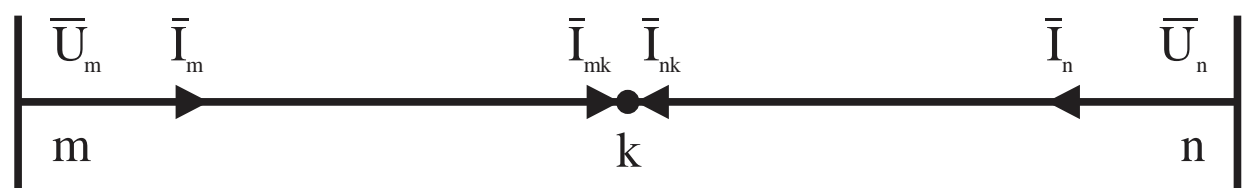

Figura 4.2 - Correntes do método de proteção diferencial baseado no Modelo $\pi$ Equivalente da linha.

Considerando os sentidos assumidos na Figura 4.2, com os fasores de tensão e corrente medidos nos terminais da linha, pode-se obter e reduzir as equações de regime permanente do modelo $\pi$ equivalente, para o quadripolo no domínio da frequência apresentado em (4.8).

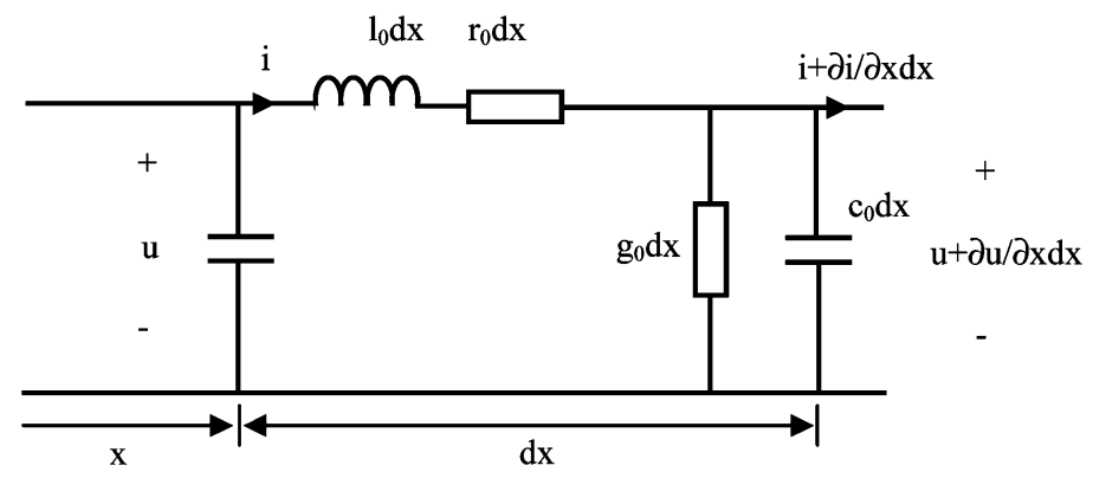

Figura 4.3 -Modelo $\pi$ Equivalente da linha de transmissão.

$$
\left[\begin{array}{c}
\bar{U}_{m} \\
\bar{I}_{m}
\end{array}\right]=\left[\begin{array}{cc}
\operatorname{ch}\left(\gamma l_{n m}\right) & -Z_{C} \operatorname{sh}\left(\gamma l_{n m}\right) \\
\frac{\operatorname{sh}\left(\gamma l_{n m}\right)}{Z_{C}} & -\operatorname{ch}\left(\gamma l_{n m}\right)
\end{array}\right] \cdot\left[\begin{array}{c}
\bar{U}_{n} \\
\bar{I}_{n}
\end{array}\right]
$$

na qual $Z_{C}$ é a impedância característica da linha, $\gamma$ é sua constante de propagação e $l_{n m}$ é a distância entre os terminais $n$ e $m$.

As correntes $\bar{I}_{m k}$ e $\bar{I}_{n k}$, obtidas a partir de uma adaptação da equação (4.8), são utilizadas como entradas da proteção diferencial percentual. Uma vez que ambas estão referenciadas ao mesmo ponto, não são afetadas pela corrente capacitiva e, a menos dos erros de medição dos TCs, sua soma é zero durante o regime permanente de carga.

Pode-se demonstrar que, se $\bar{I}_{m k}$ e $\bar{I}_{n k}$ forem utilizadas na obtenção da corrente diferencial $I_{D \emptyset}$ indicada em (4.9), durante uma falta interna, esta seria adequada para sensibilizar um relé diferencial. Por outro lado, para uma falta externa e operação em regime permanente de carga, esta corrente 
diferencial seria próxima de zero. Por sua vez, a corrente de restrição $I_{B \emptyset}$ pode ser obtida utilizando-se a equação apresentada em (4.10).

$$
\begin{gathered}
I_{D \emptyset}=\left|\bar{I}_{m k \emptyset}+\bar{I}_{n k \emptyset}\right| \\
I_{B \emptyset}=\left|\bar{I}_{m k \emptyset}-\bar{I}_{n k \emptyset}\right|
\end{gathered}
$$

nas quais $\emptyset$ representa uma das fases ou a corrente de sequência zero, sendo que esta última é utilizada para proteção contra faltas com alta resistência.

O trip segue uma lógica conhecida, na qual a corrente diferencial (ou de operação) é comparada com a corrente de restrição e com a corrente de pick-up $\left(I_{h}\right)$. Esta última é escolhida de forma a compensar a queda no valor obtido da corrente $I_{D \emptyset}$ à medida que a distância entre o ponto de comparação e o ponto onde ocorre a falta aumenta. Os autores sugerem (4.11) como condição de atuação.

$$
\left\{\begin{array}{cl}
\left(I_{D \emptyset}>I_{h}\right) e\left(I_{D}>k_{1} I_{B \emptyset}\right), & \text { se }\left(0<I_{B \emptyset}<3 I_{h}\right) \\
\text { ou } & \text { se }\left(I_{B \emptyset}>3 I_{h}\right)
\end{array}\right.
$$

nas quais $I_{h}$ é o limiar determinado levando em consideração o efeito citado acima e $k_{1}$ e $k_{2}$ são as diferentes inclinações da característica de restrição do relé diferencial percentual.

\subsection{PROTEÇÃO DIFERENCIAL BASEADA NO MODELO DE BERGERON DA LINHA DE TRANSMISSÃO}

De forma análoga ao método de proteção diferencial que utiliza as equações de regime permanente do modelo $\pi$ equivalente da linha, apresentado no Item 4.3 deste capítulo, este não é uma forma explicita de remoção da corrente capacitiva e sim uma maneira alternativa de aplicação do princípio diferencial.

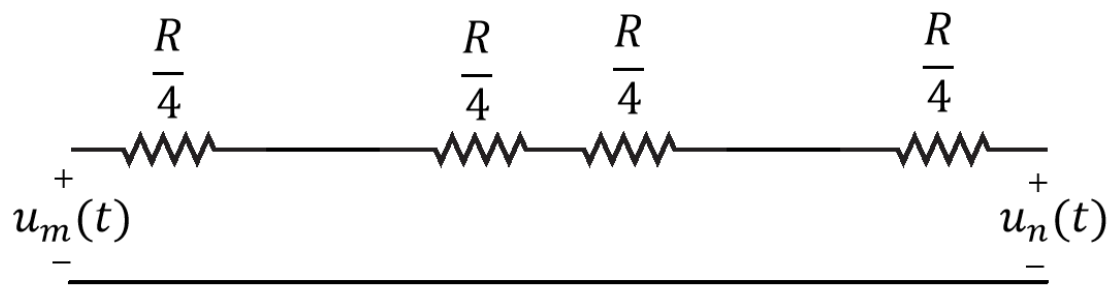

Figura 4.4 - Modelagem das perdas dividindo a linha de transmissão em duas partes iguais. 
O Modelo de Bergeron representa a linha através de seus parâmetros distribuídos, $L$ e $C$, e uma resistência concentrada $R$, como indicado na Figura 4.4. Este é um modelo exato de ondas viajantes que inclui perdas na linha pela adição do parâmetro concentrado $R$ dividido em três partes. Para considerar as perdas, a linha de transmissão é dividida em duas partes iguais e as perdas são concentradas nas extremidades, conforme ilustrado na Figura 4.4. O modelo é amplamente aplicado em softwares do tipo EMTP (Electromagnetic Transients Program) para o cálculo de transitórios eletromagnéticos em sistemas elétricos de potência.
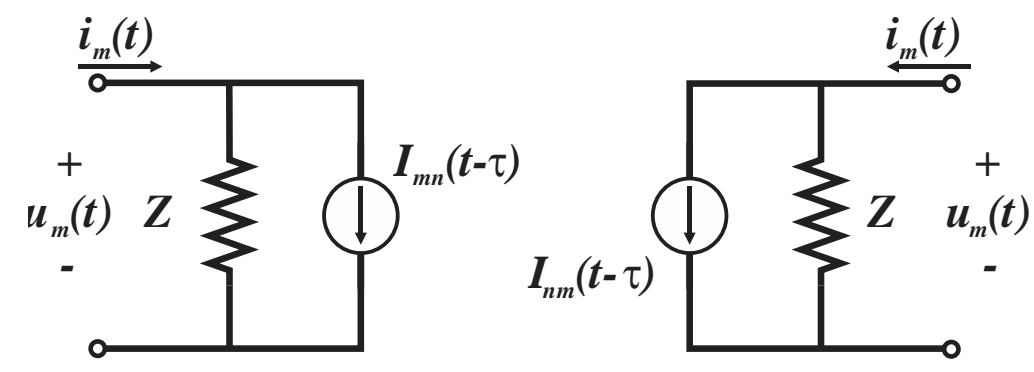

Figura 4.5- Modelo de Bergeron da linha de transmissão.

Em circuitos monofásicos o Modelo de Bergeron permite, para cada amostra de tensão e corrente $\left(u_{m}, i_{m}\right)$ obtida em um terminal, calcular essas mesmas grandezas no lado oposto da linha, utilizando as equações (4.12)-(4.16) no domínio do tempo (ARAÚJO \& NEVES, 2005).

$$
\begin{gathered}
Z_{0}=\sqrt{\frac{L_{0}}{C_{0}}} \quad Z=Z_{0}+\frac{R}{4} \\
\begin{array}{c}
Z_{0}-\frac{R}{4} \\
Z_{0}+\frac{R}{4}
\end{array} \quad \tau=\frac{l}{v}=l \sqrt{L_{0} C_{0}} \\
\begin{array}{c}
I_{m n}(t-\tau)=-\frac{1-h}{2}\left[\frac{u_{m}(t-\tau)}{Z}+i_{m}(t-\tau)\right] \\
-\frac{1+h}{2}\left[\frac{u_{n}(t-\tau)}{Z}+i_{n}(t-\tau)\right] \\
I_{n m}(t-\tau)=-\frac{1-h}{2}\left[\frac{u_{n}(t-\tau)}{Z}+i_{n}(t-\tau)\right] \\
-\frac{1+h}{2}\left[\frac{u_{m}(t-\tau)}{Z}+i_{m}(t-\tau)\right] \\
i_{m}(t)=\frac{u_{m}(t)}{Z}+I_{m n}(t-\tau)
\end{array}
\end{gathered}
$$




$$
i_{n}(t)=\frac{u_{n}(t)}{Z}+I_{n m}(t-\tau)
$$

nas quais, $L_{0}$ e $C_{0}$ são a indutância e capacitância por quilômetro da linha; $R$ é a sua resistência total; $Z_{0}$ é a sua impedância de surto; $Z$ é a impedância equivalente depois de considerar as perdas; $h$ é o coeficiente de reflexão da corrente, $l$ é o comprimento da linha; $I_{m n}$ e $I_{n m}$ são fontes de corrente fictícias representando as reflexões das ondas nos terminais da linha;. $\tau$ é o seu tempo de trânsito; $u_{m}$ e $u_{n}$ são as tensões nas extremidades da linha e $i_{m}$ e $i_{n}$ são correntes entrando na linha, como mostrado na Figura 4.4 .

Em sistemas trifásicos, a decomposição modal é geralmente utilizada, uma vez que as fases são acopladas e interferem umas nas as outras. Para tanto, podem ser utilizadas diferentes transformações. Neste artigo, a transformação de Karrenbauer é aplicada, através das equações (4.17) e (4.18).

$$
\begin{gathered}
{\left[\begin{array}{l}
i_{o} \\
i_{1} \\
i_{2}
\end{array}\right]=\frac{1}{3}\left[\begin{array}{ccc}
1 & 1 & 1 \\
1 & -1 & 0 \\
1 & 0 & -1
\end{array}\right]\left[\begin{array}{l}
i_{a} \\
i_{b} \\
i_{c}
\end{array}\right]} \\
{\left[\begin{array}{l}
i_{a} \\
i_{b} \\
i_{c}
\end{array}\right]=\left[\begin{array}{ccc}
1 & 1 & 1 \\
1 & -2 & 1 \\
1 & 1 & -2
\end{array}\right]\left[\begin{array}{l}
i_{o} \\
i_{1} \\
i_{2}
\end{array}\right]}
\end{gathered}
$$

Neste método, apresentado de forma ilustrativa na Figura 4.5, calcula-se a corrente diferencial em cada terminal, composta pelos fasores obtidos localmente $\bar{I}_{m}$ e pela corrente recebida do terminal oposto $\bar{I}_{J m}$, que corresponde a corrente $\bar{I}_{m}$ estimada a partir das grandezas do terminal oposto. Ambos são fasores locais, não sendo afetados pela corrente capacitiva. O cálculo da corrente diferencial é definido em (4.19). Observa-se que, como estas correntes têm o mesmo sentido, deve-se subtraí-las, ao invés de somá-las da maneira convencional mostrada em (3.1).

$$
d I_{m \varnothing}=\left|\bar{I}_{m \varnothing}-\bar{I}_{J m \varnothing}\right|
$$

sendo que $\emptyset$ corresponde a fase para qual está se efetuando a proteção. 


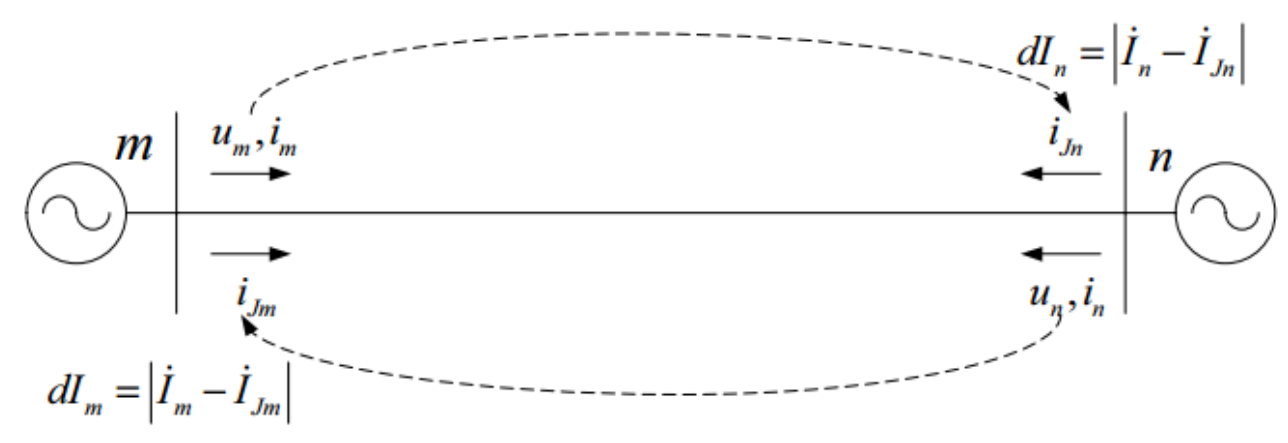

Figura 4.6 - Correntes do método de proteção diferencial baseado no Modelo de Bergeron da linha

Devido aos erros de transmissão de dados e às perdas pela aproximação da resistência $R$, devese definir uma corrente de pick-up $\left(I_{\text {set }}\right)$ adequada para que se utilize o critério de operação (4.20). Um outro fator que tem de ser considerado na escolha desta corrente é a necessidade de interpolação dos dados nos quais o tempo de trânsito não corresponde a um múltiplo do passo de cálculo do Modelo de Bergeron, o que agrega erro ao cálculo das correntes de operação e restrição (ARAÚJO \& NEVES, 2008).

$$
d I_{m \emptyset} \geq I_{\text {set }}
$$




\section{CAPÍTULO 5}

\section{APRESENTAÇÃO E ANÁLISE DOS RESULTADOS}

Neste capítulo, apresentam-se os resultados obtidos com a análise do desempenho dos algoritmos de proteção diferencial propostos na literatura aplicados às linhas de transmissão de UAT. Para uma efetiva comparação entre eles, dois tipos de análises foram realizados: análises da resposta transitória e análises da resposta em regime permanente.

A fim de se verificar as respostas no tempo dos diversos algoritmos, foram simulados casos de faltas dentro e fora da zona de proteção, bem como a energização da linha analisada com e sem curtocircuito aplicado.

Já para a averiguação da resposta de regime permanente, foram realizadas análises de sensibilidade paramétrica, variando um dos seguintes parâmetros por vez: localização da falta, resistência de falta, carregamento do sistema e força das fontes. Além disso, para cada variação desses parâmetros, foram simulados diversos tipos de curtos-circuitos: monofásicos, bifásicos, bifásicos-terra e trifásicos.

Cabe ressaltar que os resultados das simulações apresentados a seguir representam correntes primárias em pu da corrente nominal da linha e que, uma vez que o objetivo deste trabalho é comparar o desempenho dos diferentes algoritmos, optou-se pela utilização de uma única característica de restrição no plano operacional para todos eles, que possui corrente de pick-up igual a 0,3 pu e um slope de $40 \%$.

\subsection{O SISTEMA ELÉTRICO SIMULADO}

O sistema de potência escolhido para a realização das análises que compõem este trabalho é composto por uma linha de circuito duplo com 645 km de extensão e $1000 \mathrm{kV}$ operando a $60 \mathrm{~Hz}$, cuja geometria da torre é apresentada na Figura 5.1. Cada fase é composta por um feixe de 08 (oito) condutores, além de serem usados dois cabos de guarda, também indicados na figura. Este sistema corresponde a linha que está em operação no sistema elétrico interligado da China, interconectando os seus subsistemas Norte e Sul, partindo desde a subestação (SE) Jindongnan na província de Shanxi, passando pela SE Nanyang na província de Henan e finalizando na SE Jingmen na província de Hubei (XU et al., 2007). 


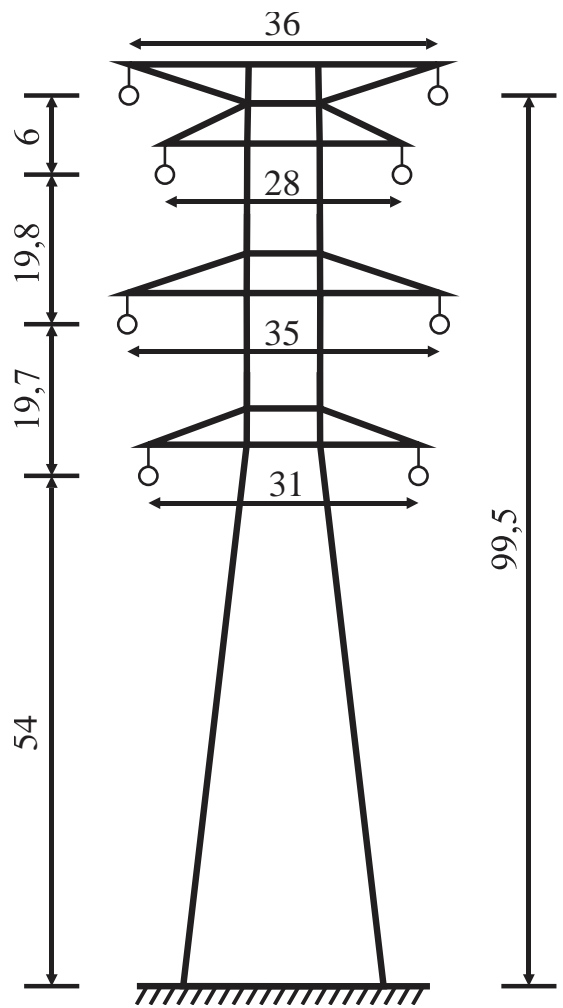

Figura 5.1 - Geometria da torre de transmissão - unidades em metros (LI et al., 2012).

Os parâmetros da linha de transmissão, obtidos a partir de resultados da utilização da rotina Line Constants do software ATP, são apresentados na Tabela 5.1. Os modos apresentados nesta tabela são modos especiais utilizados em cartão específico para a representação de circuitos duplos do software ATP, o qualmodela a linha como um circuito duplo perfeitamente transposto, a parâmetros distribuídos e constantes com a frequência, representando adequadamente o acoplamento de sequência zero entre as linhas (LEUVEN EMTP CENTER, 1987).

Tabela 5.1 - Parâmetros da Linha de Transmissão.

\begin{tabular}{cccc}
\hline & $\mathrm{R}[\Omega / \mathrm{km}]$ & $\mathrm{L}[\mathrm{H} / \mathrm{km}]$ & $\mathrm{C}[\mu \mathrm{F} / \mathrm{km}]$ \\
\hline Modo-G & 0,6536 & 2,0295 & 1,9168 \\
Modo-L & 0,0426 & 0,3439 & 4,8042 \\
Modo-IL & 0,0384 & 0,5069 & 3,5076 \\
\hline
\end{tabular}

O diagrama unifilar do sistema simulado está representado na Figura 5.2. Cada terminal é composto por sua respectiva fonte, um transformador de potencial capacitivo (TPC) e um TC. Esses equipamentos são utilizados para medição das grandezas necessárias à aplicação dos algoritmos de proteção diferencial. Todavia, faz-se a ressalva que aqui eles foram modelados como ideais, a fim de limitar às análises na comparação do desempenho dos algoritmos avaliados, sem levar em consideração os erros ocasionados por equipamentos. Os dados dos equivalentes de Thévenin foram obtidos a partir das potências de curto-circuito fornecidas por Xu et al. (2007) para cada um dos terminais da linha. Com o objetivo de simplificar a implementação do sistema, esses dados foram referenciados ao lado de alta dos transformadores para instrumento apresentados nesta mesma referência, alteração esta que não afeta 
as simulações propostas neste trabalho. Os dados das impedâncias dos equivalentes de Thévenin são apresentados na Tabela 5.2.

Tabela 5.2 -Dados das impedâncias dos equivalentes de Thévenin

\begin{tabular}{|c|c|c|}
\hline & Impedância Fonte Local [ $\Omega]$ & Impedância Fonte Remota [ $[\Omega]$ \\
\hline Sequência Positiva & j 39,16 & j 36,34 \\
\hline Sequência Negativa & j 39,16 & j 36,34 \\
\hline Sequência Zero & j 61,76 & j 72,76 \\
\hline
\end{tabular}

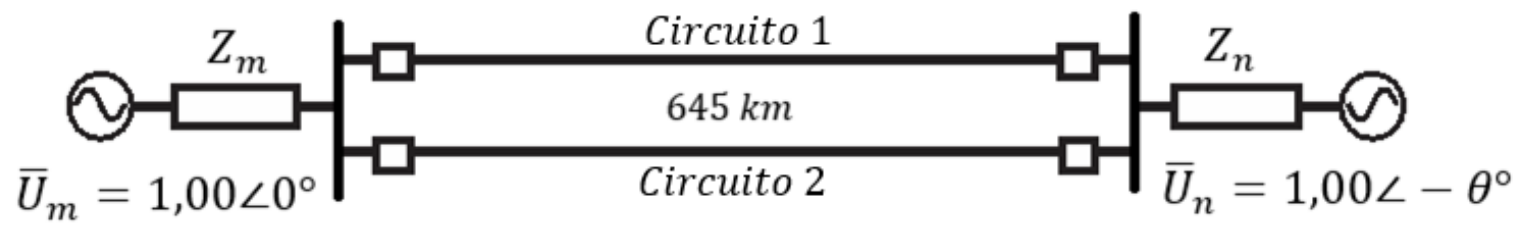

Figura 5.2 - Sistema Simulado.

\subsection{ANÁLISE DA RESPOSTA TRANSITÓRIA DA PROTEÇÃO DIFERENCIAL}

A seguir, serão apresentados os resultados das respostas no tempo de cada algoritmo avaliado, bem como os resultados da proteção diferencial percentual tradicional, ou seja, sem compensação da corrente capacitiva.

Para a realização das simulações, foi considerado um passo de integração de $8,333 \cdot 10^{-6} s$ (2000 amostras por ciclo). Já para durante o cálculo dos algoritmos de proteção diferencial, foi considerada uma taxa de amostragem de 20 amostras por ciclo, mesma taxa utilizada por Xu et al. (2007), e o algoritmo de estimação de fasores utilizado foi o Filtro Cosseno Modificado da ABB, detalhado em Hart et al. (2000).

Todas as simulações de falta foram realizadas iniciando a simulação em regime permanente e aplicando os curtos-circuitos após 300 ms de simulação, bem como a energização. Nas figuras que representam a resposta transitória da proteção diferencial utilizando os diversos algoritmos (Figuras 5.3 a 5.22), foram plotados apenas pontos que representam o regime transitório de falta, ou seja, os pontos obtidos após 300 ms de simulação. Onde é necessário para o correto entendimento da figura, o ponto que corresponde ao início da falta é indicado por uma seta vermelha.

Como foi dito anteriormente, as simulações desenvolvidas para este trabalho incluem casos com e sem aplicação de faltas em diversas condições de carregamento da linha. Contudo, serão apresentados alguns dos casos mais adversos: falta monofásica, falta monofásica externa, energização da linha sem curto-circuito e energização da linha com curto-circuito, todos estes com a condição de 
carregamento de defasagem de $10^{\circ}$ entre as barras local e remota. Além disso, as faltas aqui apresentadas foram aplicadas na metade do circuito 1 da linha analisada.

\subsubsection{Sistema com falta monofásica}

Durante o regime de falta, a presença da corrente capacitiva não dificulta o desempenho do sistema de proteção, uma vez que ela contribui para a corrente diferencial. Contudo, é necessário verificar se os métodos de remoção afetam a segurança e a confiabilidade da atuação do sistema de proteção. Aplicou-se, então uma falta monofásica na metade do circuito 1 da linha analisada. Os resultados obtidos a partir das tensões e correntes vistas nos terminais da linha, mas referentes ao circuito 1, são mostrados nas Figuras de 5.3 a 5.7.

Observa-se na Figura 5.3 que, como era esperado, se não for aplicado nenhum método de remoção da corrente capacitiva, esta atua como falsa corrente diferencial, ocasionando a atuação indevida da proteção diferencial durante o regime permanente de pré-falta.

De forma geral, os métodos funcionam corretamente, atuando apenas para a fase afetada pela falta. O método que faz uso do Modelo $\pi$ Equivalente da linha, apesar de restringir corretamente as fases sãs, fica na iminência de atuação nas mesmas. Nesta condição, qualquer fator que afete o desempenho do relé pode leva-lo a uma atuação indevida.

Por sua vez, o método da Memória de Corrente Capacitiva acarreta em uma não atuação da proteção, ao restringir a fase defeituosa. Esta situação evidencia o fato de que este método superestima a corrente capacitiva durante a falta, já que uma vez detectado o defeito, não mais atualiza-se o valor da corrente capacitiva, sendo usado o valor de pré-falta durante o defeito. De fato, durante a falta, há uma queda da tensão na fase envolvida, diminuindo assim a corrente capacitiva da linha. Uma vez que este algoritmo remove o valor absoluto da corrente de pré-falta, retira, com isso, parte da corrente diferencial gerada pelo curto-circuito. 


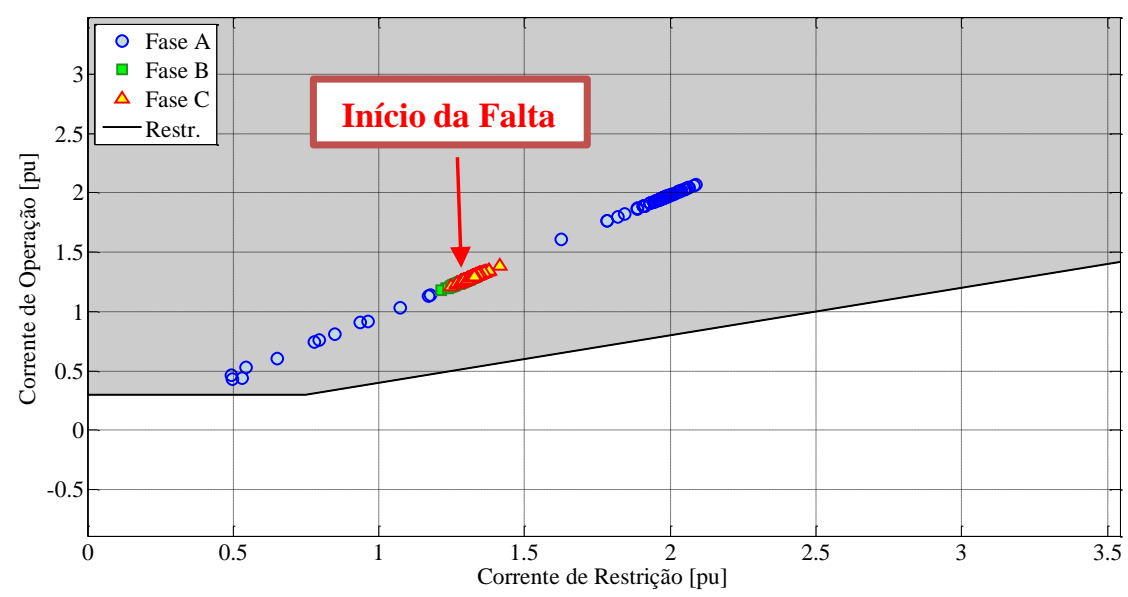

Figura 5.3 - Resposta transitória para falta monofásica na metade do circuito 1: Correntes Sem Compensação (pontos de instantes após o momento da falta).

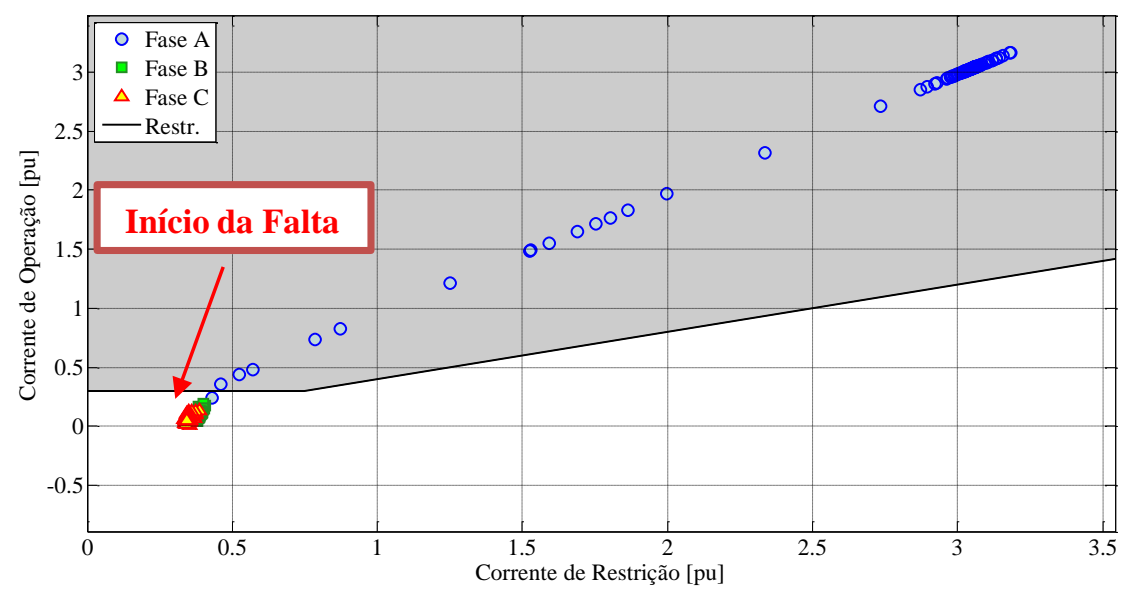

Figura 5.4 - Resposta transitória para falta monofásica na metade do circuito 1: Método das Capacitâncias Concentradas (pontos de instantes após o momento da falta).

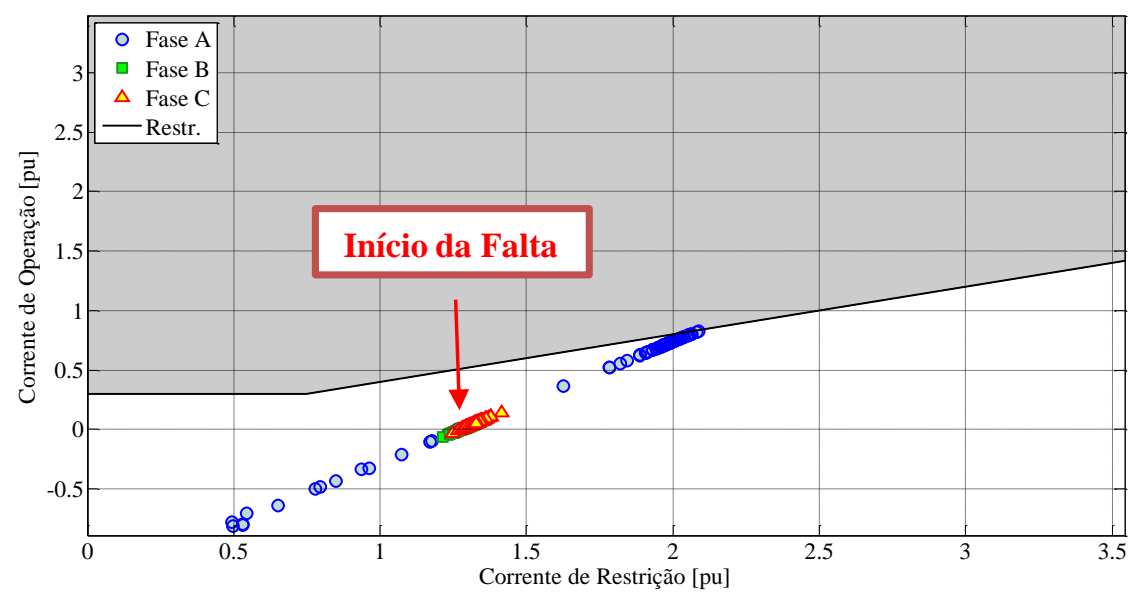

Figura 5.5 - Resposta transitória para falta monofásica na metade do circuito 1: Método da Memória de Corrente Capacitiva (pontos de instantes após o momento da falta). 


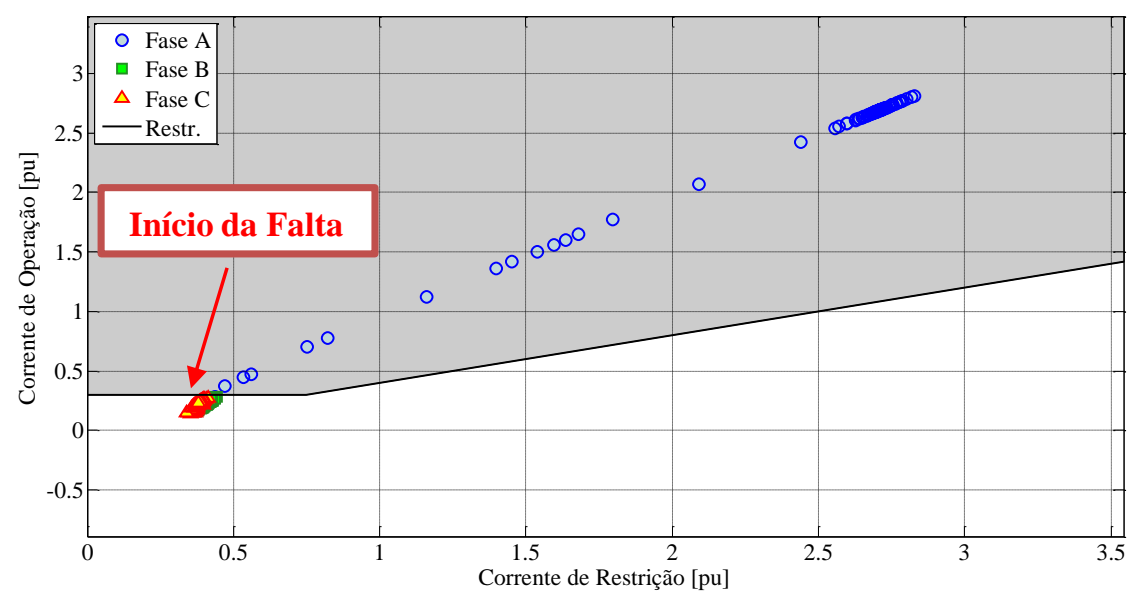

Figura 5.6 - Resposta transitória para falta monofásica na metade do circuito 1: Modelo $\pi$-Equivalente da linha (pontos de instantes após o momento da falta).

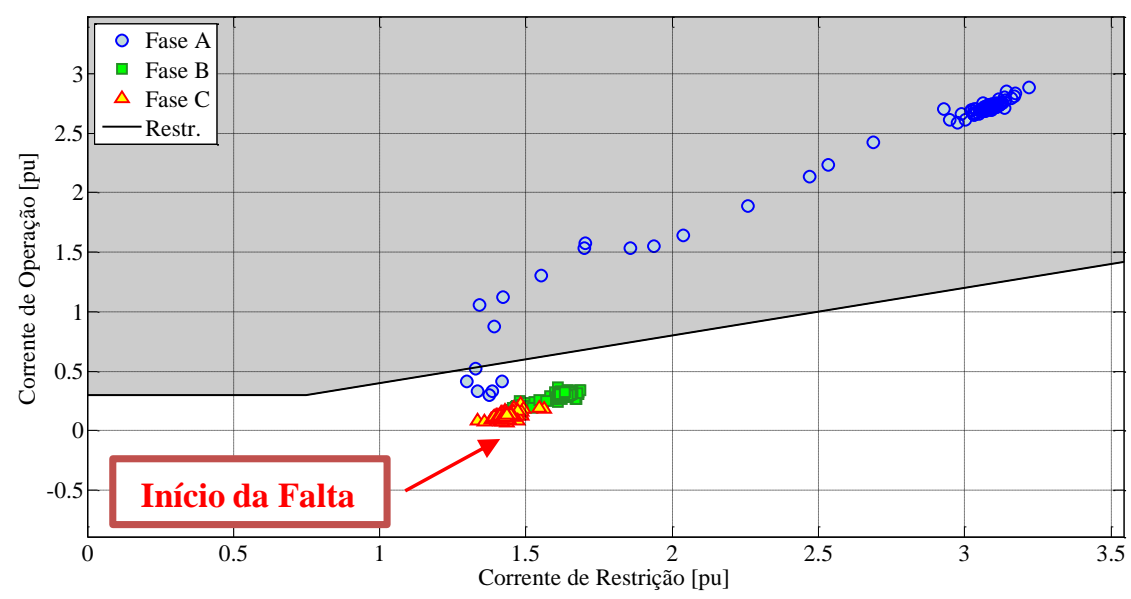

Figura 5.7 - Resposta transitória para falta monofásica na metade do circuito 1: Modelo de Bergeron da linha (pontos de instantes após o momento da falta).

\subsubsection{Falta monofásica externa a montante do terminal local}

Uma condição que também merece destaque é a falta externa à região protegida pela proteção diferencial. As Figuras de 5.8 a 5.12 contêm os resultados obtidos nesta situação, referentes à proteção do circuito 1. Observa-se que, durante a falta externa, se não for aplicado nenhum dos métodos estudados, a falsa corrente diferencial gerada pelas capacitâncias da linha causa a atuação indevida do relé. Notadamente, nesse caso, todos os métodos resultam na correta restrição da atuação da proteção diferencial. 


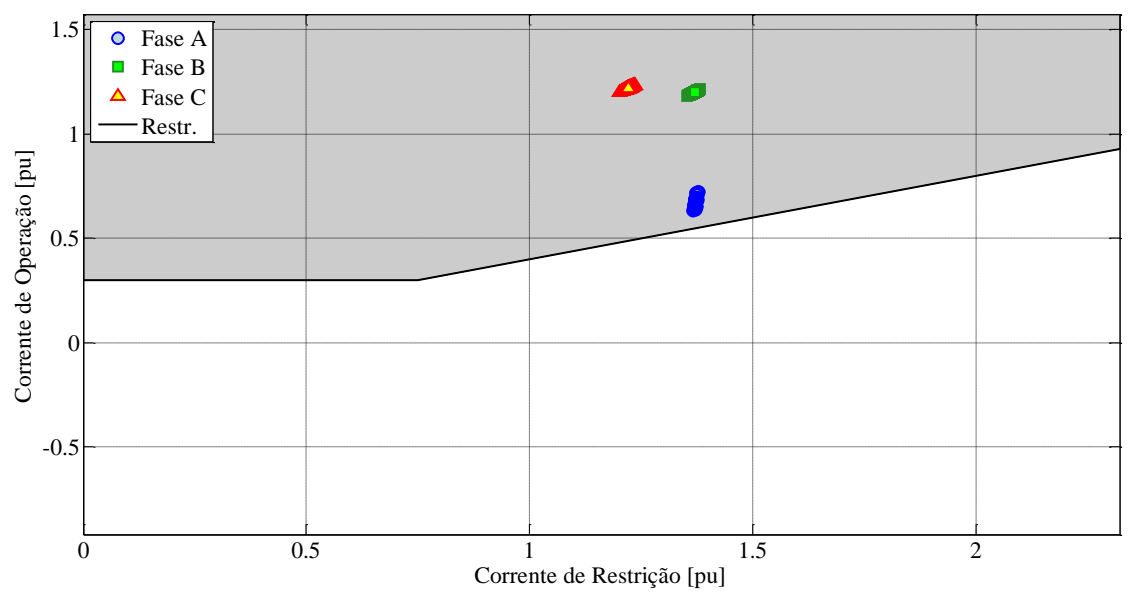

Figura 5.8 - Resposta transitória para falta monofásica externa: Correntes Sem Compensação (pontos de instantes após o momento da falta).

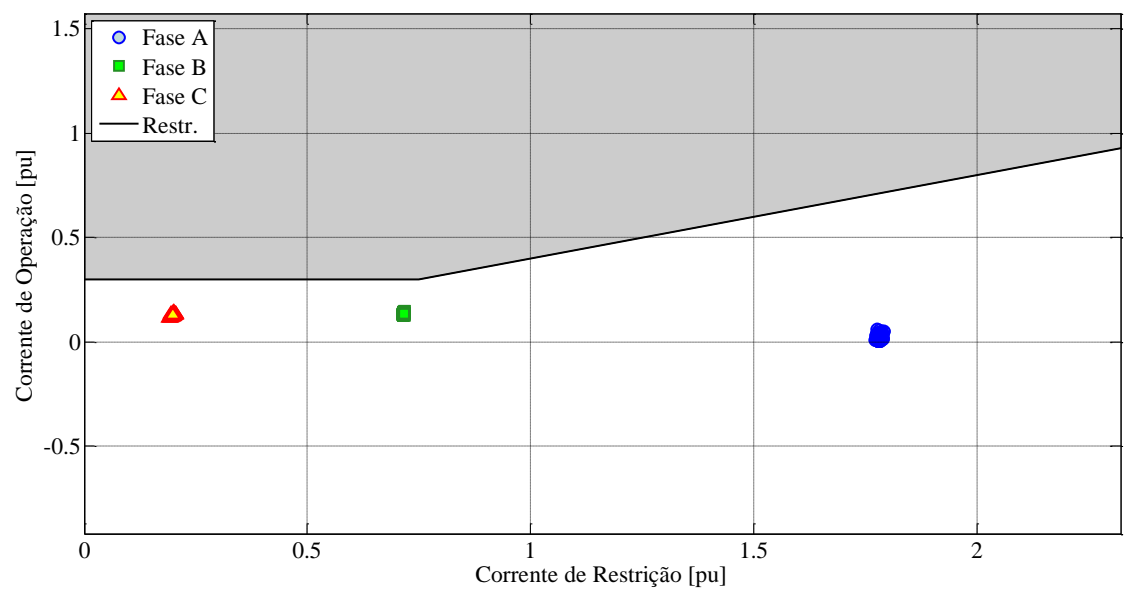

Figura 5.9 - Resposta transitória para falta monofásica externa: Método das Capacitâncias Concentradas (pontos de instantes após o momento da falta).

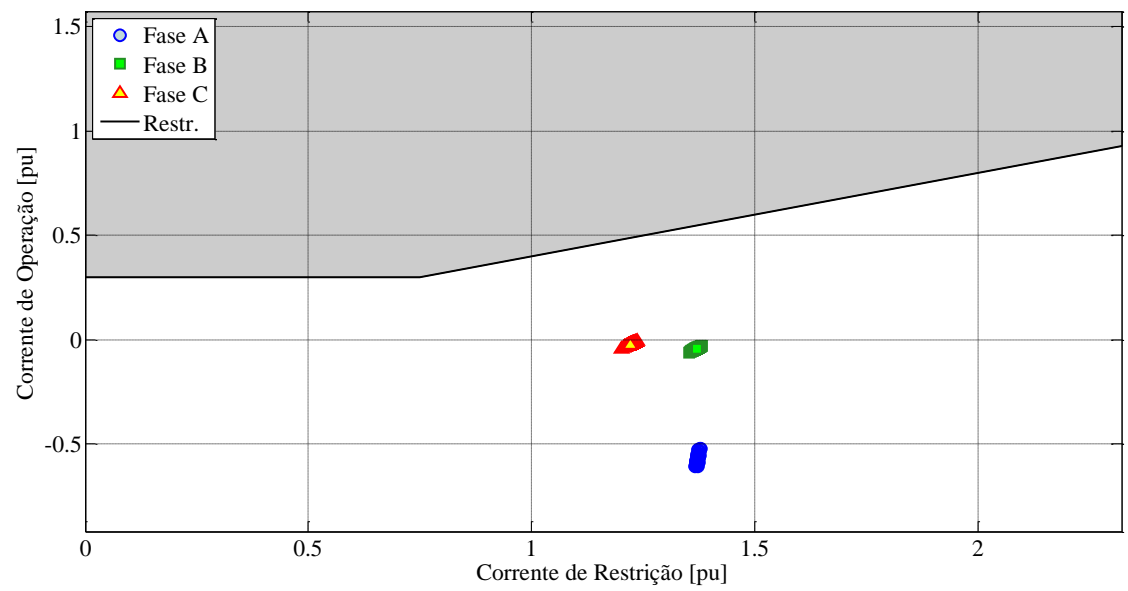

Figura 5.10 - Resposta transitória para falta monofásica externa: Método da Memória de Corrente Capacitiva (pontos de instantes após o momento da falta). 


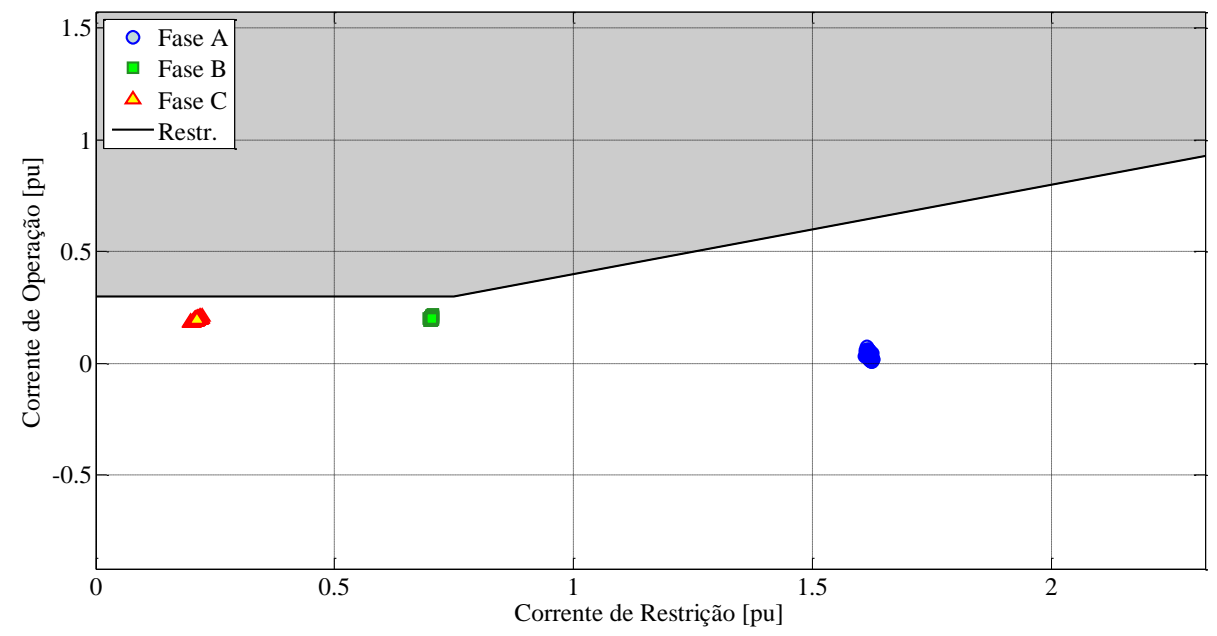

Figura 5.11 - Resposta transitória para falta monofásica externa: Modelo $\pi$-Equivalente da linha (pontos de instantes após o momento da falta).

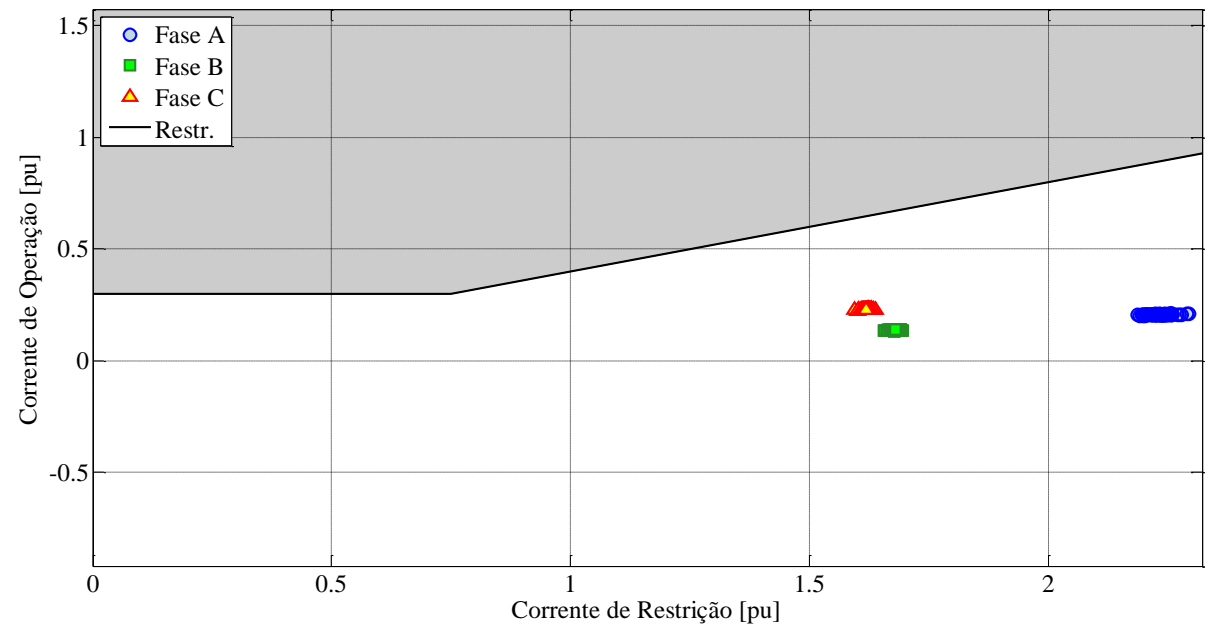

Figura 5.12 - Resposta transitória para falta monofásica externa: Modelo de Bergeron da linha (pontos de instantes após o momento da falta).

\subsubsection{Energização do circuito 1}

A energização da linha de transmissão constitui o caso mais crítico para a proteção diferencial em relação à presença de corrente capacitiva. Como neste caso a corrente de operação é igual à corrente de restrição, a atuação da proteção diferencial depende apenas da amplitude da corrente diferencial e de seu pick-up (XUE, et al., 2012). Deste modo, um ajuste muito sensível irá causar a atuação indevida da proteção, enquanto que a redução excessiva da sensibilidade prejudica a confiabilidade para faltas durante a energização. As Figuras de 5.13 a 5.17 apresentam os resultados obtidos pela proteção do circuito 1 quando de sua energização, estando o circuito 2 já energizado. 
Mais uma vez, nota-se que, quando não é realizada a compensação da corrente capacitiva, ocorre a atuação indevida da proteção diferencial para todas as fases. Com exceção do Método da Memória de Corrente Capacitiva, todas as alternativas se mostram eficientes ao manter a restrição durante a energização. Este método não atua, pois, durante a energização, a corrente diferencial de regime permanente é zero, não havendo memória para ser utilizada pelo mesmo.

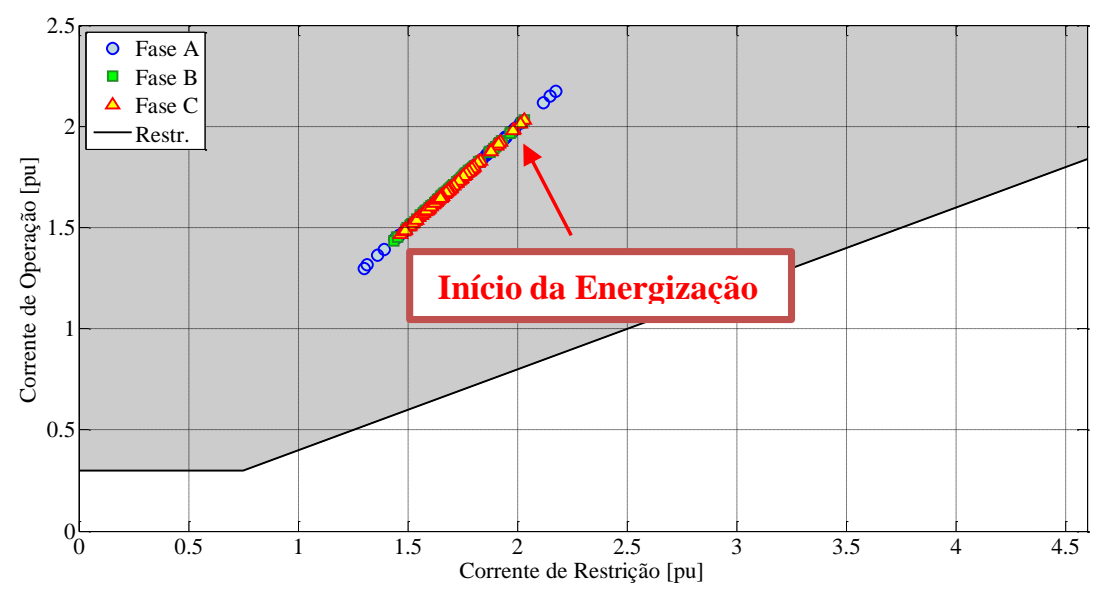

Figura 5.13 - Resposta transitória para a energização do circuito 1: Correntes Sem Compensação (pontos de instantes após o momento da energização).

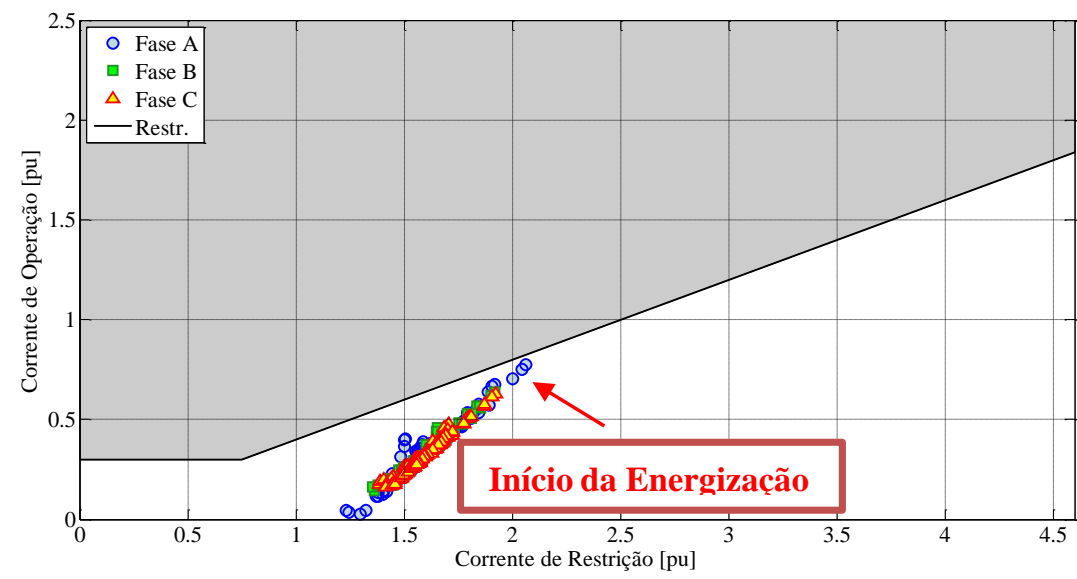

Figura 5.14 - Resposta transitória para a energização do circuito 1: Método das Capacitâncias Concentradas (pontos de instantes após o momento da energização). 


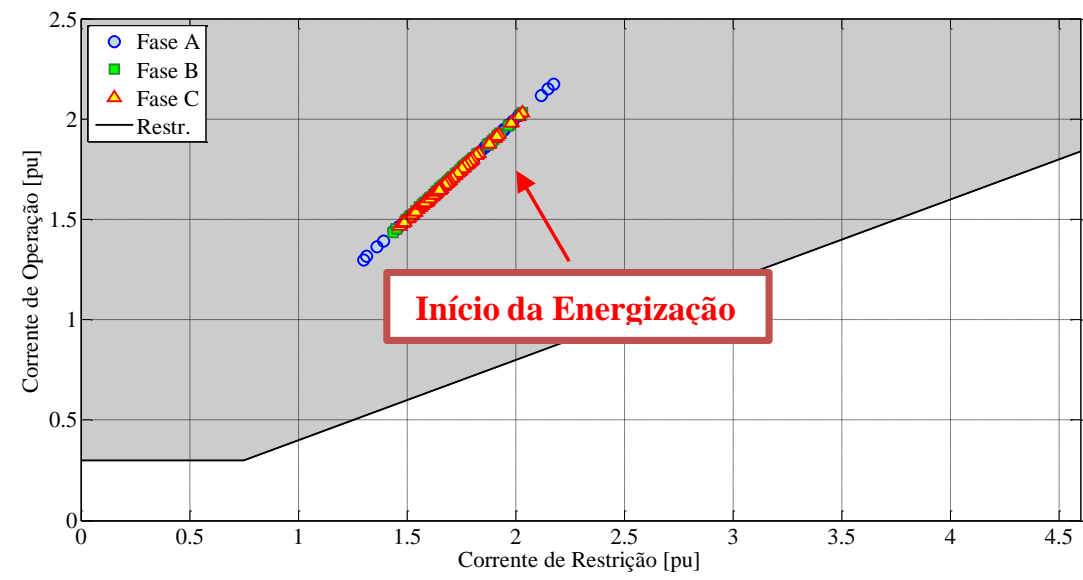

Figura 5.15 - Resposta transitória para a energização do circuito 1: Método da Memória de Corrente Capacitiva (pontos de instantes após o momento da energização).

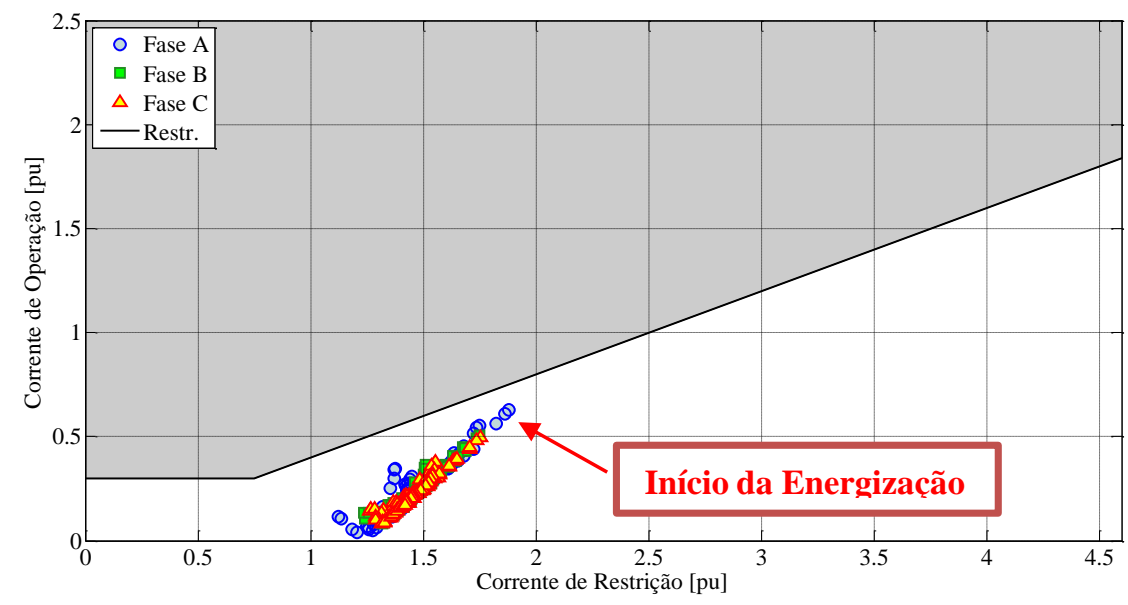

Figura 5.16 - Resposta transitória para a energização do circuito 1: Modelo $\pi$-Equivalente da linha (pontos de instantes após o momento da energização).

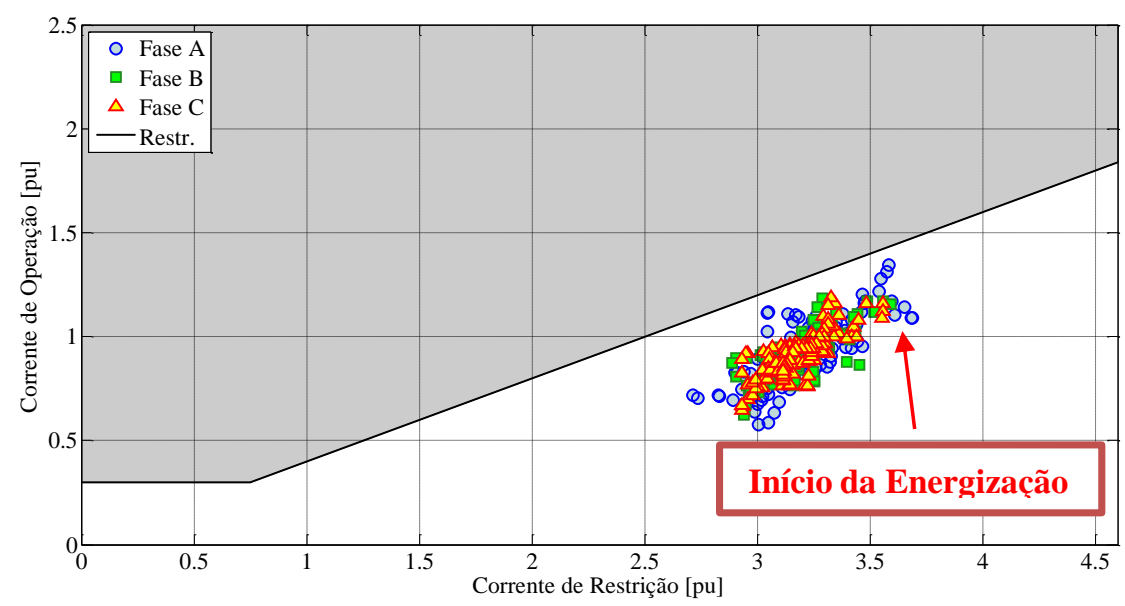

Figura 5.17 - Resposta transitória para a energização do circuito 1: Modelo de Bergeron da linha (pontos de instantes após o momento da energização). 


\subsubsection{Energização do circuito 1 sob falta}

Para a análise da resposta transitória da proteção diferencial, realizou-se, por fim, a simulação da energização do circuito 1 em conjunto com uma falta monofásica na metade do mesmo, estando o circuito 2 já energizado, com o intuito de verificar se o ajuste escolhido para a proteção diferencial prejudica a confiabilidade para faltas durante a energização, bem como a eficácia dos métodos. Os resultados são mostrados nas Figuras de 5.18 a 5.22, os quais dizem respeito à proteção do circuito 1.

Pode-se verificar mais uma vez que a presença da corrente capacitiva contribui para a corrente diferencial, ocasionando a atuação da proteção independentemente de se utilizar algum método de compensação da mesma.

O método da Memória de Corrente Capacitiva, cujo resultado é apresentado na Figura 5.20, possui o mesmo desempenho da proteção diferencial percentual tradicional, pois durante a energização, este não possui memória de corrente para ser subtraída da corrente diferencial.

Para os demais métodos de compensação da corrente capacitiva, a ocorrência do curto durante a energização ocasiona instabilidade no cálculo das correntes de operação e restrição, o que não permite que os métodos identifiquem corretamente a fase defeituosa. Contudo, tal instabilidade não impede que a proteção diferencial elimine o curto, atuando para as três fases do sistema.

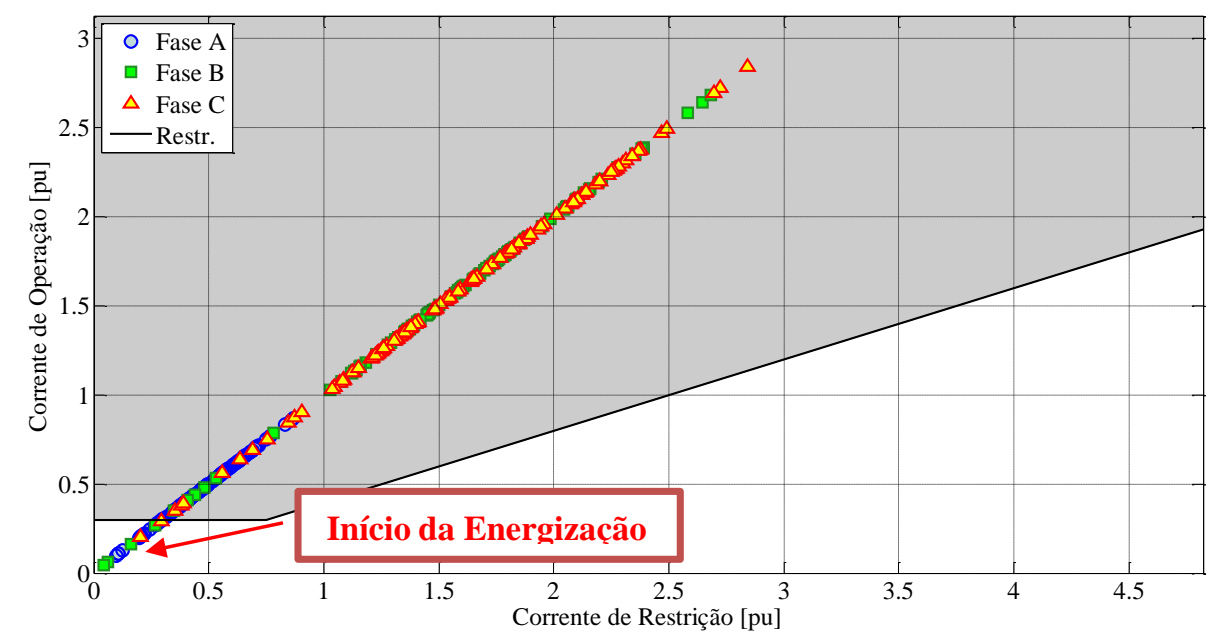

Figura 5.18 - Resposta transitória para a energização do circuito 1 sob falta: Correntes Sem Compensação (pontos de instantes após o momento da energização). 


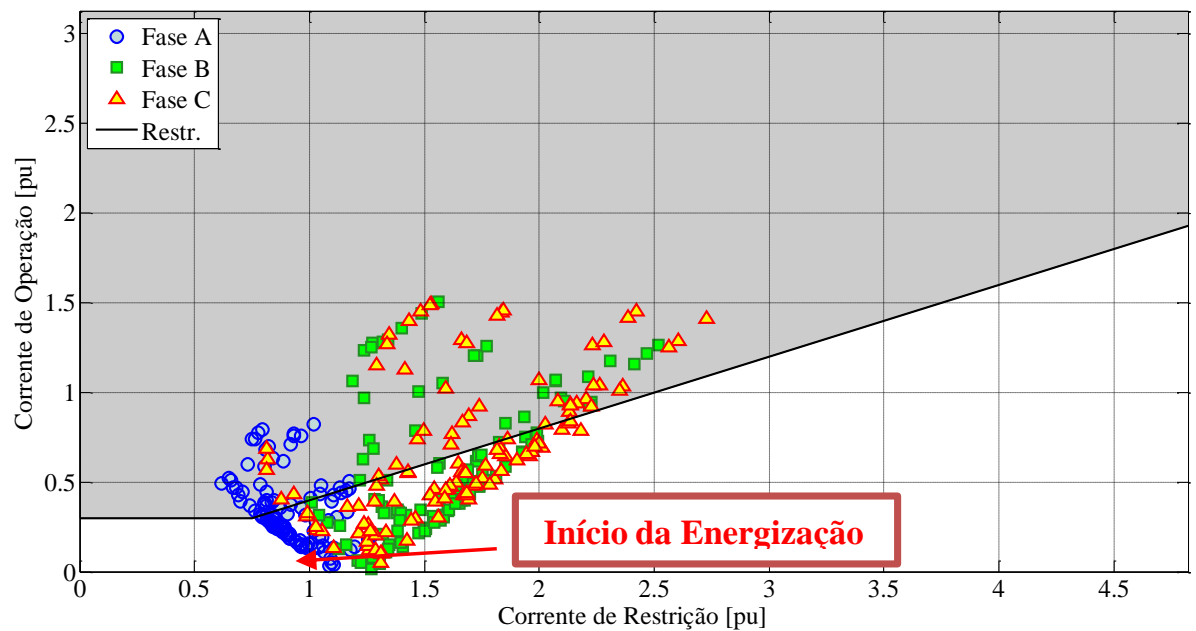

Figura 5.19 - Resposta transitória para a energização do circuito 1 sob falta: Método das Capacitâncias Concentradas (pontos de instantes após o momento da energização).

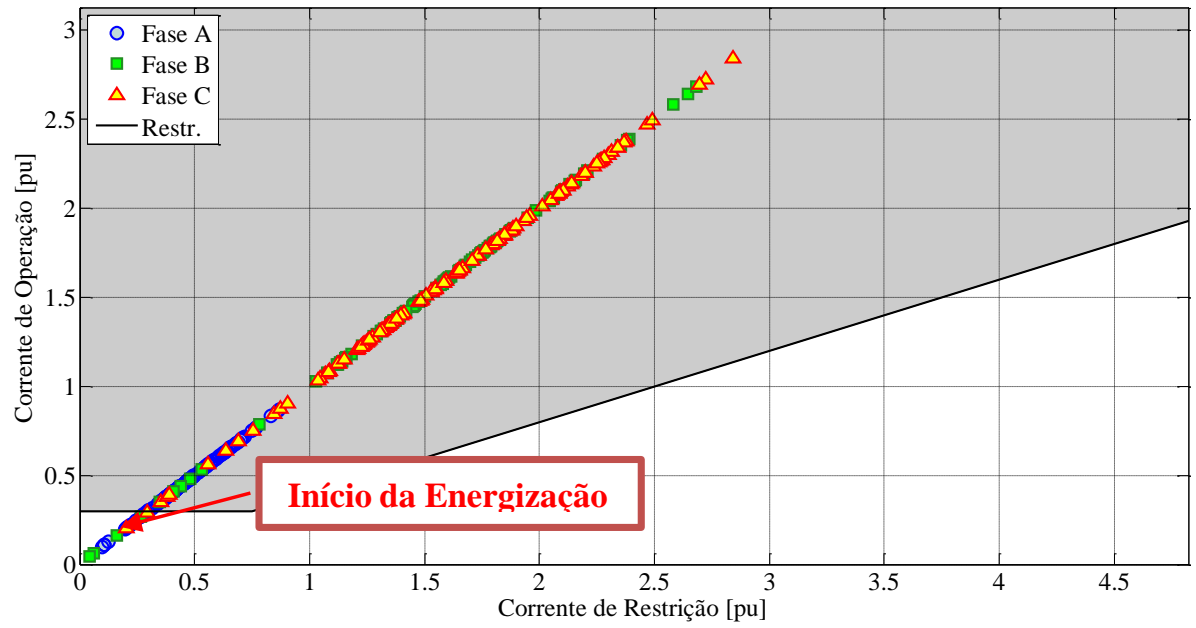

Figura 5.20 - Resposta transitória para a energização do circuito 1 sob falta: Método da Memória de Corrente Capacitiva (pontos de instantes após o momento da energização).

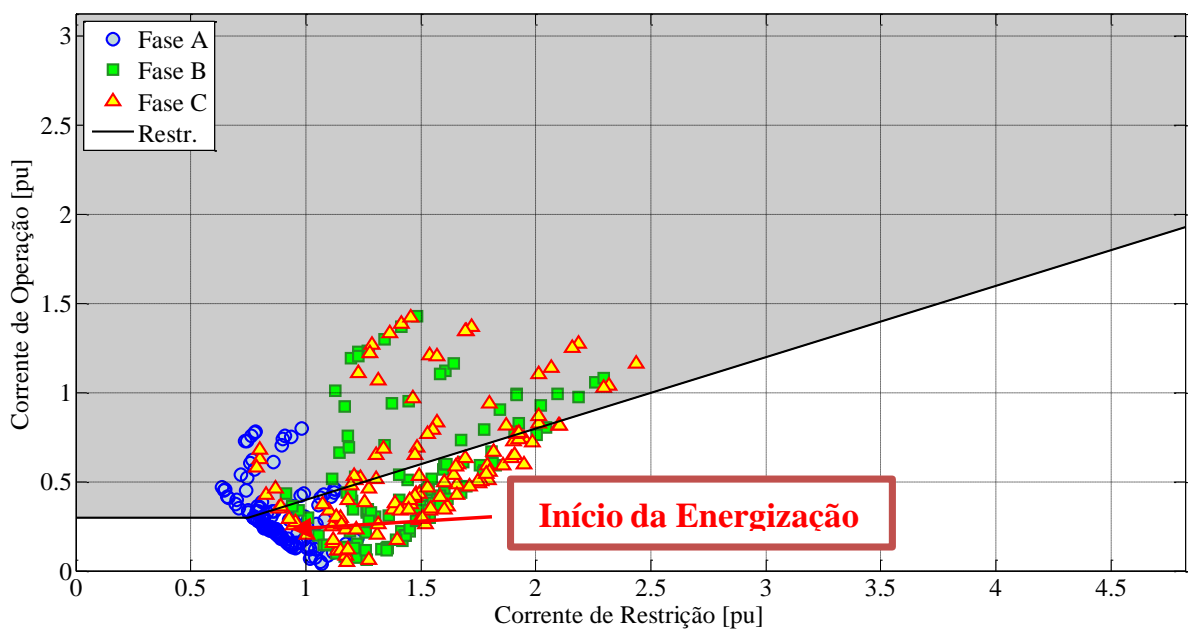

Figura 5.21 - Resposta transitória para a energização do circuito 1 sob falta: Modelo $\pi$-Equivalente da linha (pontos de instantes após o momento da energização). 


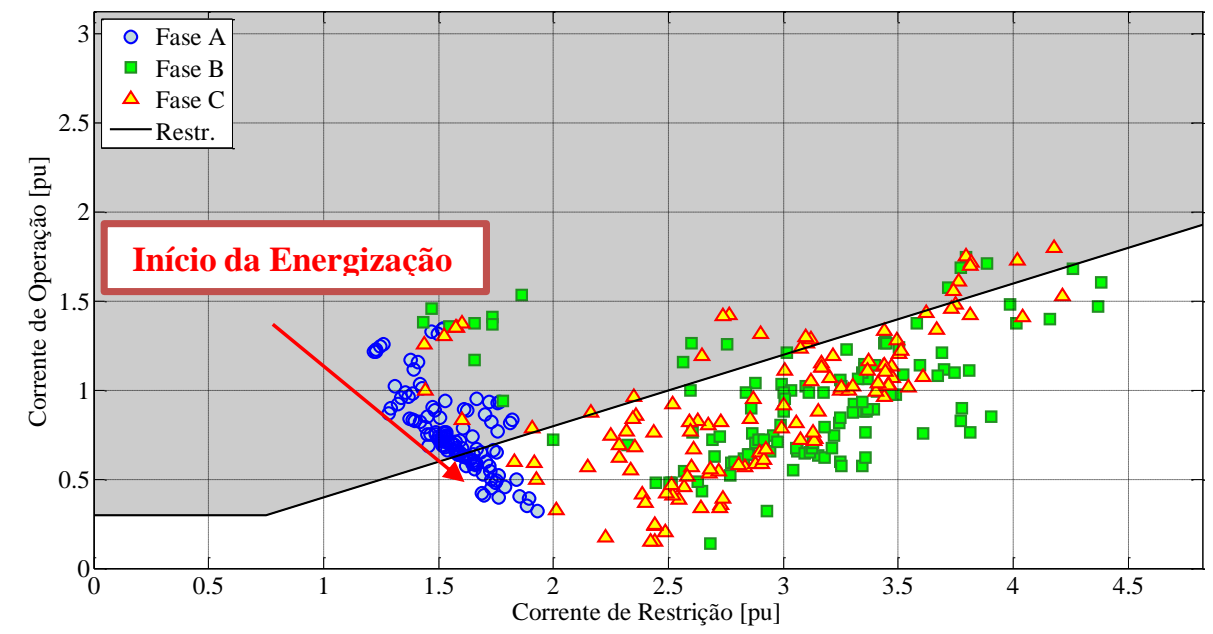

Figura 5.22 - Resposta transitória para a energização do circuito 1 sob falta: Modelo de Bergeron da linha (pontos de instantes após o momento da energização).

\subsection{ANÁLISES DE SENSIBILIDADE PARAMÉTRICA}

Com o intuito de avaliar mais profundamente a atuação dos algoritmos, torna-se interessante realizar análises de sensibilidade paramétrica, na qual os parâmetros do sistema que interferem na atuação da proteção diferencial podem ser variados separadamente. Através deste tipo de simulação, pode-se fazer análises mais aprofundadas, verificando se os métodos permitem uma correta atuação da proteção para um número expressivo de faltas às quais uma linha de transmissão está sujeita.

Para tanto, são apresentados os resultados das respostas de regime permanente da proteção diferencial percentual do circuito 1 ao se variar alguns parâmetros fundamentais do sistema, a saber: localização da falta, resistência de falta, carregamento do sistema e força das fontes.

Cabe ressaltar que, para cada variação desses parâmetros, foram simulados diversos tipos de curtos-circuitos no circuito 1: monofásicos, bifásicos, bifásicos-terra e trifásicos. Contudo, são apresentados a seguir apenas alguns dos casos de análises mais relevantes.

O sistema base aqui utilizado para realizar as simulações com variação dos parâmetros do sistema tem como premissas: $10^{\circ}$ de defasagem entre as barras local e remota, resistência de falta igual a zero para faltas envolvendo a terra, aplicação dos curtos-circuitos na metade do circuito 1 da linha de transmissão e impedâncias das fontes local e remota obtidas a partir das potências de curto-circuito fornecidas por Xu et al. (2007) para cada um dos terminais da linha.

\subsubsection{Variação da Localização da Falta}

Primeiramente, com a intensão de avaliar o comportamento dos métodos para faltas ocorridas em diferentes pontos da linha de transmissão, foram simulados os diversos tipos de curtos-circuitos e, 
para cada caso, variou-se a localização da falta desde $0 \%$ até $100 \%$ do comprimento da linha, em passos de $1 \%$.

\subsubsection{Sistema com falta monofásica}

Os resultados do desempenho da proteção do circuito 1 para um curto-circuito monofásico na fase A, variando-se a localização da falta, são apresentados nas Figuras de 5.23 a 5.27.

A partir da análise da Figura 5.23, pode-se constatar que durante uma falta monofásica, caso não haja compensação da corrente capacitiva, a restrição das fases sãs não é feita corretamente, independentemente da localização da falta.

Observa-se na Figura 5.26 que, considerando uma parametrização da proteção diferencial com uma corrente de pick-up de 0,3 pu, o método que faz uso do Modelo $\pi$ Equivalente da linha não restringe a atuação da proteção nas fases sãs para faltas localizadas de $0 \%$ a $16 \%$ e de $83 \%$ a $100 \%$ do terminal local, ou seja, para faltas ocorridas próximas as barras. Como resultado, a estratégia de religamento monopolar, caso estivesse sendo utilizada, atuaria de forma indevida. Isto ocorre porque o método não é capaz de remover totalmente a corrente capacitiva presente no sistema e as faltas próximas a barra são mais severas. Para evitar isso, seria necessário adotar uma corrente de pick-up superior a 0,53 pu. Em contrapartida, reduz-se a sensibilidade da proteção, o que pode prejudicar a confiabilidade da mesma.

O método que faz uso do Modelo de Bergeron tem comportamento similar ao do Modelo $\pi$ Equivalente da linha, não restringindo as fases sãs para faltas localizadas entre 95\% e 100\% da linha, conforme pode-se verificar na Figura 5.27. A não atuação deste método somente para uma das extremidades da linha evidencia que o mesmo é mais sensível à assimetria entre as fontes.

De forma geral, a maioria dos métodos atua corretamente para a fase defeituosa. Contudo, o método da Memória da Corrente Capacitiva ocasiona uma não atuação da proteção diferencial para curtos-circuitos monofásicos aplicados entre $40 \%$ e $61 \%$ do comprimento da linha, a partir do terminal local. Como foi dito anteriormente, ao não considerar a queda da tensão na fase defeituosa durante a falta, este método superestima a corrente capacitiva, retirando parte da corrente diferencial gerada pela corrente de curto-circuito. Para faltas ocorridas mais próximas as extremidades da linha, esta superestimação da corrente capacitiva é compensada pelo elevado valor da corrente de curto-circuito, de forma que a proteção diferencial consegue atuar corretamente. Contudo, para faltas situadas em torno da metade do circuito 1 , as contribuições de curto-circuito vindas das fontes diminuem, o que intensifica o problema de superestimação da corrente capacitiva da linha. 


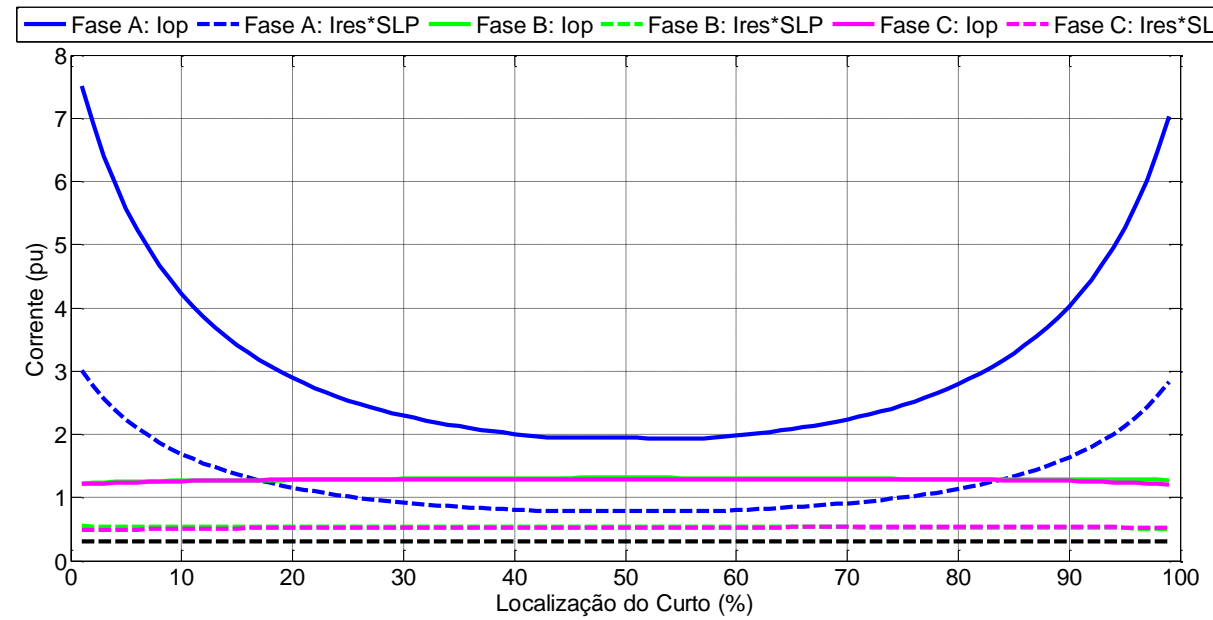

Figura 5.23 - Falta monofásica no circuito 1 com variação da localização: correntes sem compensação.

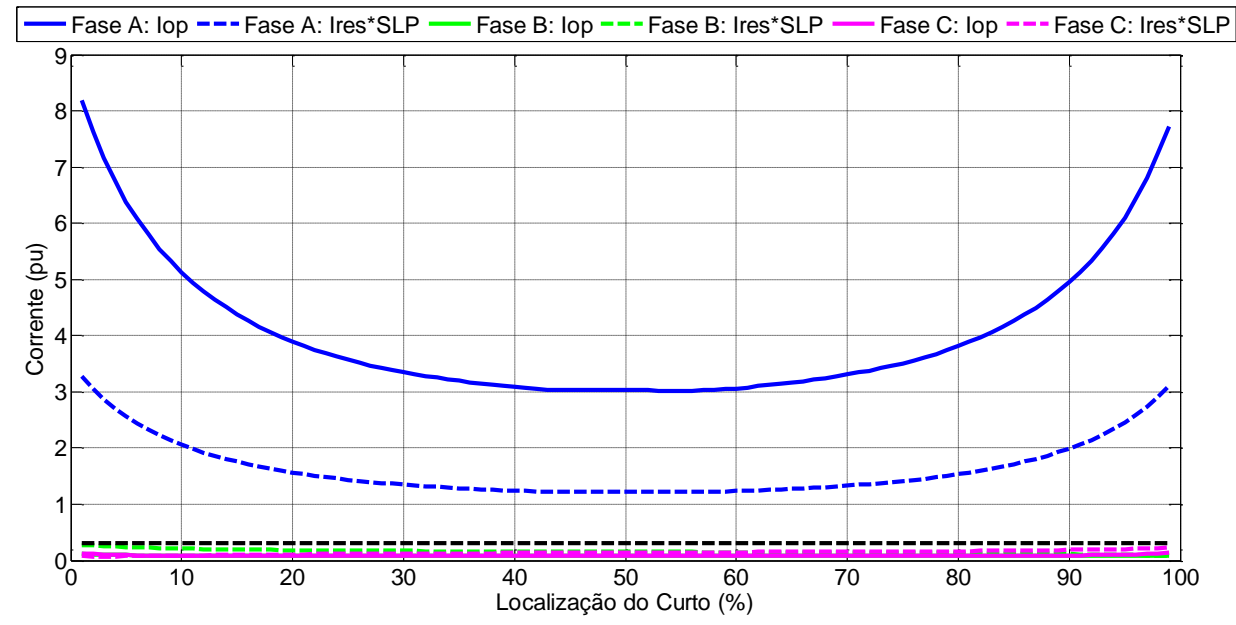

Figura 5.24 - Falta monofásica no circuito 1 com variação da localização: Método das Capacitâncias Concentradas.

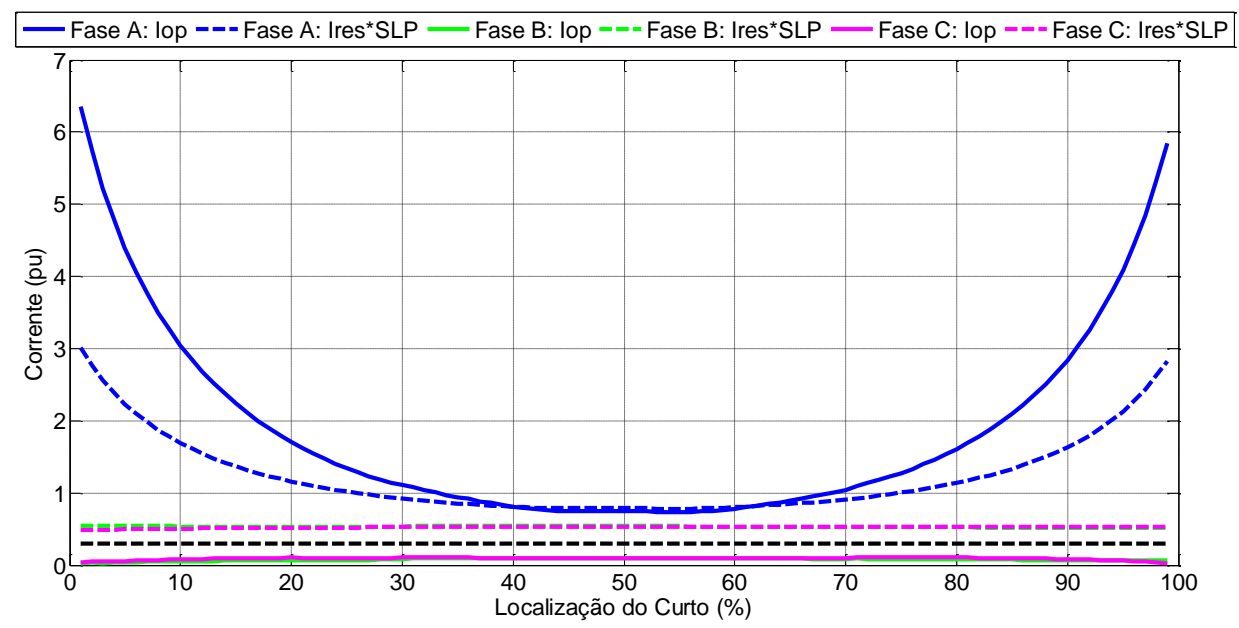

Figura 5.25 - Falta monofásica no circuito 1 com variação da localização: Método da Memória de Corrente Capacitiva. 


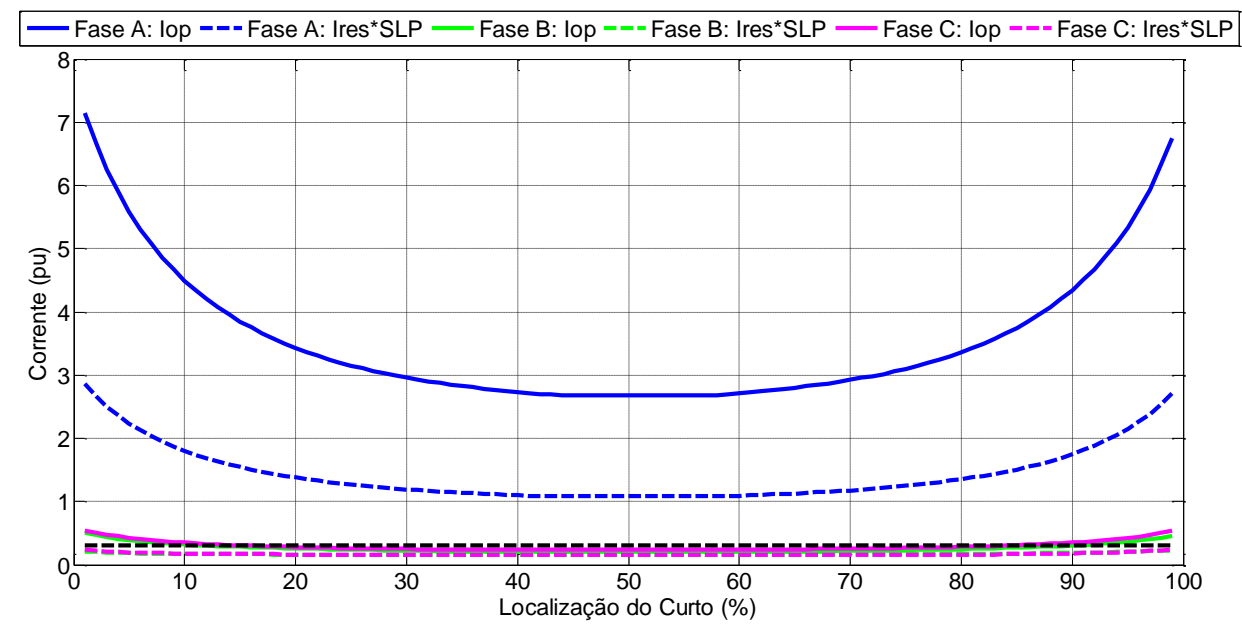

Figura 5.26 - Falta monofásica no circuito 1 com variação da localização: Modelo $\pi$-Equivalente da linha.

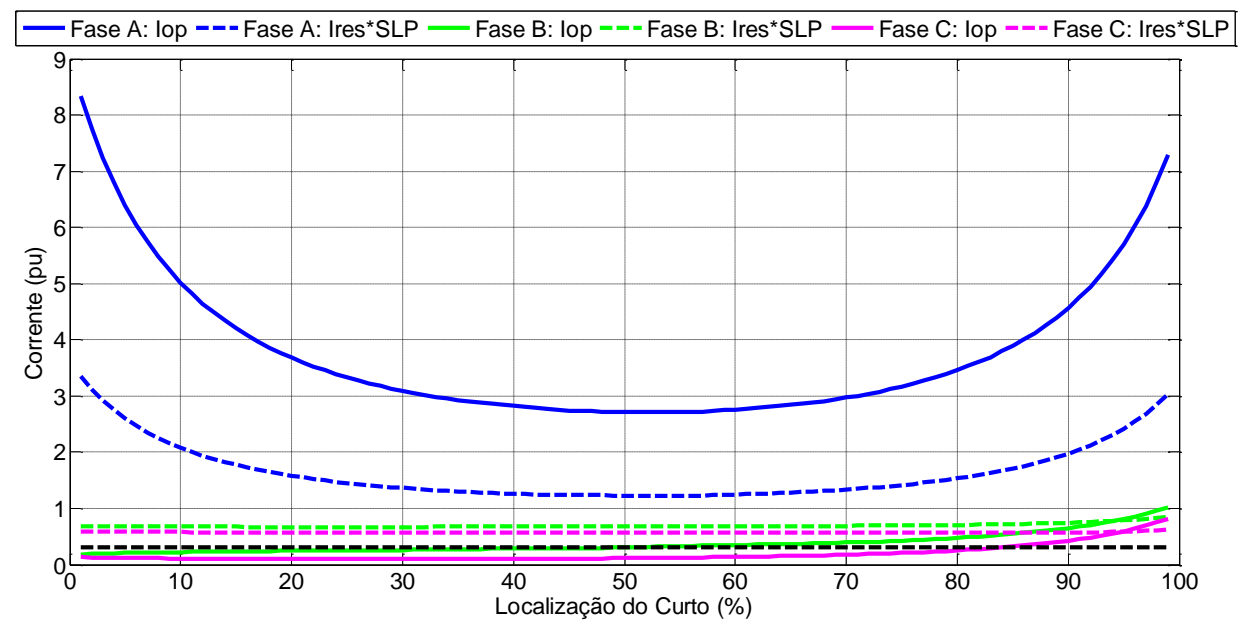

Figura 5.27 - Falta monofásica no circuito 1 com variação da localização: Modelo de Bergeron da linha.

\subsubsection{Sistema com falta bifásica}

As Figuras de 5.28 a 5.32 ilustram o desempenho dos algoritmos para um curto-circuito bifásico nas fases A e B no circuito 1, variando-se a sua localização ao longo da linha.

Observa-se que durante uma falta bifásica, todos os métodos atuam corretamente para as fases defeituosas e restringem a fase sã, não sendo observado nesse caso a atuação indevida das proteções que utilizam os Modelos $\pi$ Equivalente e Bergeron para faltas ocorridas próximas aos terminais. Esse fato ocorre pois, para o sistema estudado, esse tipo de curto-circuito é mais severo que o curto-circuito monofásico, o que pode ser constatado pela ordem de grandezas das correntes de operação e restrição.

Pelo mesmo motivo, o método da Memória da Corrente Capacitiva também funciona corretamente pois, apesar de não considerar a queda da tensão na fase defeituosa durante a falta, 
superestimando a corrente capacitiva e retirando parte da corrente diferencial gerada pela corrente de curto-circuito, esta corrente é suficientemente elevada para sensibilizar o relé.

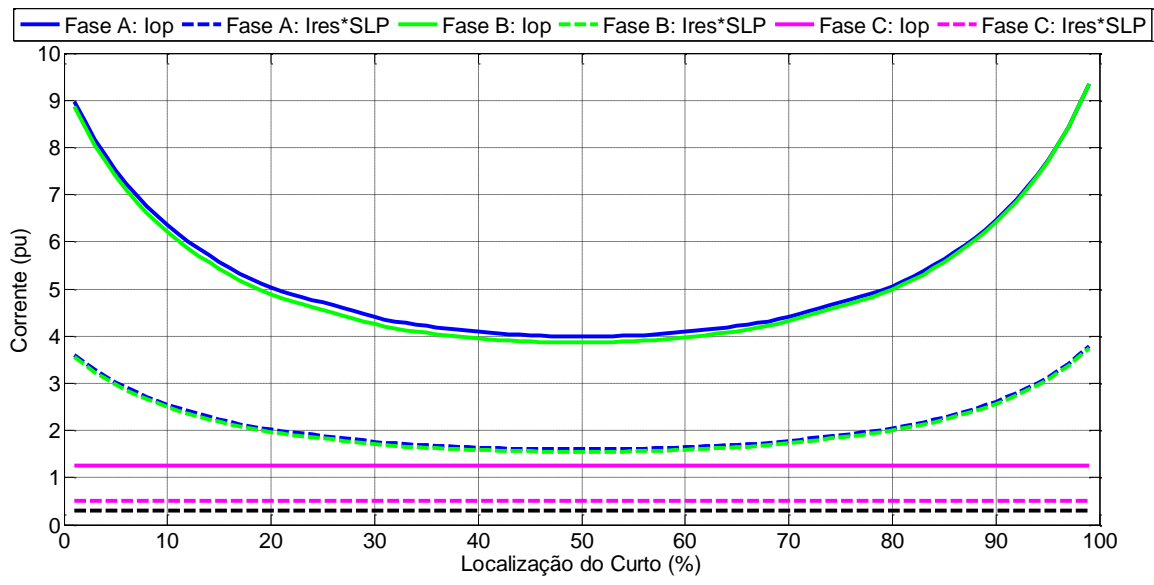

Figura 5.28 - Falta bifásica no circuito 1 com variação da localização: Correntes Sem Compensação.

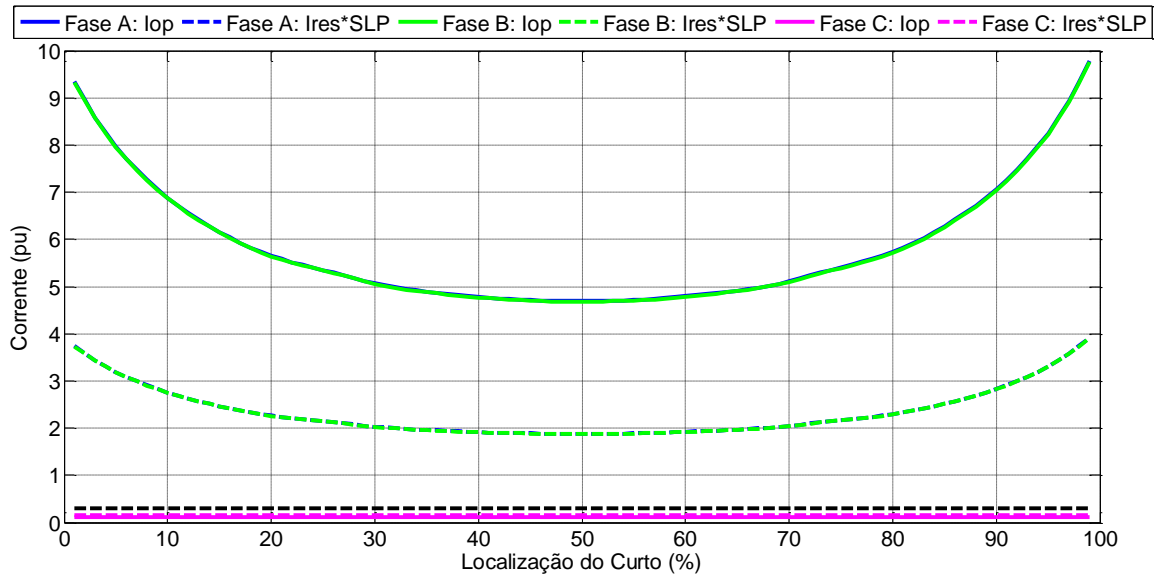

Figura 5.29- Falta bifásica no circuito 1 com variação da localização: Método das Capacitâncias Concentradas.

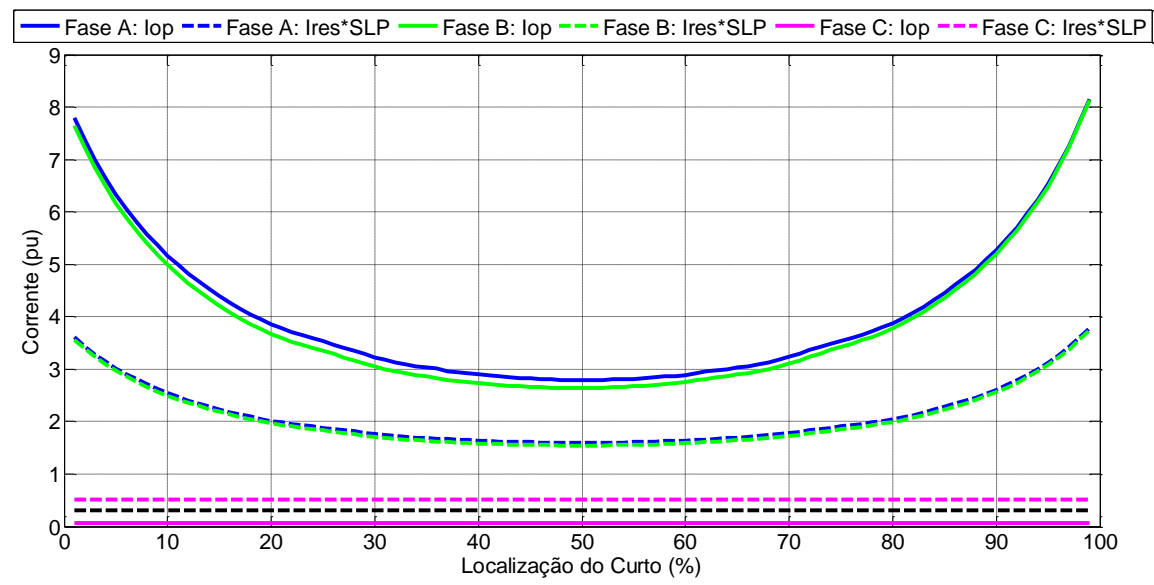

Figura 5.30 - Falta bifásica no circuito 1 com variação da localização: Método da Memória de Corrente Capacitiva. 


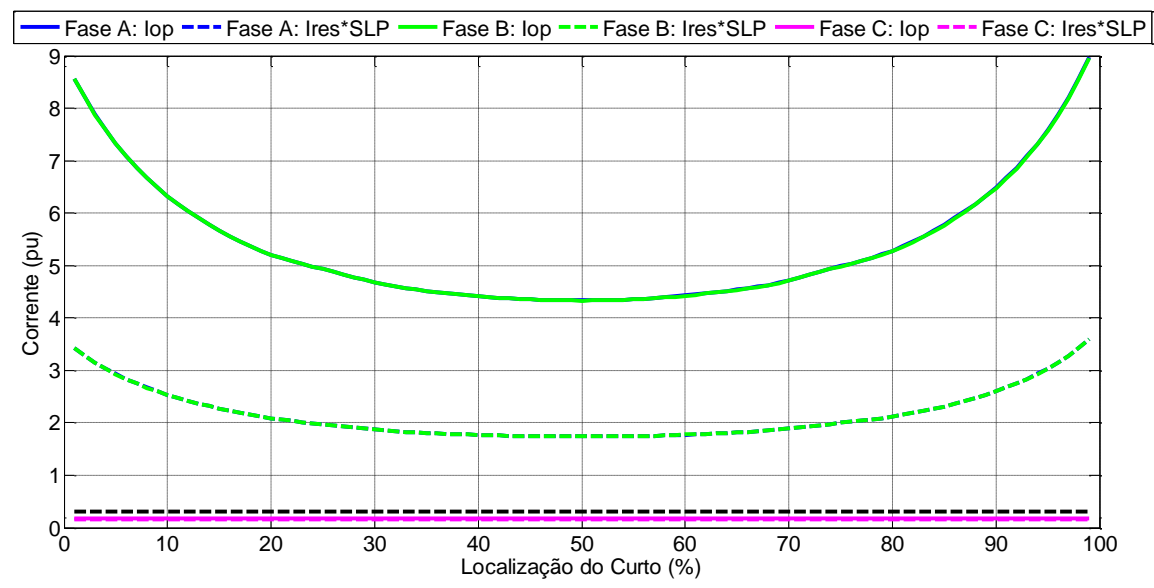

Figura 5.31 - Falta bifásica no circuito 1 com variação da localização: Modelo $\pi$-Equivalente da linha.

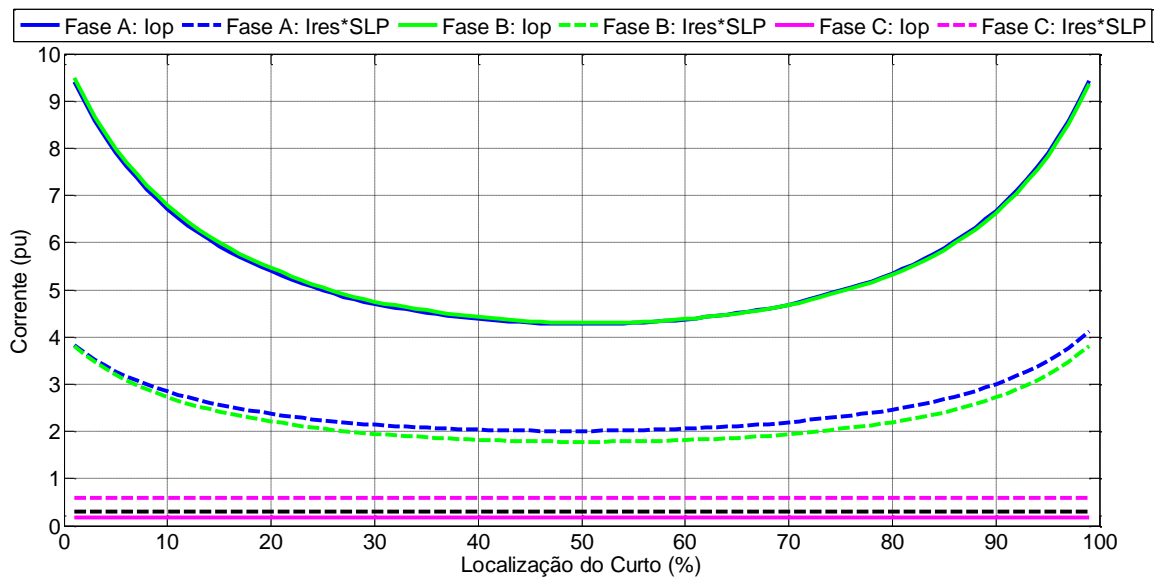

Figura 5.32 - Falta bifásica no circuito 1 com variação da localização: Modelo de Bergeron da linha.

\subsubsection{Variação da Resistência de Falta}

Outro parâmetro avaliado foi a resistência de falta, que tem uma influência tal que quanto maior o seu valor, menor a corrente de operação, dificultando assim a correta atuação da proteção diferencial. Foram simulados os diversos tipos de curtos-circuitos que envolvem a terra no circuito $1 \mathrm{e}$, para cada caso, variou-se a resistência de falta desde $0 \Omega$ até $500 \Omega$, em passos de $5 \Omega$.

\subsubsection{Sistema com falta monofásica}

Os resultados da simulação do curto-circuito monofásico na fase A do circuito 1, variando-se a resistência de falta, são apresentados nas Figuras de 5.33 a 5.37.

De forma geral, a maioria dos métodos atua conforme o esperado, restringindo corretamente para as fases sãs e atuando para a fase defeituosa. Conforme pode ser observado na Figura 5.35, o método da Memória da Corrente Capacitiva, apesar de restringir corretamente as fases sãs, não atua para a fase defeituosa para curtos-circuitos com resistência de falta superiores a $110 \Omega$. A justificativa para este fato é muito similar a apresentada anteriormente para este mesmo método: a superestimação da corrente 
capacitiva. A medida que se aumenta a resistência de falta, diminui-se a corrente de curto-circuito e, superestimando a corrente capacitiva, retira-se com isso uma parcela da corrente de curto. A corrente de curto restante não é capaz de sensibilizar o relé.

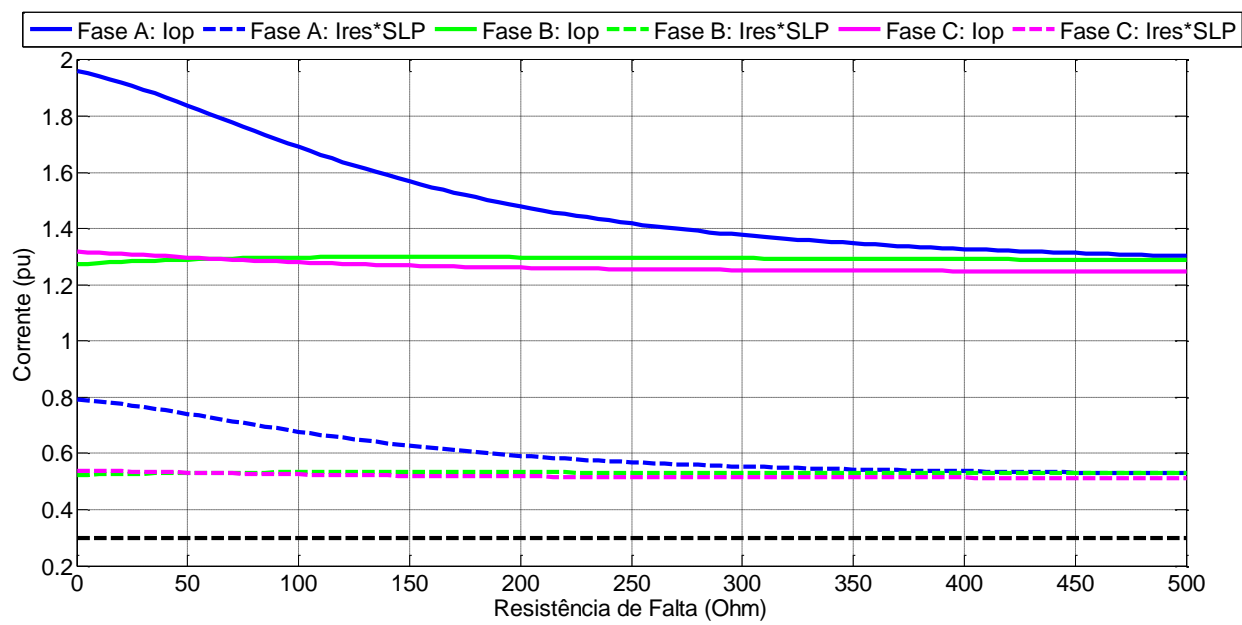

Figura 5.33 - Falta monofásica no circuito 1 com variação da resistência de falta: Correntes Sem Compensação.

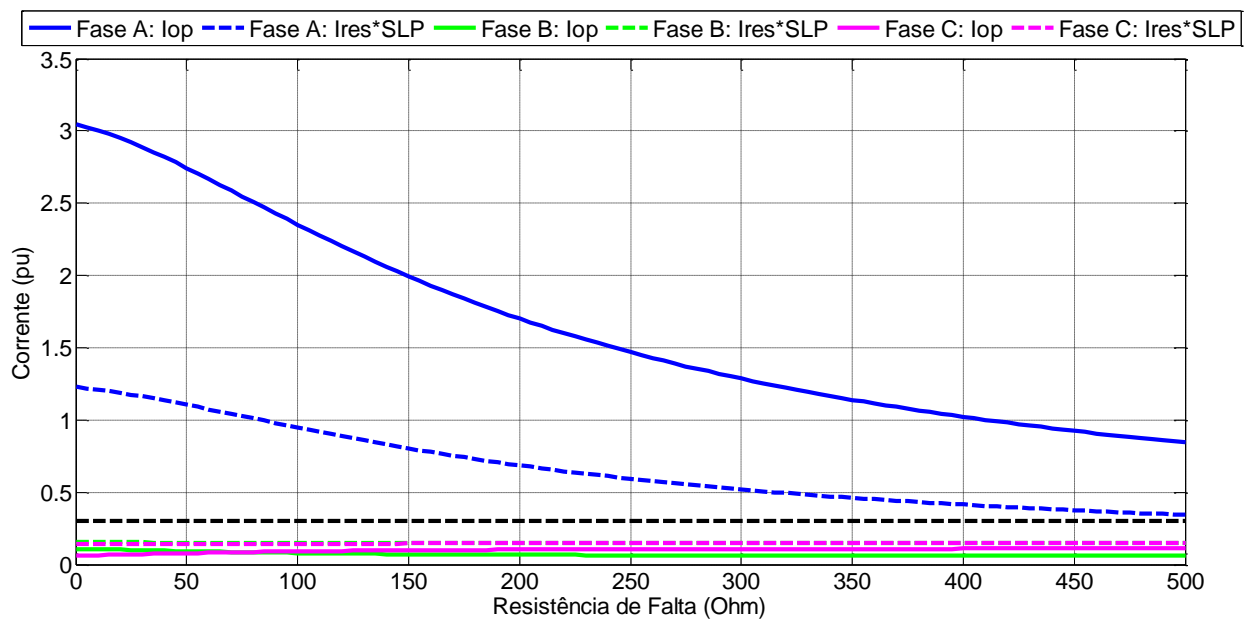

Figura 5.34- Falta monofásica no circuito 1 com variação da resistência de falta: Método das Capacitâncias Concentradas. 


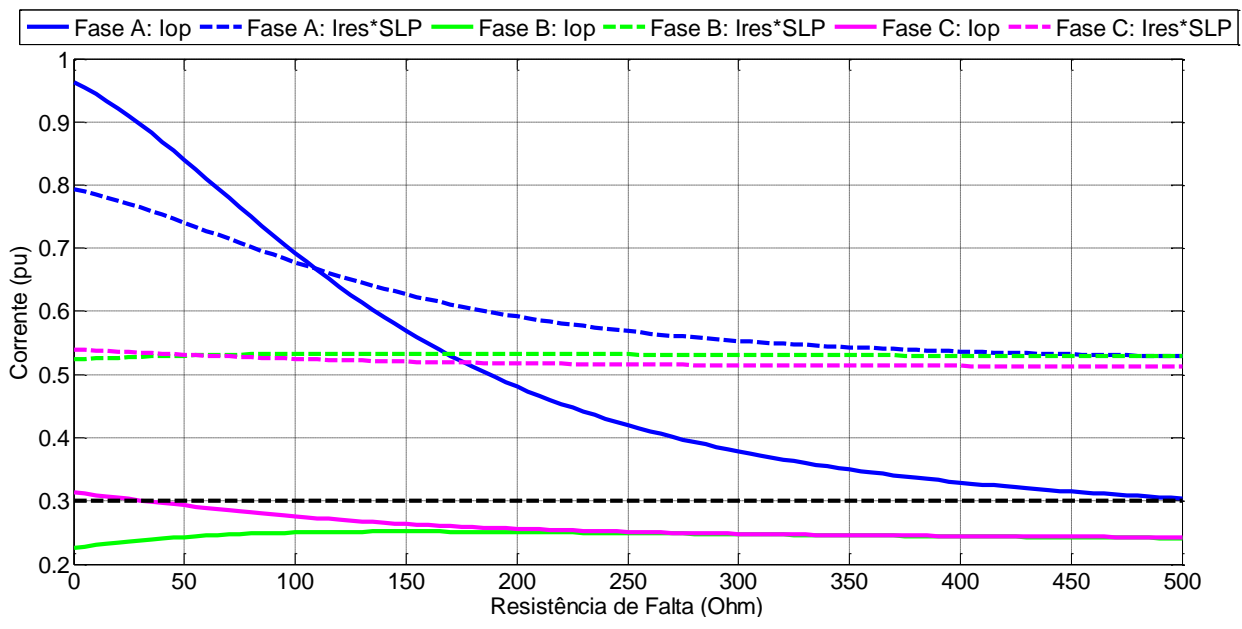

Figura 5.35 - Falta monofásica no circuito 1 com variação da resistência de falta: Método da Memória de Corrente Capacitiva.

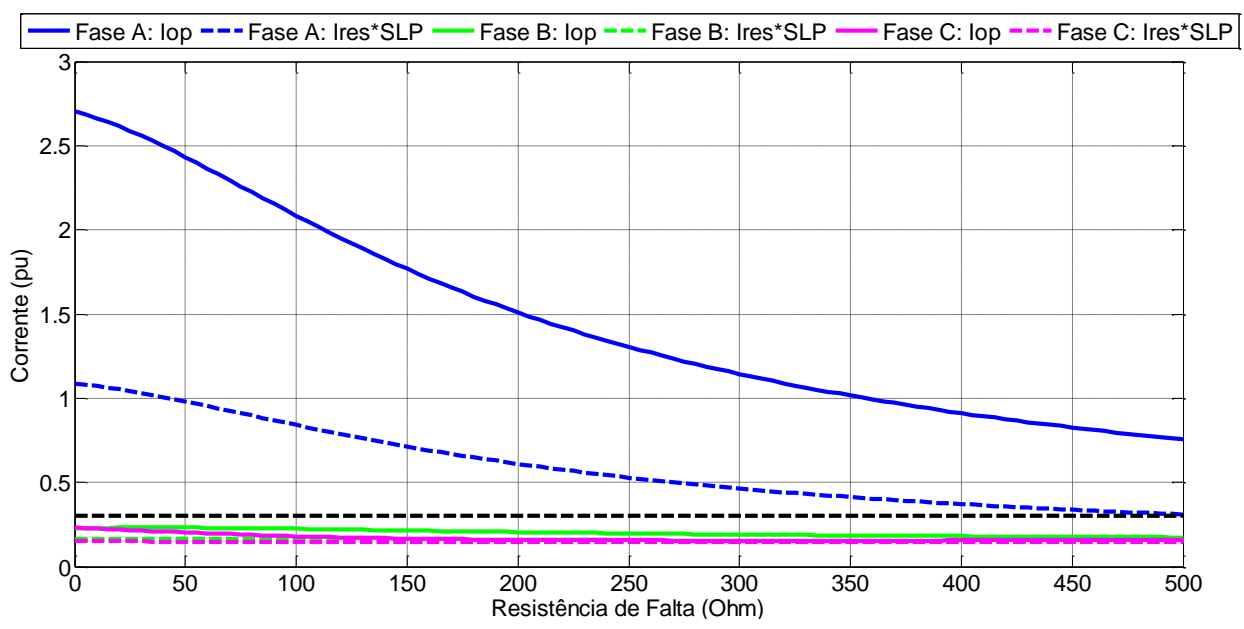

Figura 5.36 - Falta monofásica no circuito 1 com variação da resistência de falta: Modelo $\pi$-Equivalente da linha.

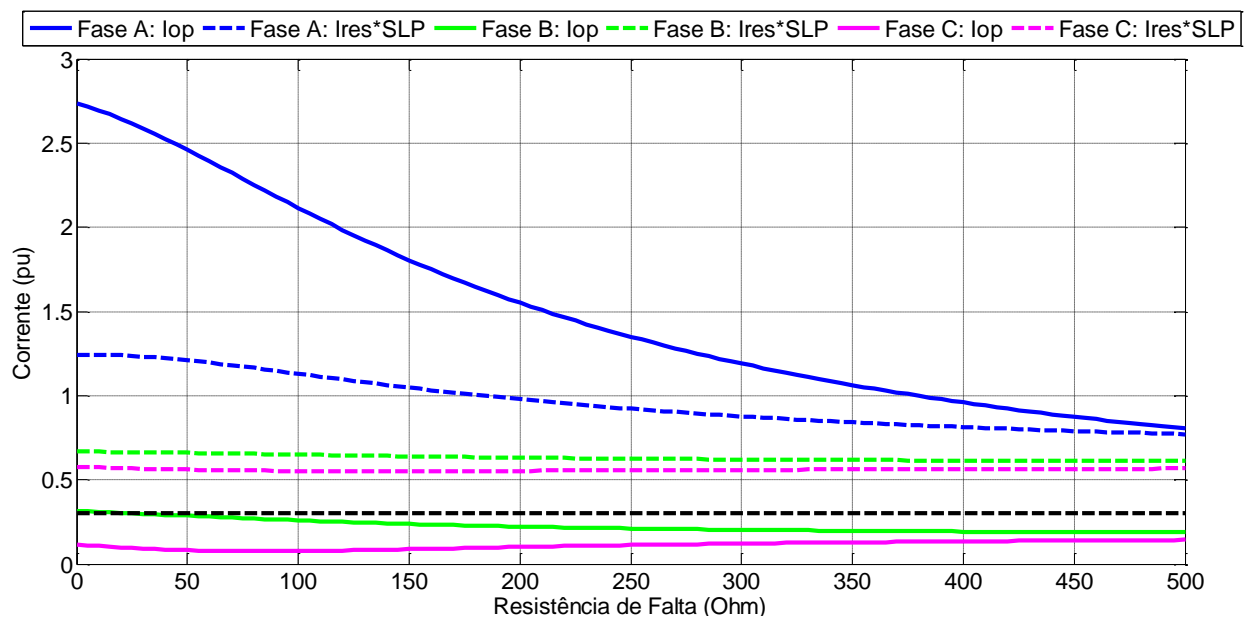

Figura 5.37 - Falta monofásica no circuito 1 com variação da resistência de falta: Modelo de Bergeron da linha. 


\subsubsection{Sistema com falta bifásica-terra}

Através das Figuras 5.38 a 5.42, são expostos os resultados da simulação do curto-circuito bifásico-terra nas fases A e B do circuito 1, variando-se a resistência de falta.

Observa-se que durante um curto-circuito bifásico-terra, todos os métodos atuam corretamente para as fases defeituosas e restringem a fase sã. Esta situação pode ser explicada pelo fato de que, para o sistema estudado, o curto-circuito bifásico é mais severo que o curto monofásico, diminuindo assim a influência da resistência de falta na atuação da proteção diferencial. Este fato é evidenciado ao se comparar a magnitude da corrente de operação para a falta bifásico-terra - da ordem de 4 pu da corrente nominal da linha - com a magnitude da mesma para a falta monofásica - cerca de 2,5 pu.

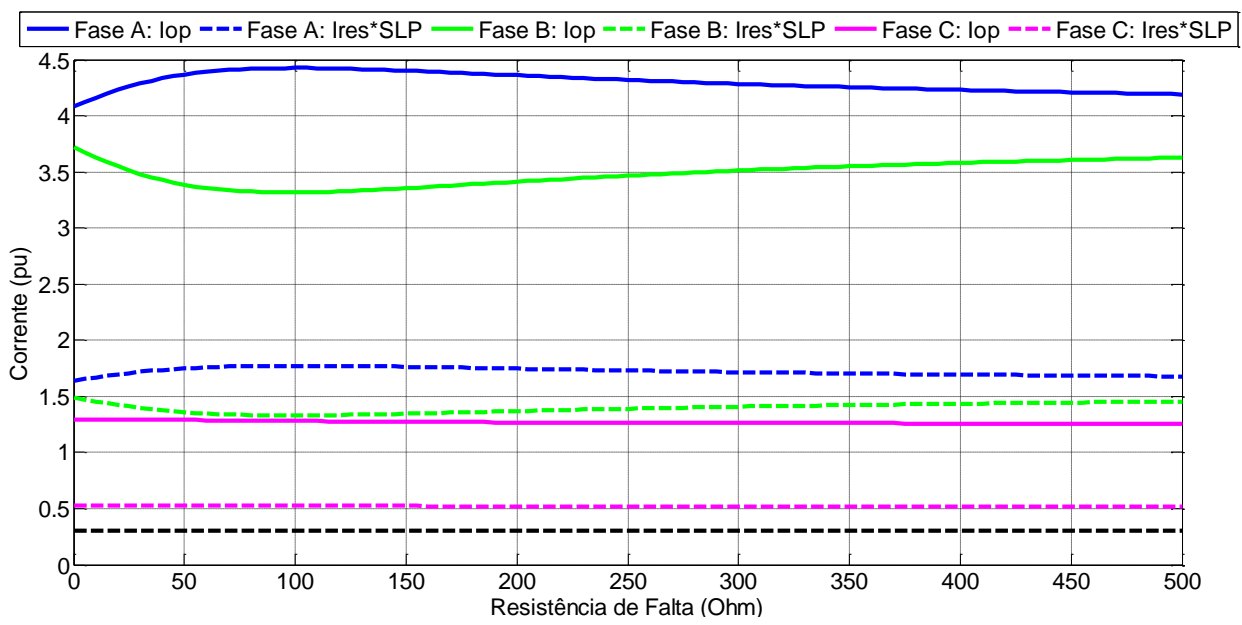

Figura 5.38 - Falta bifásico-terra no circuito 1 com variação da resistência de falta: Correntes Sem Compensação.

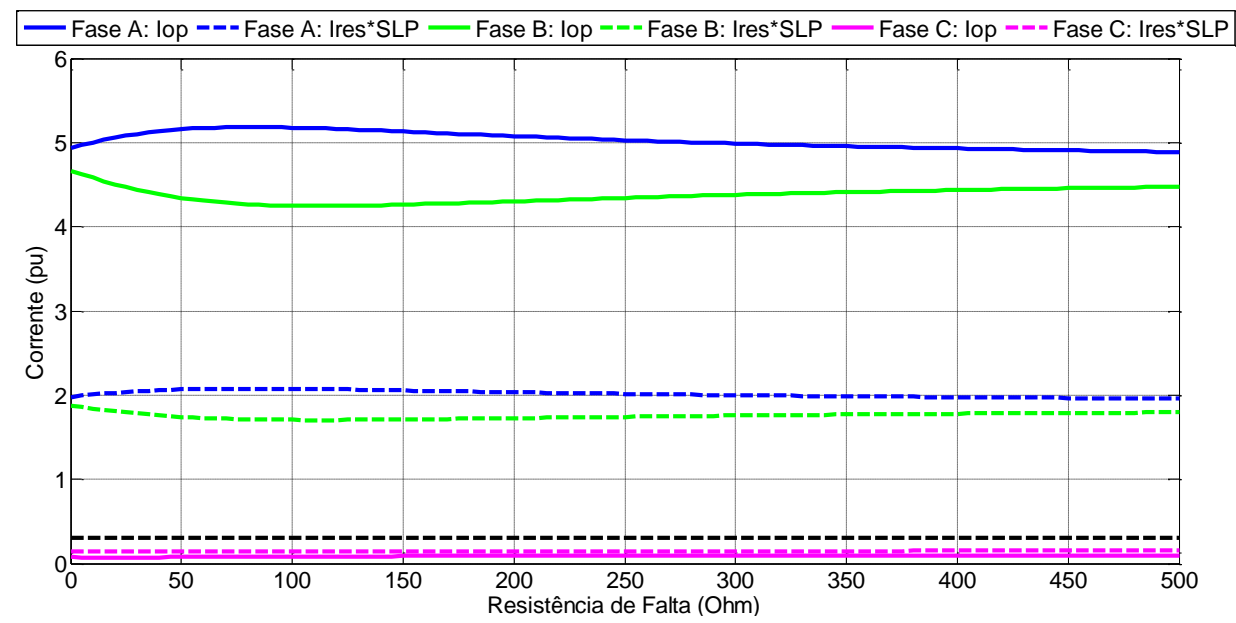

Figura 5.39- Falta bifásico-terra no circuito 1 com variação da resistência de falta: Método das Capacitâncias

Concentradas. 


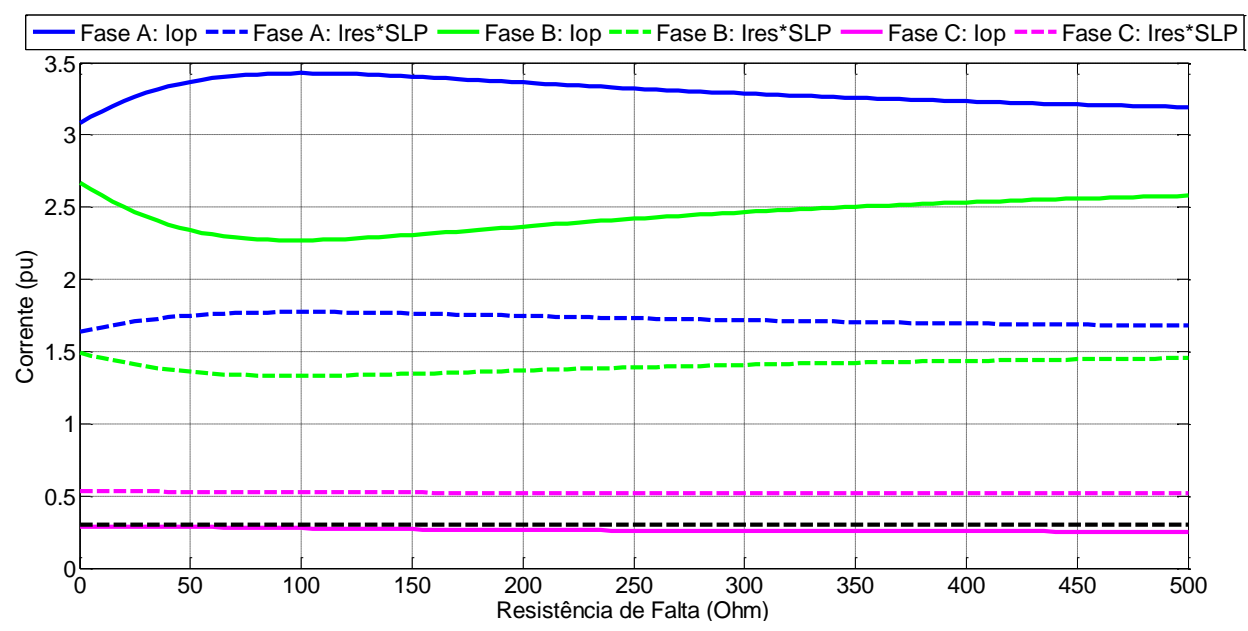

Figura 5.40 - Falta bifásico-terra no circuito 1 com variação da resistência de falta: Método da Memória de Corrente Capacitiva.

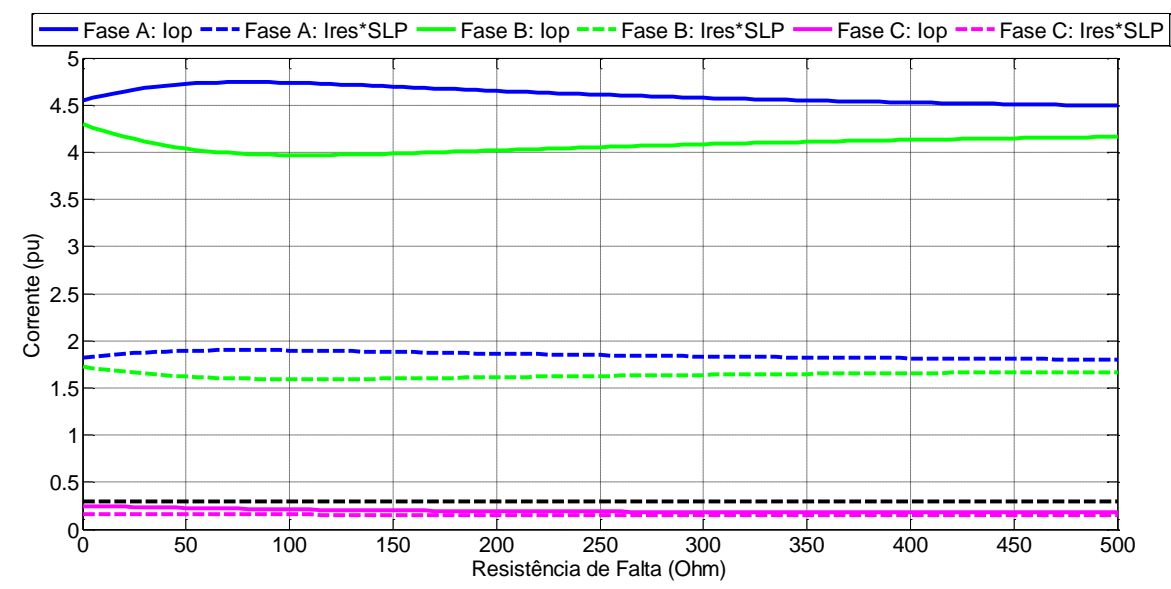

Figura 5.41 - Falta bifásico-terra no circuito 1 com variação da resistência de falta: Modelo $\pi$-Equivalente da linha.

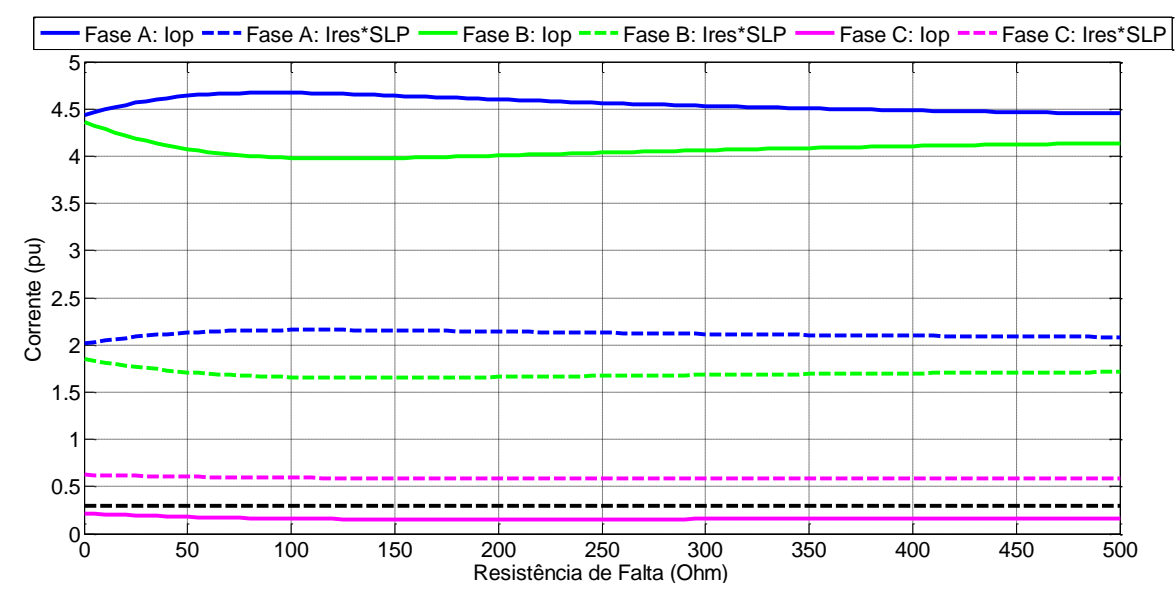

Figura 5.42 - Falta bifásico-terra no circuito 1 com variação da resistência de falta: Modelo de Bergeron da linha. 


\subsubsection{Variação do Carregamento do Sistema}

Com intuito de se verificar o comportamento da proteção diferencial diante de várias situações de carregamento do sistema, foram simulados os diversos tipos de curtos-circuitos no circuito 1 e, para cada caso, variou-se o ângulo entre as barras local e remota desde $-90^{\circ}$ até $90^{\circ}$, em passos de $5^{\circ}$, considerando-se o módulo da tensão em ambas as barras igual a 1 pu.

\subsubsection{Sistema com falta monofásica}

As Figuras 5.43 a 5.47 apresentam o desempenho dos métodos quando da aplicação de uma falta monofásica na fase A no circuito 1.

Analisando a Figura 5.43, pode-se perceber que o aumento da corrente de carga, ocasiona um crescimento da corrente de restrição e uma diminuição da corrente diferencial. Isto é, quanto maior o carregamento do sistema, menor a influência da corrente capacitiva. Este fato é evidenciado pela constatação de que a proteção diferencial percentual convencional, a qual não leva em consideração a corrente capacitiva, restringe corretamente as fases sãs para carregamentos maiores que $50^{\circ}$ e menores que $-50^{\circ}$.

Com a aplicação de qualquer dos métodos de compensação da corrente capacitiva, as fases sãs são restringidas corretamente, independente do carregamento do sistema. Cabe ressaltar que o Método das Capacitâncias Concentradas (Figura 5.44) só consegue restringir corretamente as fases sãs para carregamentos próximos a zero devido ao valor da corrente de pick-up, o que evidencia a importância de uma escolha correta do mesmo.

Uma observação importante é que, para correntes de carga muito elevadas, a corrente de operação da fase defeituosa fica menor que a corrente de restrição, de modo que a proteção diferencial não detecta o curto-circuito. Contudo, isto só ocorre para valores de carregamento muito elevados, da ordem de $70^{\circ}$ ou mais de defasagem entre as barras local e remota, os quais não são comumente aplicados na prática. De fato, ângulos da ordem de $\pm 30^{\circ}$ a $\pm 40^{\circ}$ são tipicamente considerados como limites operação (SAADAT, 2010).

O Método das Capacitâncias Concentradas e o método que faz uso do Modelo $\pi$ Equivalente da LT não atuam corretamente para defasagens entre as barras superiores $80^{\circ}$ e inferiores a $-80^{\circ}$. Já o método que utiliza o Modelo de Bergeron da linha, não atua para defasagens inferiores a $-75^{\circ}$. Nota-se a assimetria de atuação deste modelo deve-se ao fato que este é mais susceptível a força das fontes, sendo a fonte local mais fraca. 
Por fim, o Método da Memória de Corrente Capacitiva não funciona corretamente para nenhum carregamento do sistema simulado, chegando perto da atuação apenas quando o carregamento se aproxima de zero. Isto ocorre pois, como foi dito anteriormente, este algoritmo superestima a corrente capacitiva. Cabe salientar que as simulações aqui apresentadas são de curtos-circuitos aplicados na metade da linha.

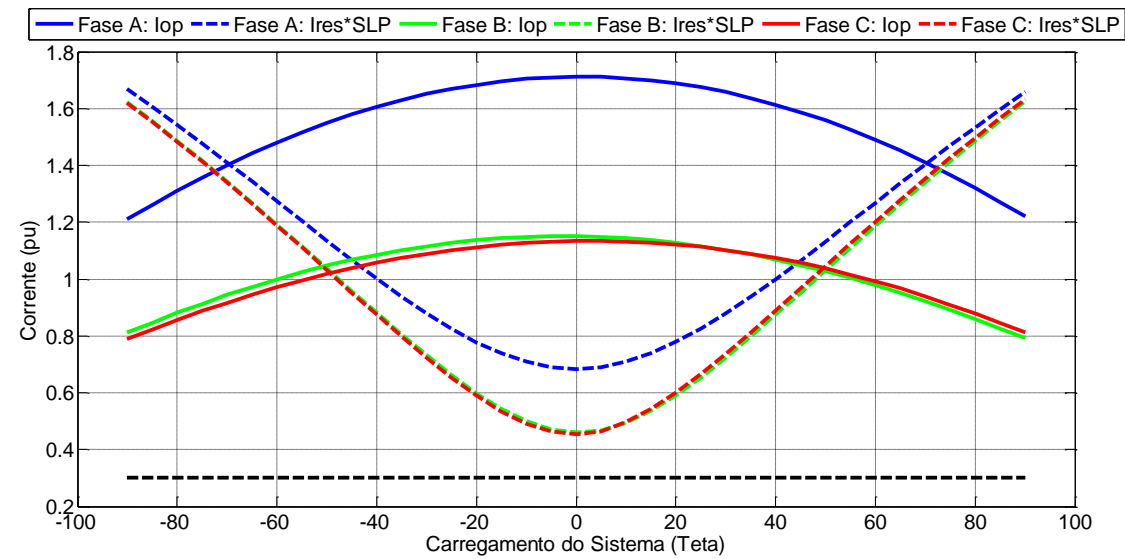

Figura 5.43 - Falta monofásica no circuito1 com variação do carregamento do sistema: Correntes Sem Compensação.

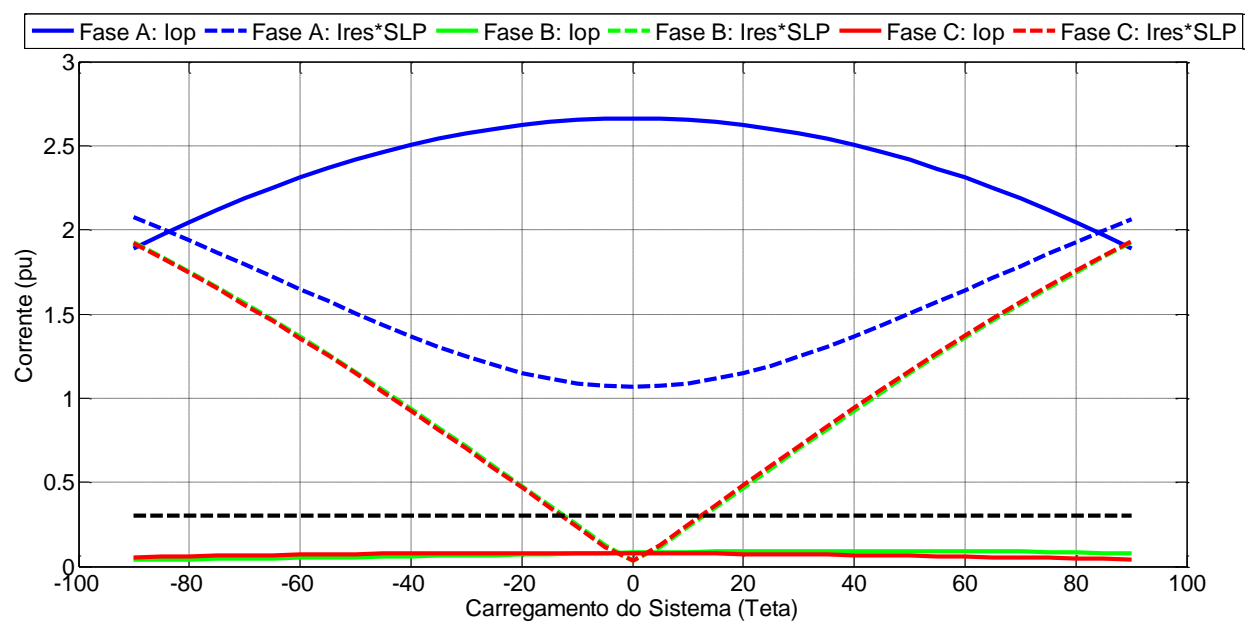

Figura 5.44 - Falta monofásica no circuito1 com variação do carregamento do sistema: Método das Capacitâncias Concentradas. 


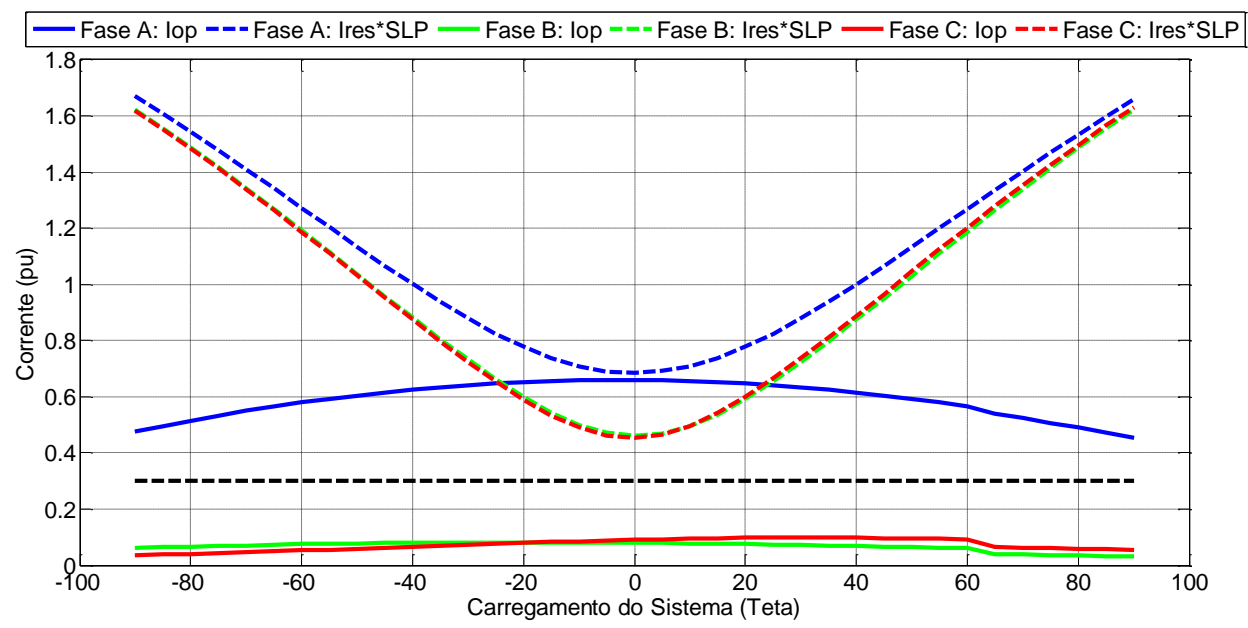

Figura 5.45 - Falta monofásica no circuito1 com variação do carregamento do sistema: Método da Memória de Corrente Capacitiva.

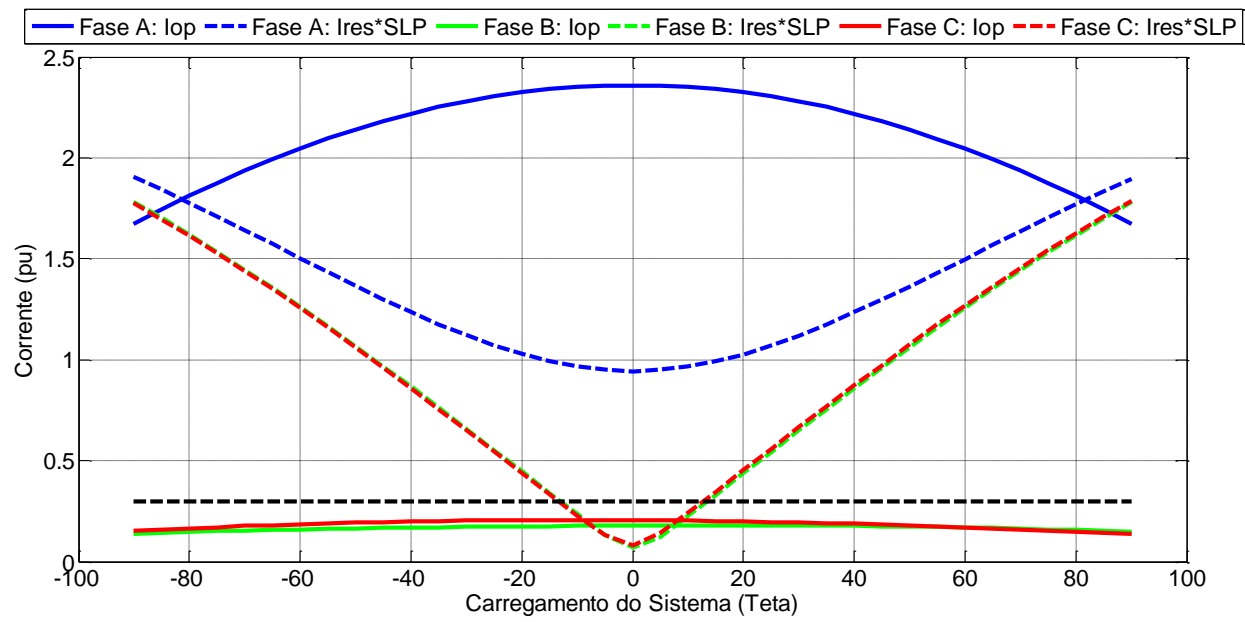

Figura 5.46 - Falta monofásica no circuito1 com variação do carregamento do sistema: Modelo $\pi$-Equivalente da linha.

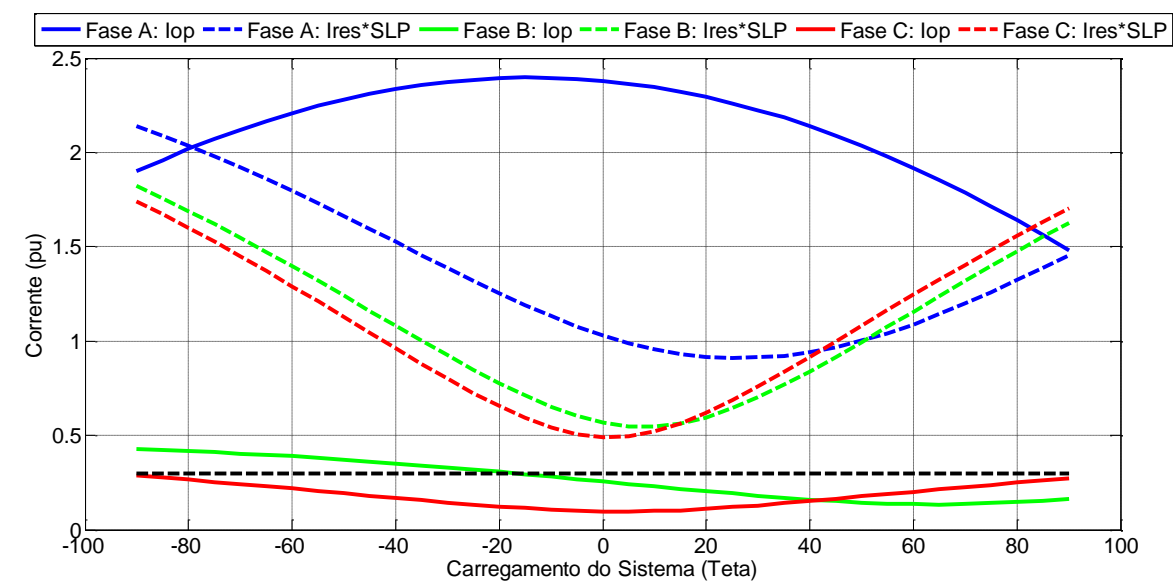

Figura 5.47 - Falta monofásica no circuito1 com variação do carregamento do sistema: Modelo de Bergeron da linha. 


\subsubsection{Sistema com falta bifásica}

Através das Figuras 5.48 a 5.52, são expostos os resultados da simulação do curto-circuito bifásico nas fases A e B do circuito 1, variando-se o carregamento do sistema.

Observando-se a Figura 5.48, nota-se que para um curto-circuito bifásico, se não houver compensação da corrente capacitiva, a restrição da fase sã não é feita corretamente, para valores de defasagens entre as barras de $-45^{\circ}$ a $45^{\circ}$. Mais uma vez constata-se que quanto menor o carregamento do sistema, maior a influência da corrente capacitiva.

De forma geral, a atuação da proteção diferencial utilizando os métodos é satisfatória, atuando apenas para as fases afetadas pela falta. Isto ocorre pois, como foi dito anteriormente, para esse sistema o curto-circuito bifásico é mais severo que o monofásico. O Método da Memória de Corrente Capacitiva não atua corretamente para defasagens maiores que $85^{\circ}$ e menores que $-85^{\circ}$, contudo, valores de carregamento desta ordem não são realizados na prática.

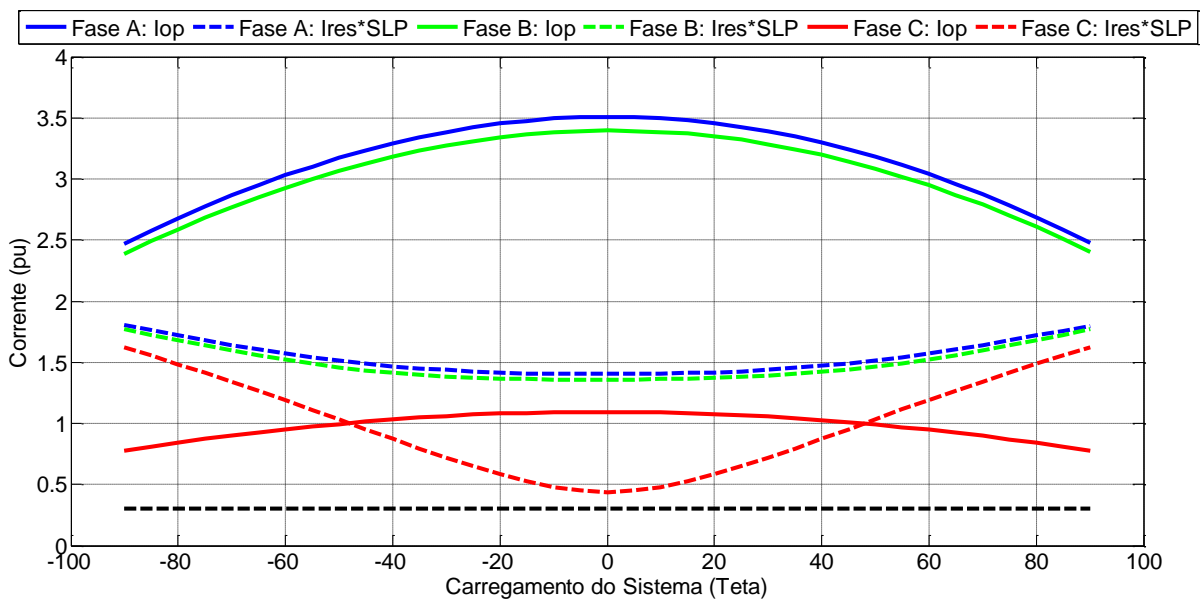

Figura 5.48 - Falta bifásica no circuito1 com variação do carregamento do sistema: Correntes Sem Compensação.

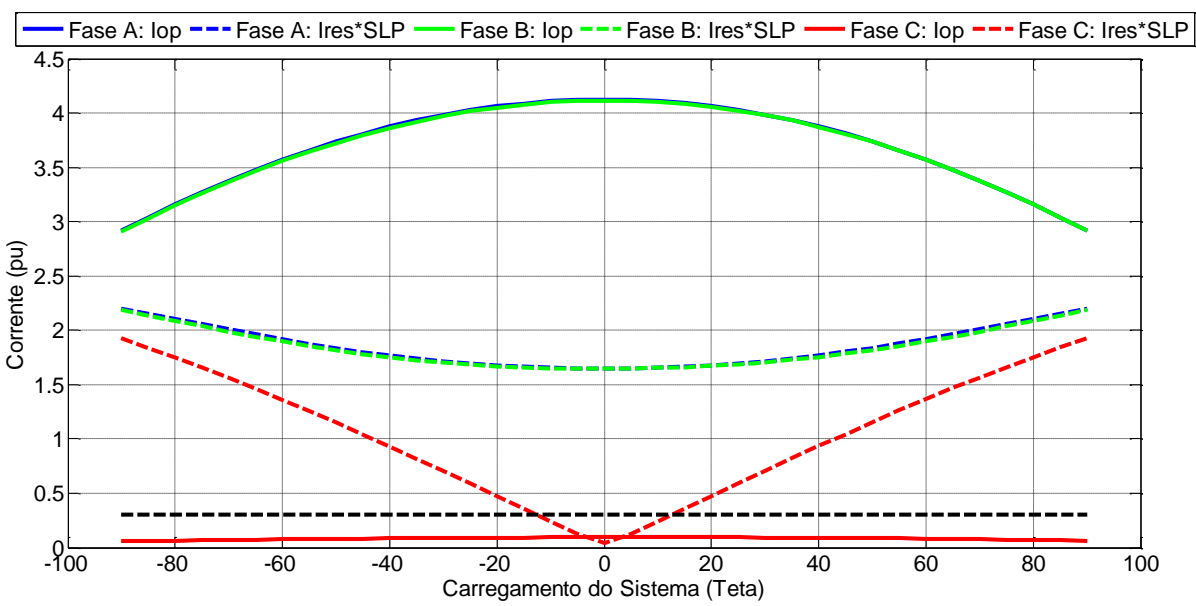


Figura 5.49 - Falta bifásica no circuito1 com variação do carregamento do sistema: Método das Capacitâncias Concentradas.

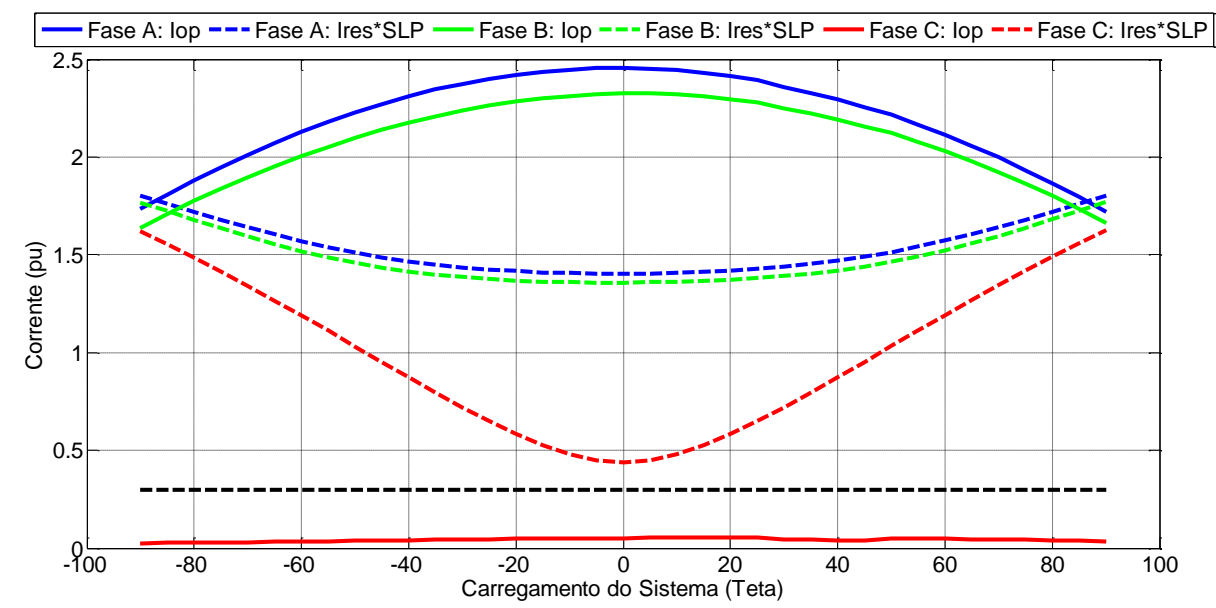

Figura 5.50 - Falta bifásica no circuito1 com variação do carregamento do sistema: Método da Memória de Corrente Capacitiva.

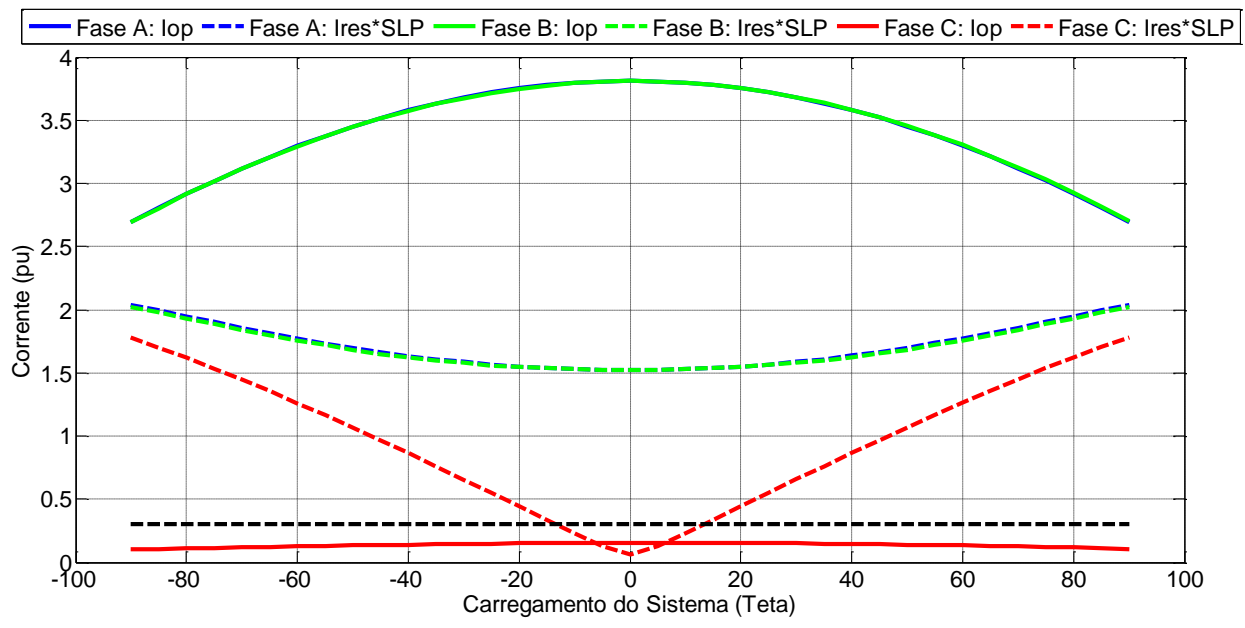

Figura 5.51 - Falta bifásica no circuito1 com variação do carregamento do sistema: Modelo $\pi$-Equivalente da linha.

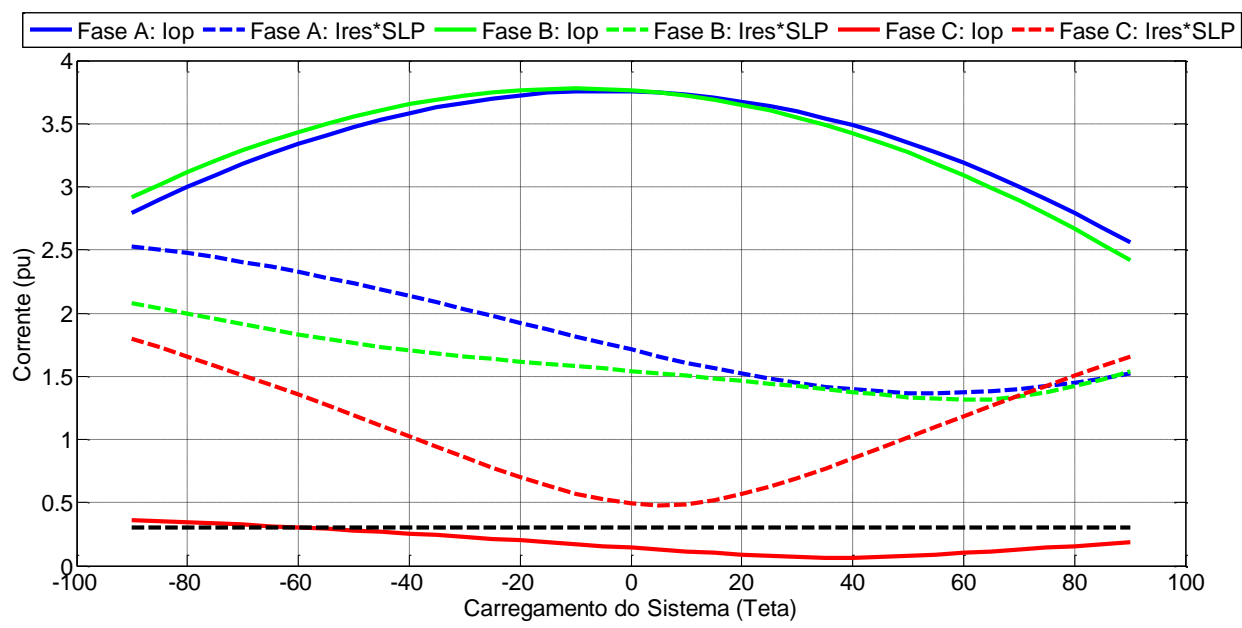


Figura 5.52 - Falta bifásica no circuito1 com variação do carregamento do sistema: Modelo de Bergeron da linha.

\subsubsection{Sistema com falta bifásico-terra}

As Figuras 5.53 a 5.57 contém os resultados da simulação de um curto bifásico-terra nas fases A e B do circuito 1, variando-se o carregamento do sistema.

Nota-se que os métodos que adaptam a proteção diferencial percentual possuem comportamento semelhante com resultados os obtidos para o curto-circuito bifásico.

A única diferença de atuação pode ser observada através da Figura 5.55, que mostra os resultados para a proteção diferencial que utiliza o Método da Memória da Corrente Capacitiva. Este método não atua corretamente para defasagens entre as barras superiores a $75^{\circ}$ e inferiores a $-75^{\circ}$. Esta diminuição da faixa de atuação correta deste método se dá devido o envolvimento da terra neste curtocircuito.

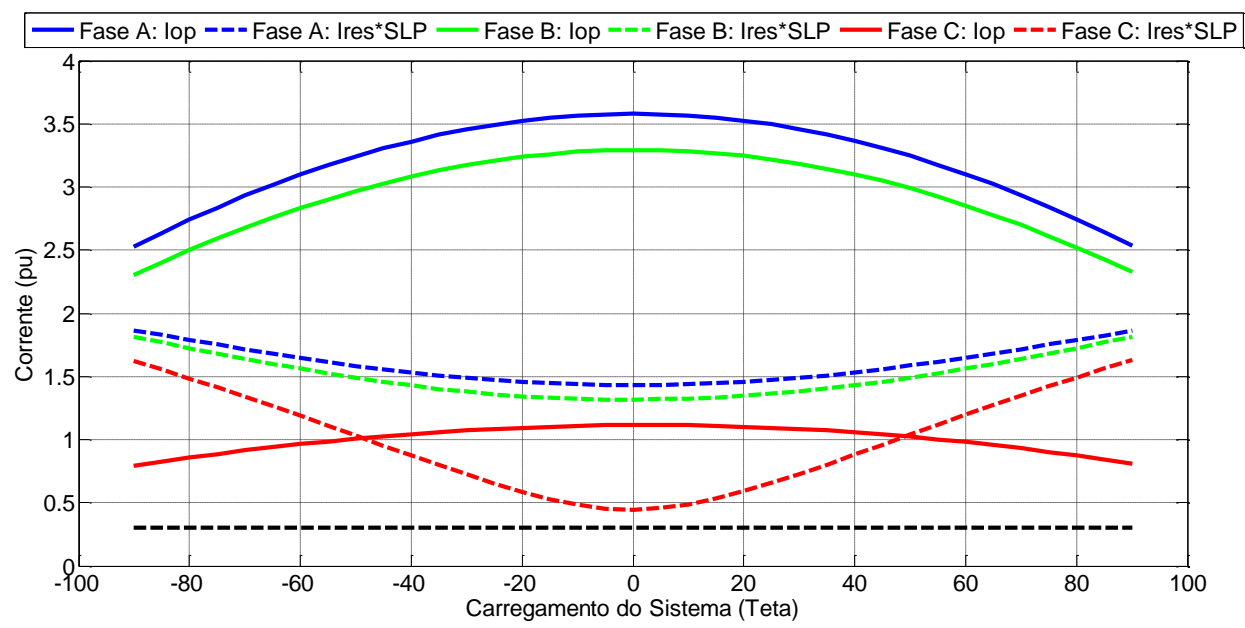

Figura 5.53 - Falta bifásico-terra no circuito 1 com variação do carregamento do sistema: Correntes Sem Compensação.

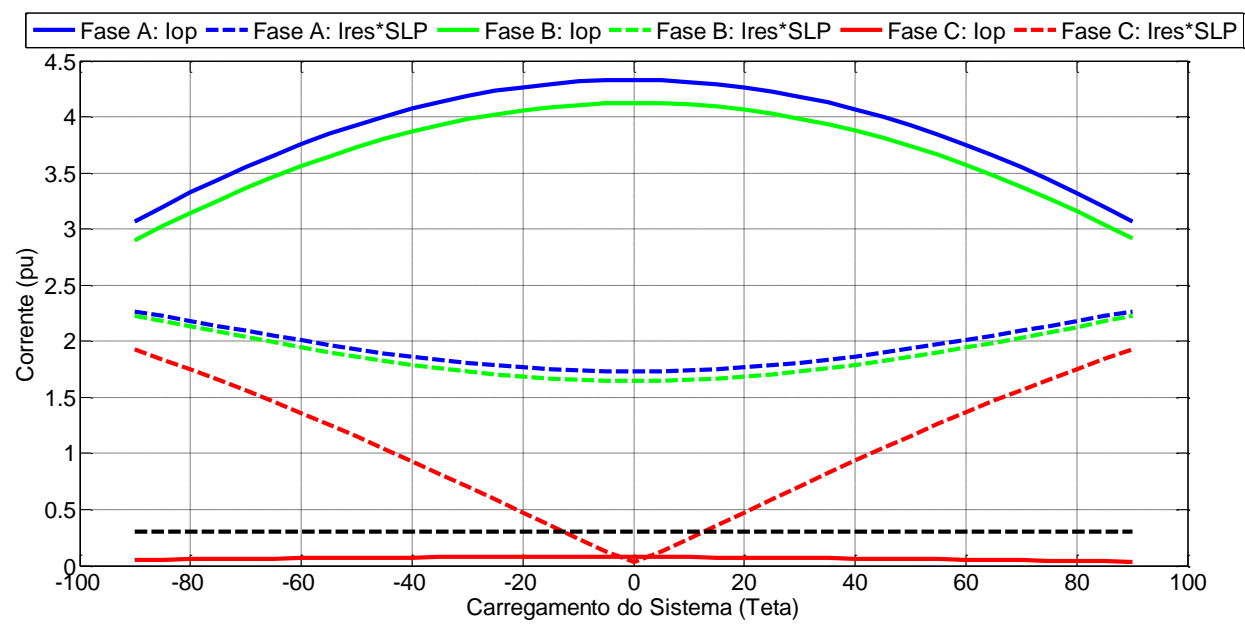

Figura 5.54- Falta bifásico-terra no circuito 1 com variação do carregamento do sistema: Método das Capacitâncias Concentradas. 


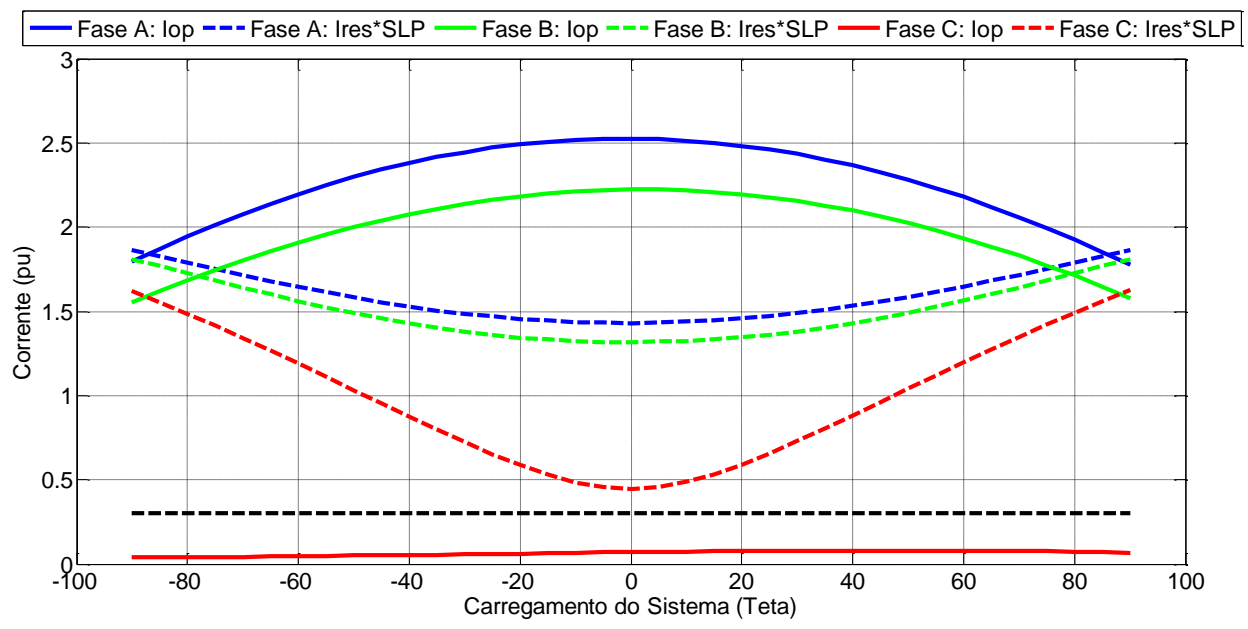

Figura 5.55 - Falta bifásico-terra no circuito 1 com variação do carregamento do sistema: Método da Memória de Corrente Capacitiva.

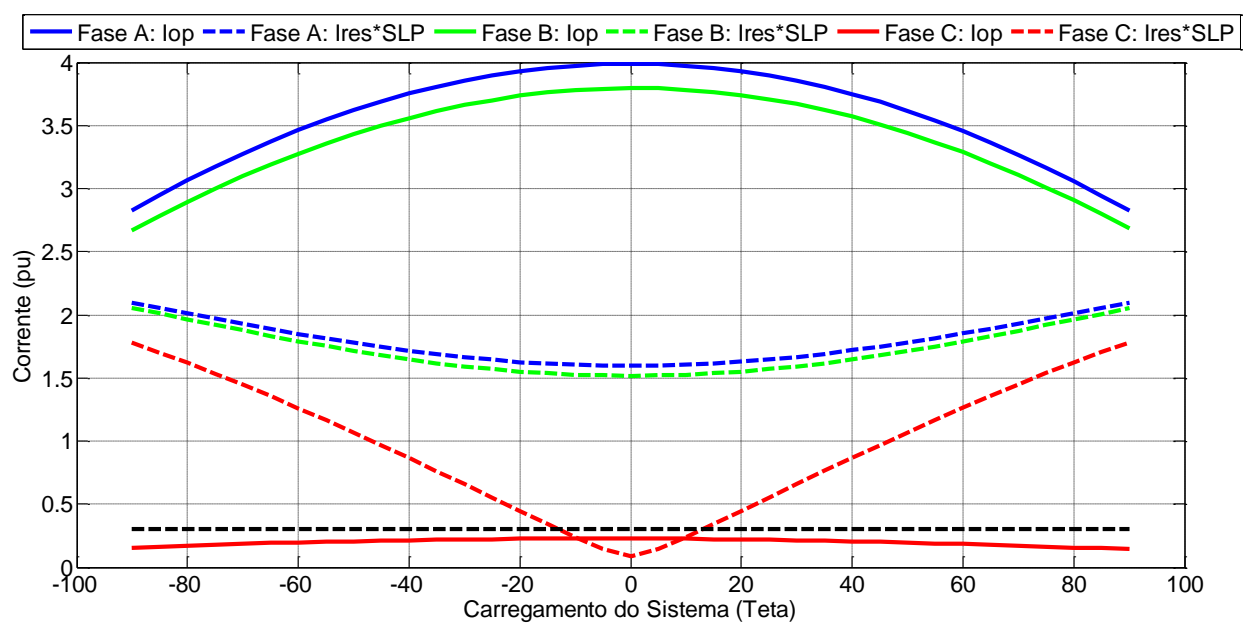

Figura 5.56 - Falta bifásico-terra no circuito 1 com variação do carregamento do sistema: Modelo $\pi$-Equivalente da linha.

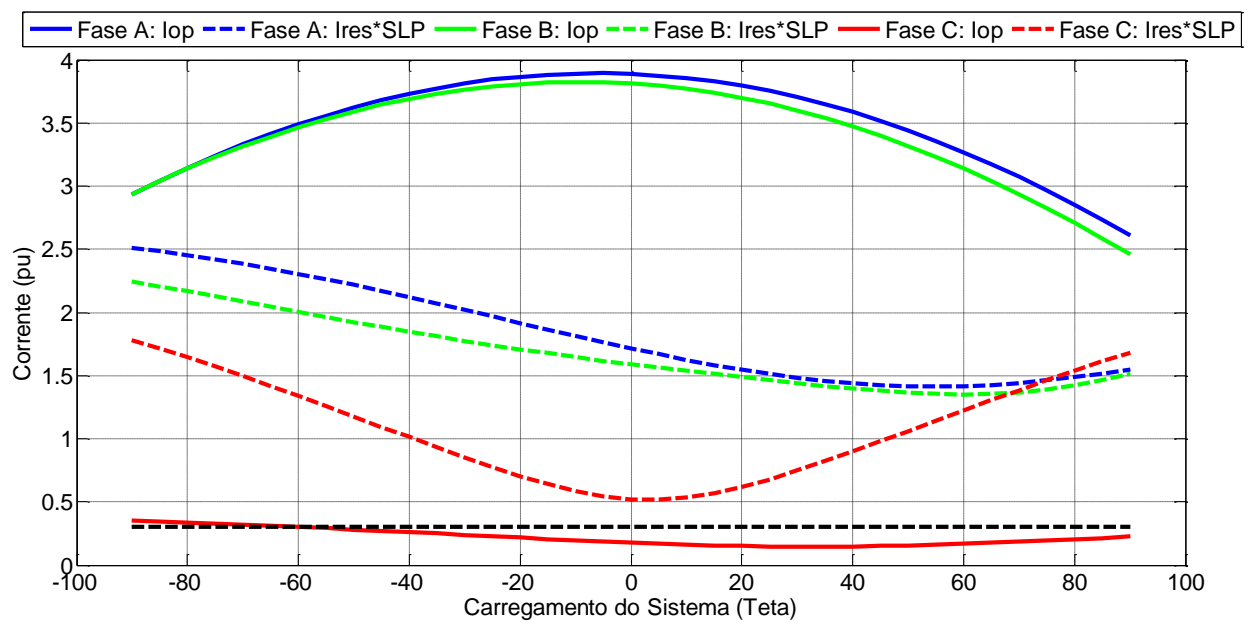

Figura 5.57 - Falta bifásico-terra no circuito 1com variação do carregamento do sistema: Modelo de Bergeron da linha. 


\subsubsection{Variação da Força da Fonte Local}

Apresenta-se a seguir o desempenho dos métodos avaliados frente à variação da força da fonte local, ou seja, da sua capacidade de contribuição para a corrente de curto-circuito. Para tanto, variou-se os valores das impedâncias de sequência positiva e zero da fonte local, com base em seus valores nominais, apresentados na Tabela 5.2.

Primeiramente, foram simulados os diversos tipos de curtos-circuitos no circuito $1 \mathrm{e}$, para cada caso, variou-se a impedância da fonte local desde 0,1 até 10 vezes o seu valor real, mantendo o valor da impedância da fonte remota inalterado.

\subsubsection{Sistema com falta monofásica}

As Figuras 5.58 a 5.62 apresentam o desempenho dos métodos quando da aplicação de uma falta monofásica na fase A no circuito 1.

Analisando a Figura 5.58, pode-se perceber que para um curto monofásico, se não houver compensação da corrente capacitiva, a restrição das fases sãs não é satisfatória, independentemente do valor da impedância da fonte local.

Com relação a restrição das fases que não são afetadas pela falta, se for aplicado qualquer dos métodos de compensação da corrente capacitiva, para todos os casos simulados estas são restringidas corretamente.

Já quanto à atuação para a fase defeituosa, grande parte dos métodos atua corretamente. Somente o Método da Memória de Corrente Capacitiva não funciona corretamente para a fase defeituosa para valores da impedância da fonte local superiores a $70 \%$ do seu valor original. Isto ocorre pois, aumentando-se a impedância a fonte local, diminui-se a contribuição de corrente desta fonte para o curto-circuito. Como o Método da Memória de Corrente Capacitiva retira parte da corrente diferencial como falsa corrente capacitiva, o relé não consegue ser sensibilizado. Uma observação importante é que as simulações aqui apresentadas são de curtos-circuitos aplicados na metade da linha. 


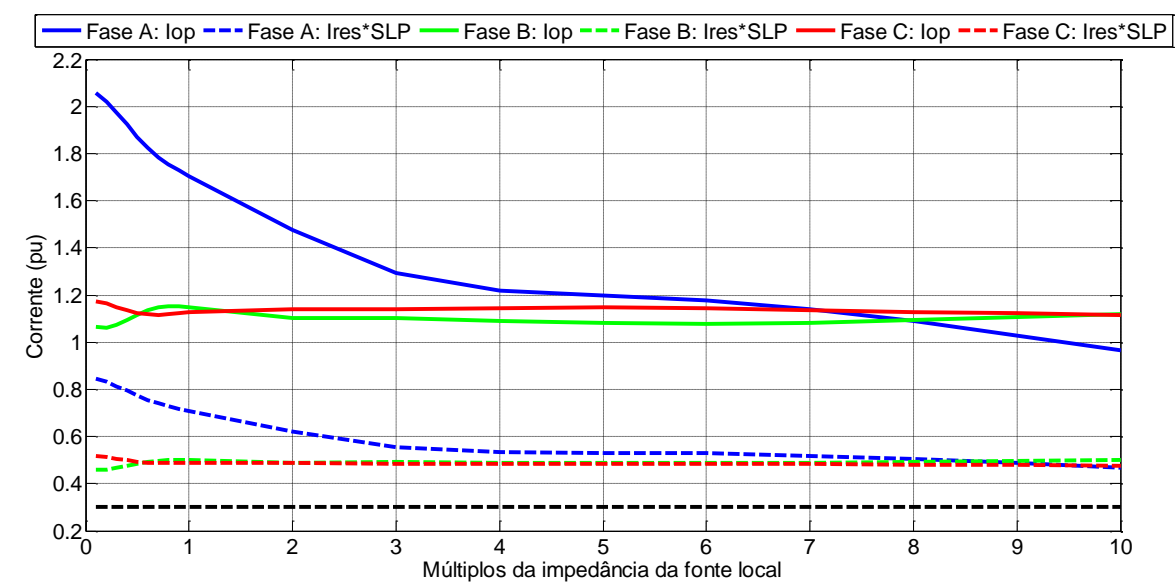

Figura 5.58 - Falta monofásica no circuito 1 com variação da força da fonte local: Correntes Sem Compensação.

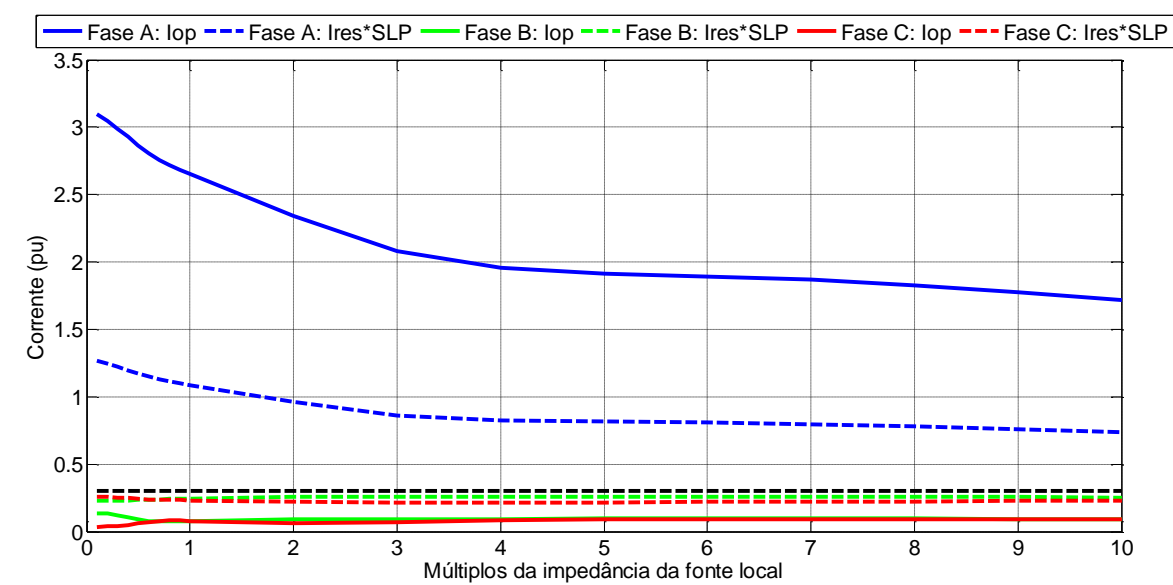

Figura 5.59- Falta monofásica no circuito 1 com variação da força da fonte local: Método das Capacitâncias Concentradas.

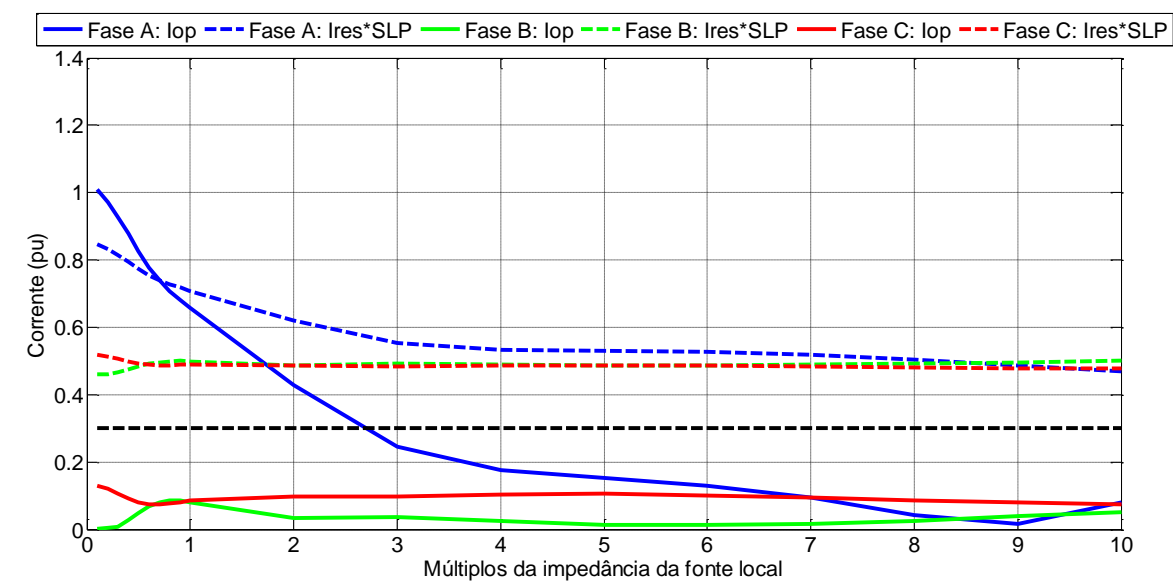

Figura 5.60 - Falta monofásica no circuito 1 com variação da força da fonte local: Método da Memória de Corrente Capacitiva. 


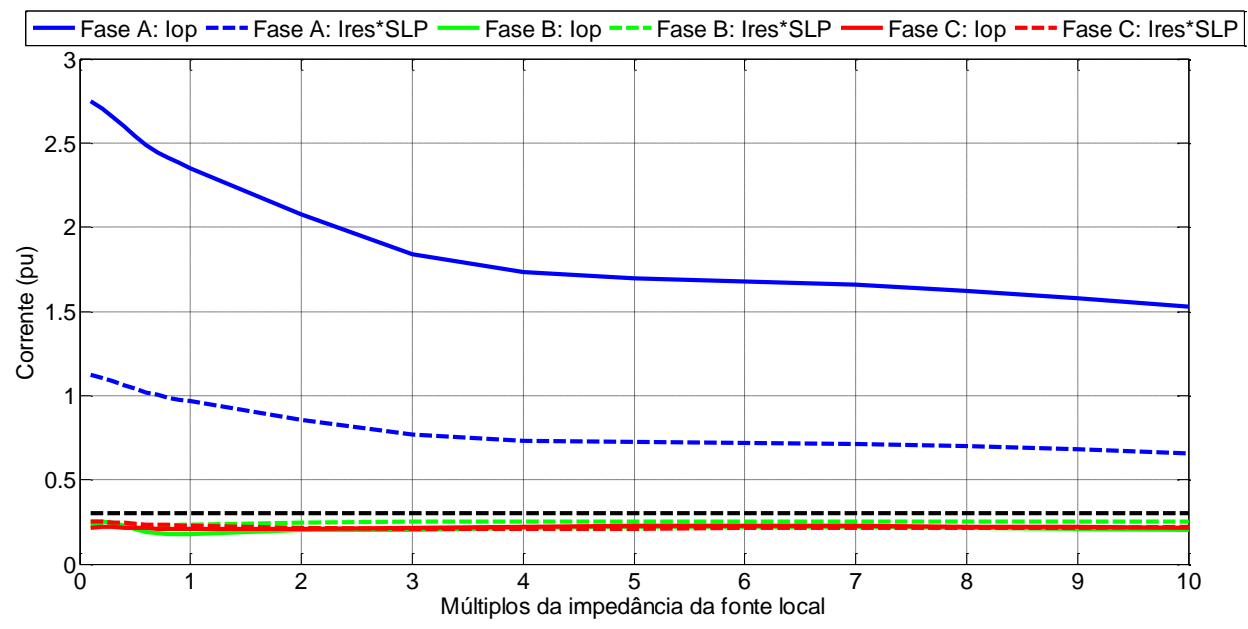

Figura 5.61 - Falta monofásica no circuito 1 com variação da força da fonte local: Modelo $\pi$-Equivalente da linha.

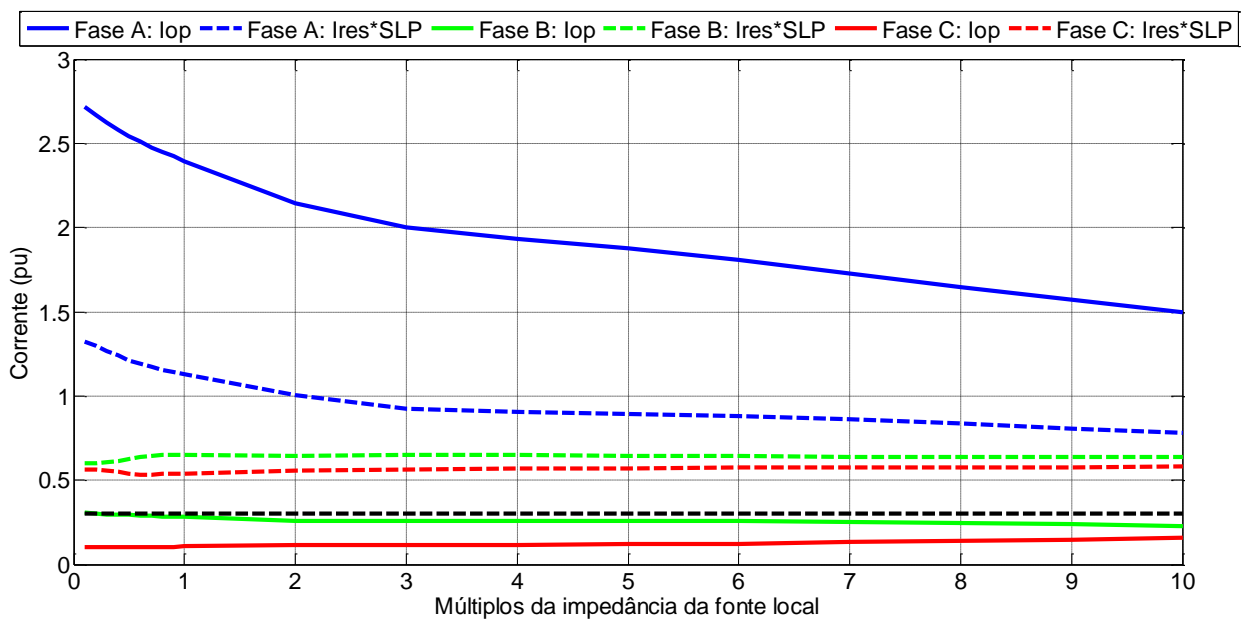

Figura 5.62 - Falta monofásica no circuito 1 com variação da força da fonte local: Modelo de Bergeron da linha.

\subsubsection{Sistema com falta bifásica}

Os resultados da simulação do curto-circuito bifásico nas fases A e B do circuito 1, variandose a força da fonte local, são apresentados nas Figuras de 5.63 a 5.67.

Da mesma forma que para o curto monofásico, se não houver compensação da corrente capacitiva, a restrição das fases sãs não é satisfatória, independentemente do valor da impedância da fonte local.

Se for aplicado qualquer dos métodos de compensação da corrente capacitiva, a atuação da proteção diferencial é satisfatória, pois restringe a fase sã e atua para as fases afetadas pela falta, independentemente da força da fonte local. Isto ocorre pois, como foi dito anteriormente, para esse sistema a falta bifásica é mais severa que a monofásica. 


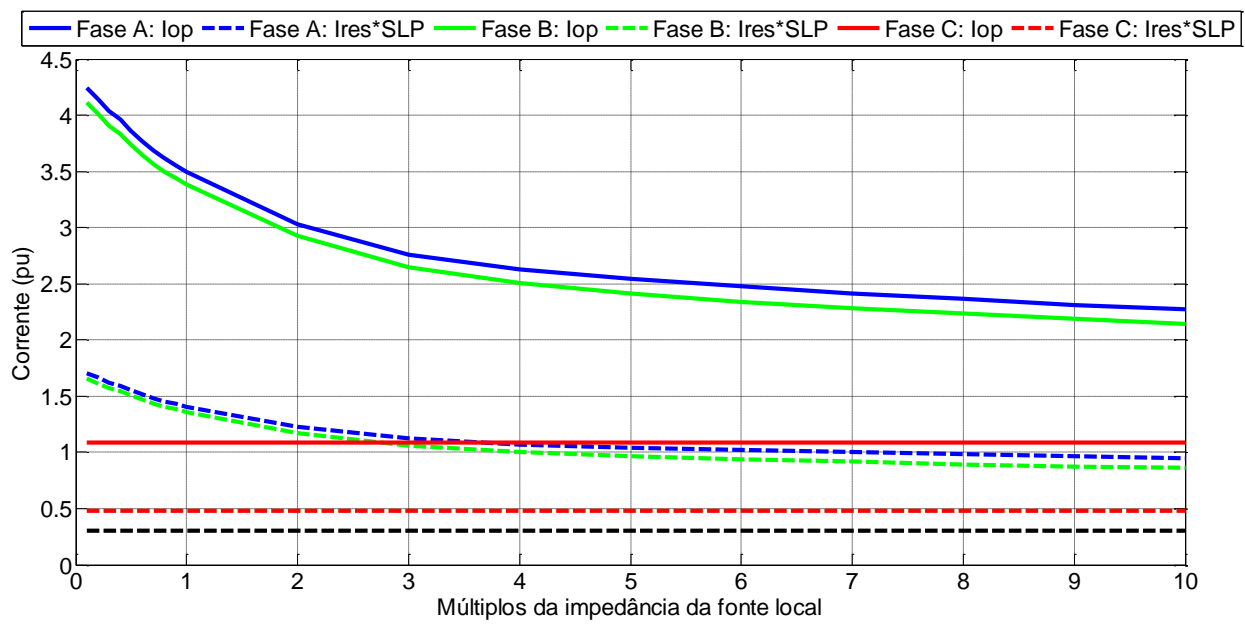

Figura 5.63 - Falta bifásica no circuito 1 com variação da força da fonte local: Correntes Sem Compensação.

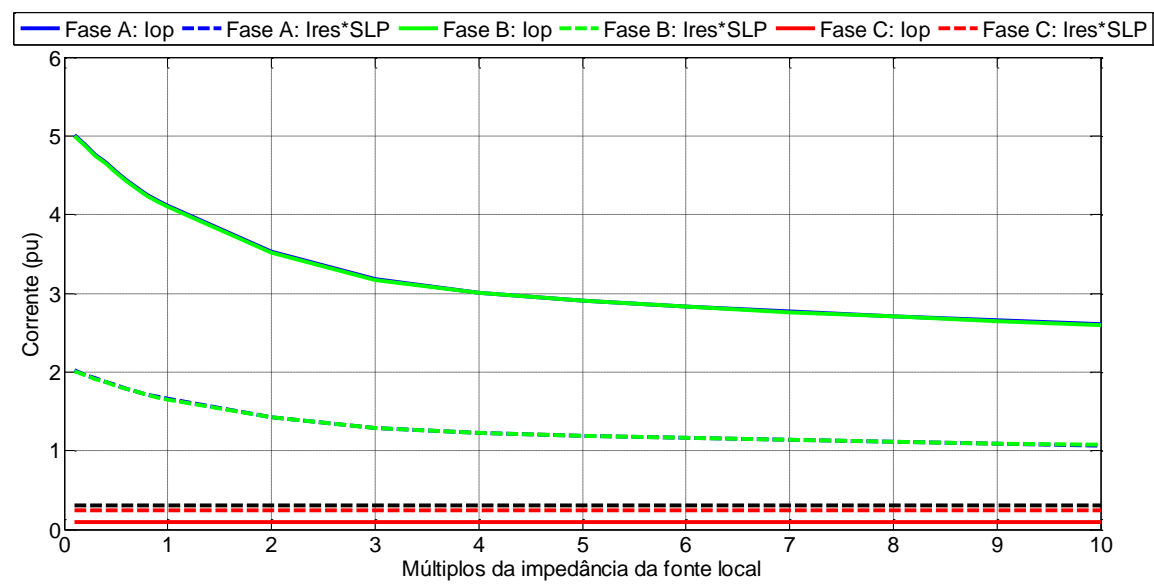

Figura 5.64- Falta bifásica no circuito 1 com variação da força da fonte local: Método das Capacitâncias Concentradas.

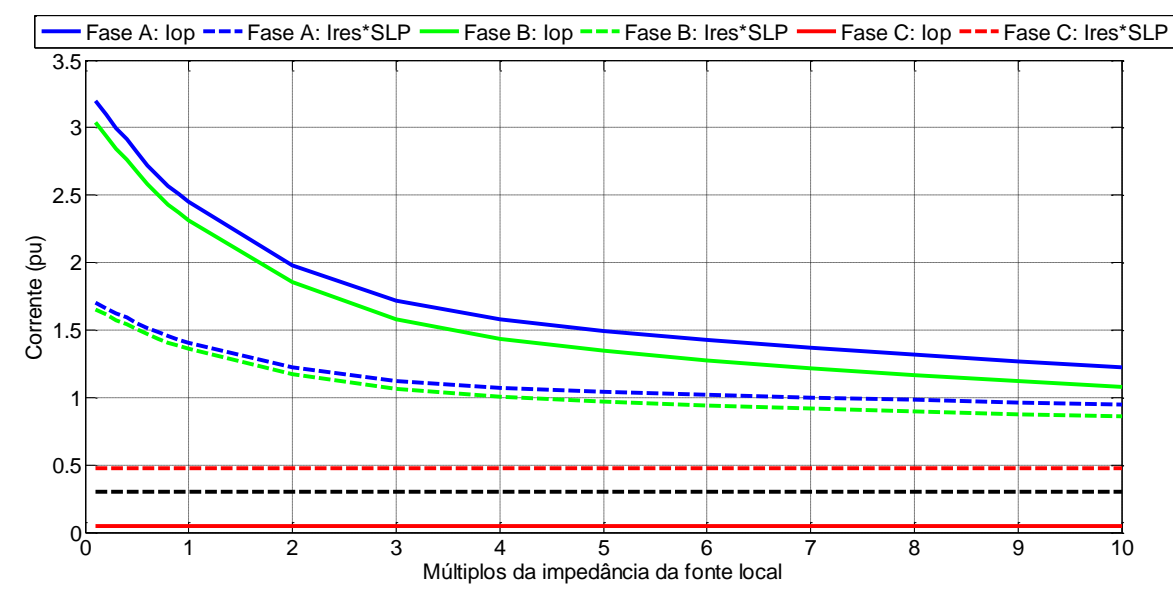

Figura 5.65 - Falta bifásica no circuito 1 com variação da força da fonte local: Método da Memória de Corrente Capacitiva. 


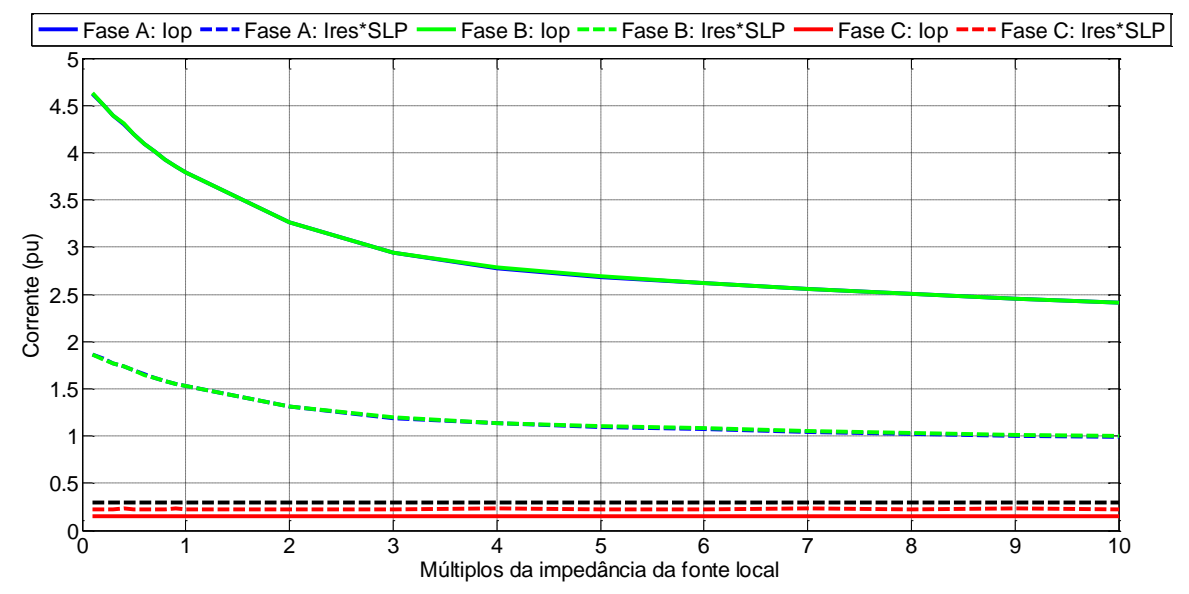

Figura 5.66 - Falta bifásica no circuito 1 com variação da força da fonte local: Modelo $\pi$-Equivalente da linha.

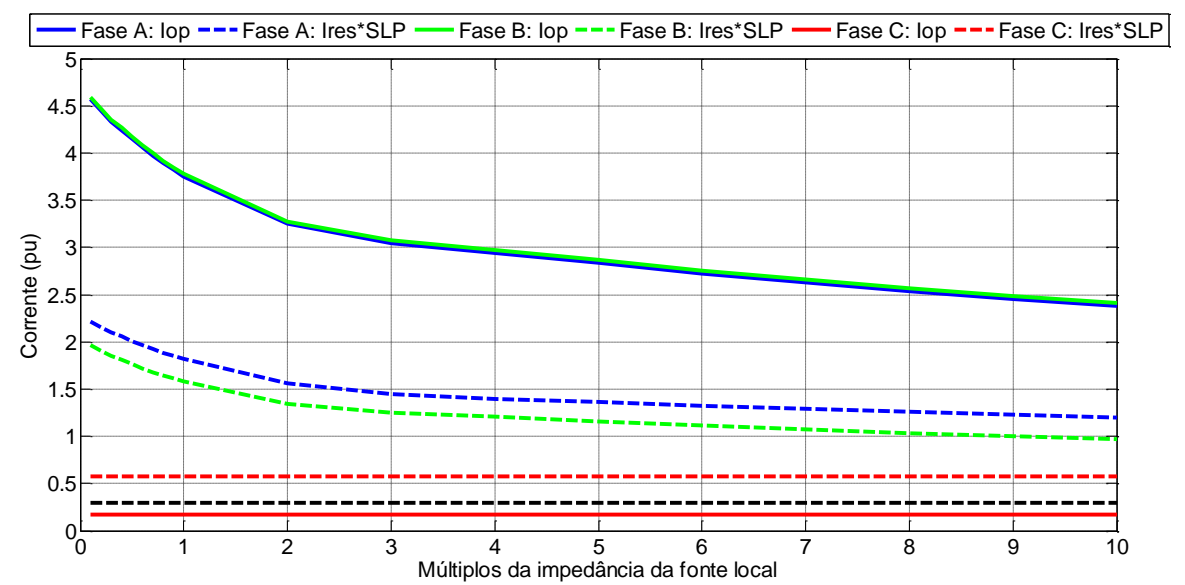

Figura 5.67 - Falta bifásica no circuito 1 com variação da força da fonte local: Modelo de Bergeron da linha.

\subsubsection{Variação da Força da Fonte Remota}

Por fim, foram simulados os diversos tipos de curtos-circuitos e, para cada caso, variou-se a impedância da fonte remota desde 0,1 até 10 vezes o seu valor real, mantendo o valor da impedância da fonte local inalterado.

Os resultados das simulações variando-se a força da fonte remota são muito semelhantes aos apresentados para a variação da força da fonte local pois, originalmente, os valores das impedâncias das duas fontes são muito próximos.

\subsubsection{Sistema com falta monofásica}

As Figuras 5.68 a 5.72 contém os resultados da simulação de um curto monofásico na fase A no circuito 1, variando-se o valor da impedância da fonte remota. 
Analisando a Figura 5.68, pode-se perceber que para um curto monofásico, se não houver compensação da corrente capacitiva, a restrição das fases sãs não é satisfatória, independentemente do valor da impedância da fonte remota.

Se forem aplicados os métodos de compensação da corrente capacitiva, para todos os casos simulados as fases não afetadas pelo curto-circuito são restringidas corretamente.

Já para a fase defeituosa, o Método da Memória de Corrente Capacitiva é o único que não atua corretamente para valores da impedância da fonte local superiores a 70\% do seu valor original. Ressaltase novamente que as simulações aqui apresentadas são de curtos-circuitos aplicados na metade da linha.

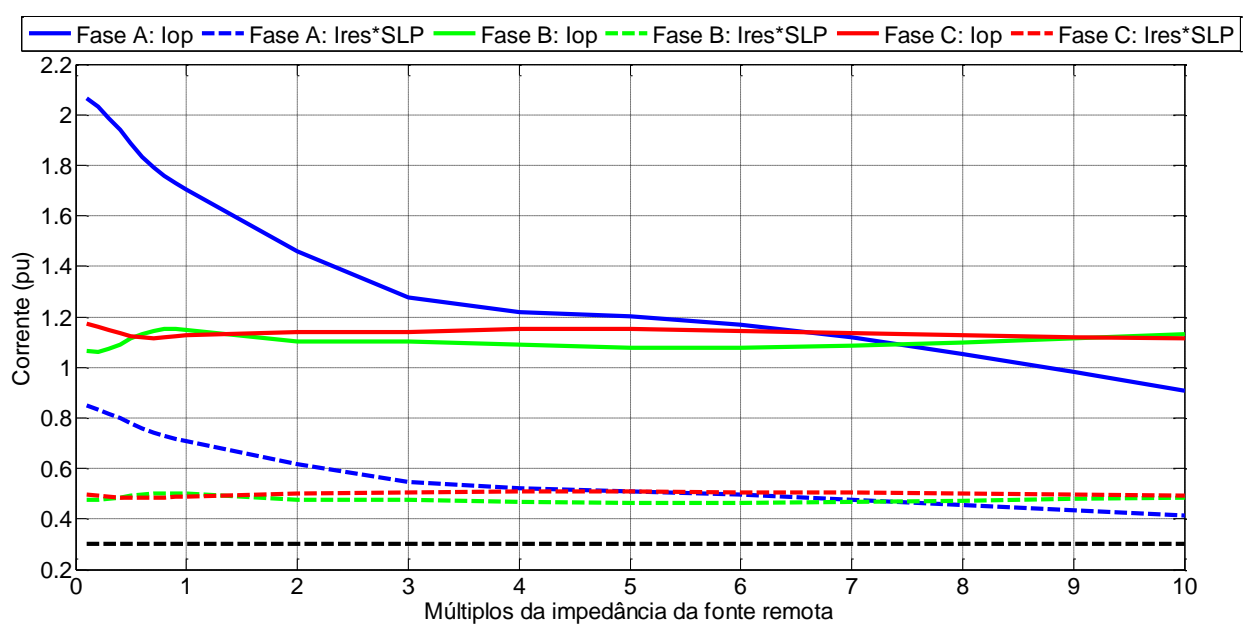

Figura 5.68 - Falta monofásica no circuito 1 com variação da força da fonte remota: Correntes Sem Compensação.

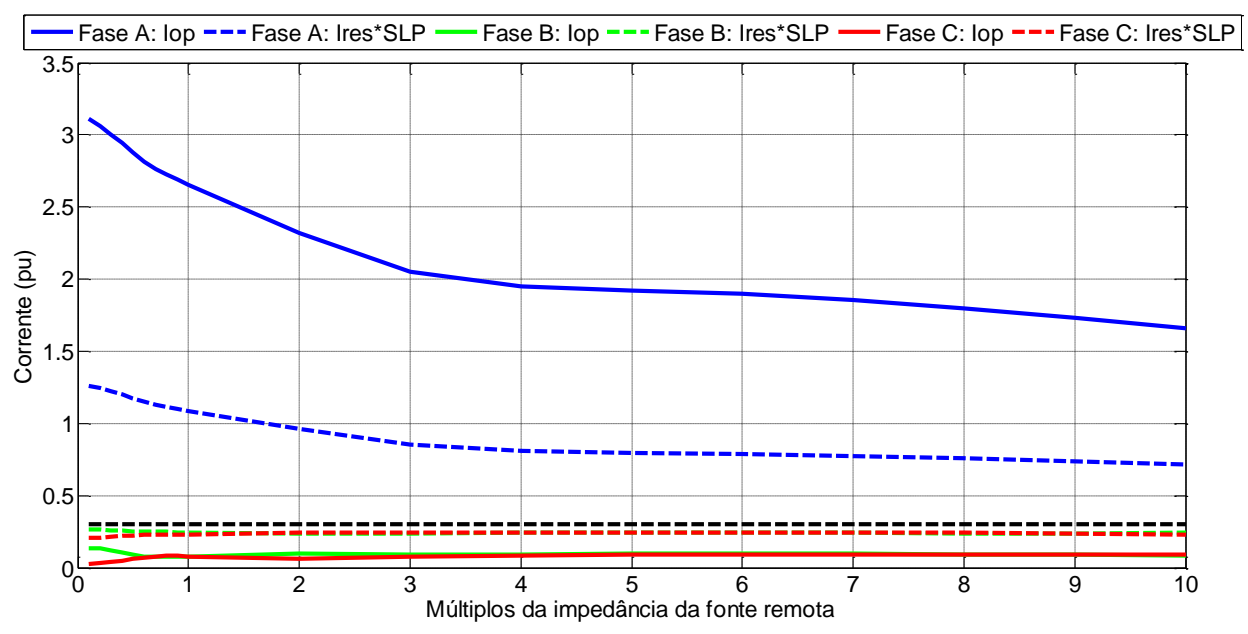

Figura 5.69- Falta monofásica no circuito 1 com variação da força da fonte remota: Método das Capacitâncias Concentradas. 


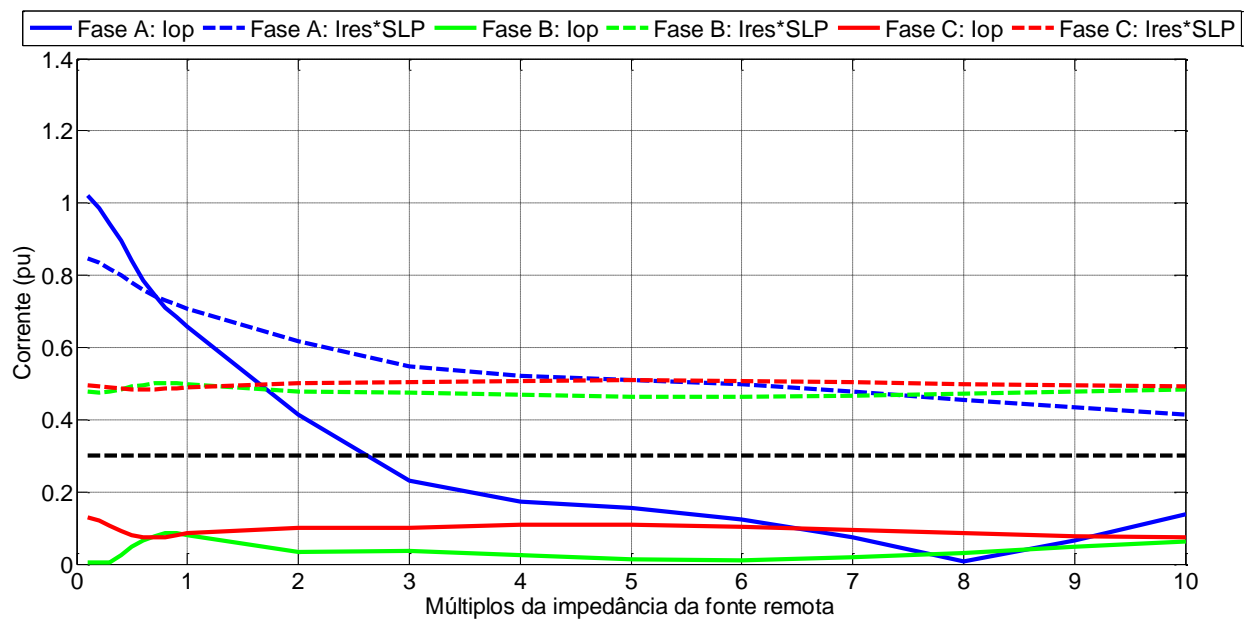

Figura 5.70 - Falta monofásica no circuito 1 com variação da força da fonte remota: Método da Memória de Corrente Capacitiva.

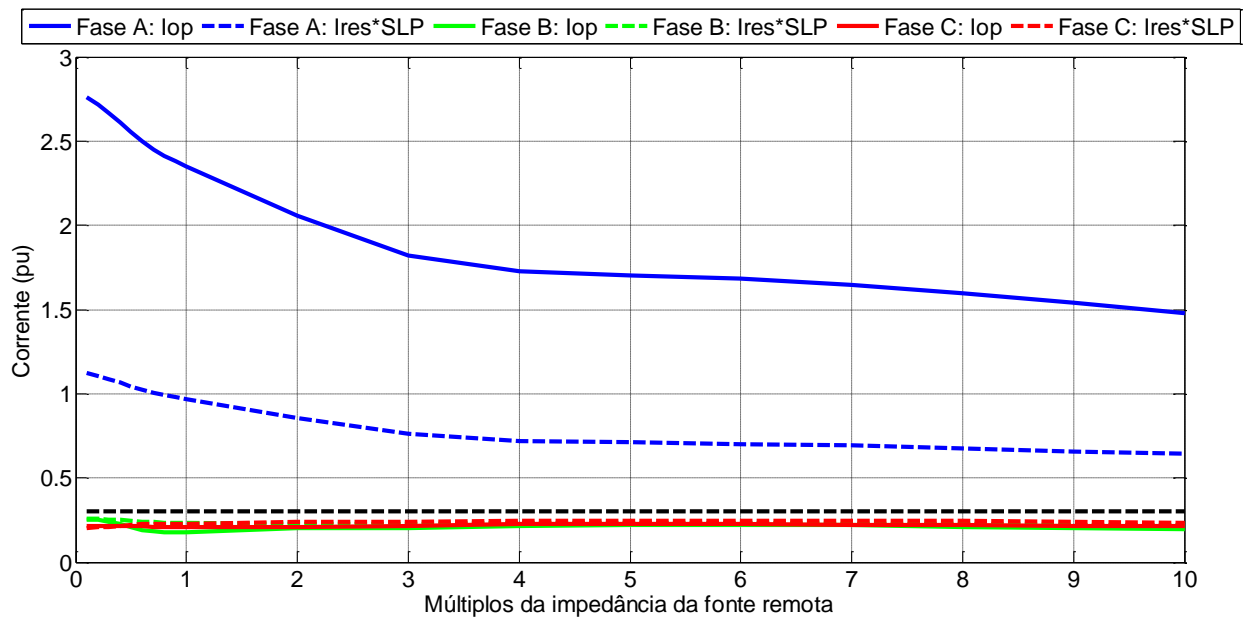

Figura 5.71 - Falta monofásica no circuito 1 com variação da força da fonte remota: Modelo $\pi$-Equivalente da linha.

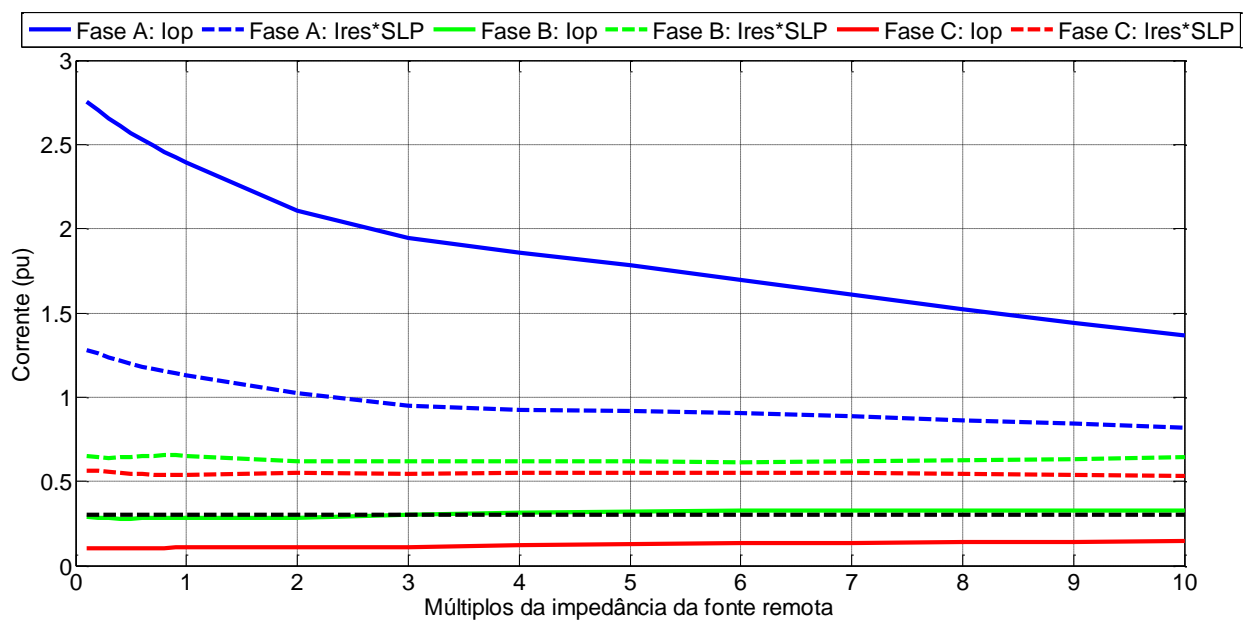

Figura 5.72 - Falta monofásica no circuito 1 com variação da força da fonte remota: Modelo de Bergeron da linha. 


\subsubsection{Sistema com falta bifásica}

Através das Figuras 5.73 a 5.77, são expostos os resultados da simulação do curto-circuito bifásico nas fases A e B do circuito 1, variando-se a impedância da fonte remota.

Se não houver compensação da corrente capacitiva, a restrição da fase sã não é feita corretamente, independentemente do valor da impedância da fonte remota. Contudo, a atuação da proteção diferencial utilizando os métodos é satisfatória, atuando apenas para as fases afetadas pela falta.

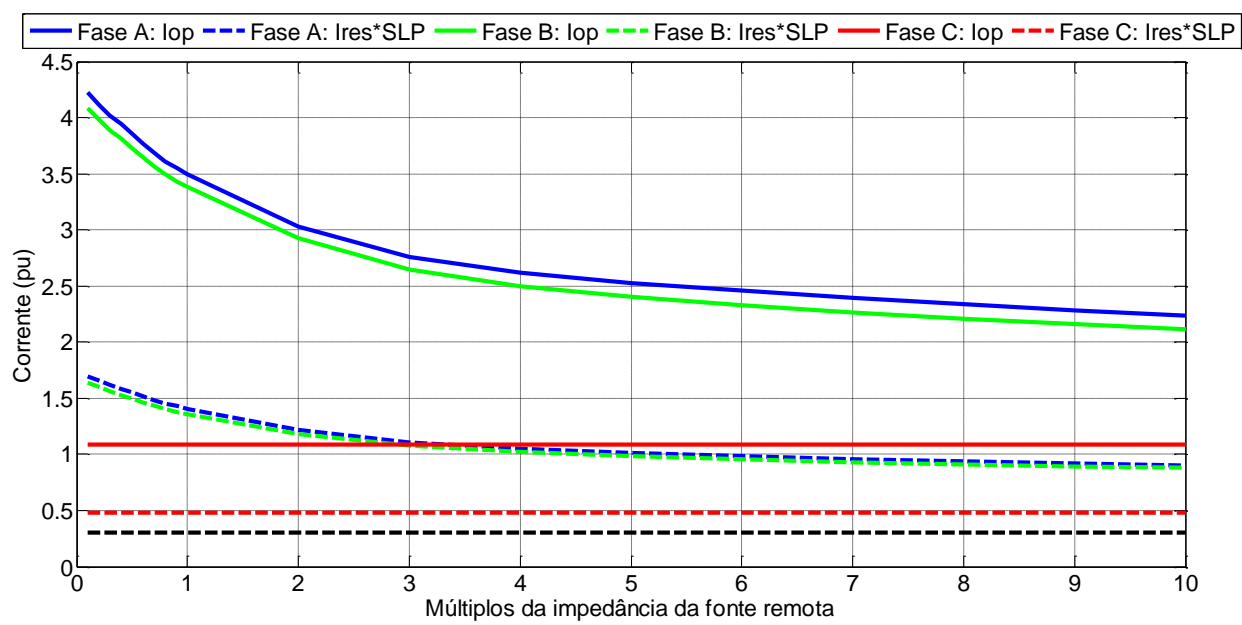

Figura 5.73 - Falta bifásica no circuito 1 com variação da força da fonte remota: Correntes Sem Compensação.

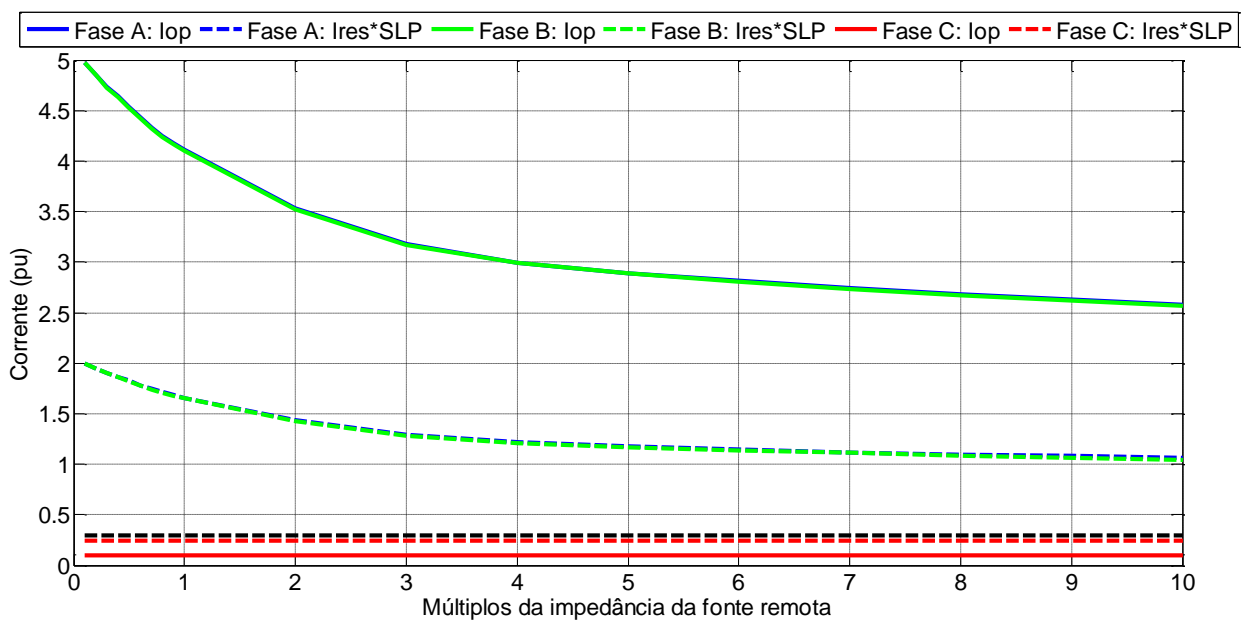

Figura 5.74- Falta bifásica no circuito 1 com variação da força da fonte remota: Método das Capacitâncias Concentradas. 


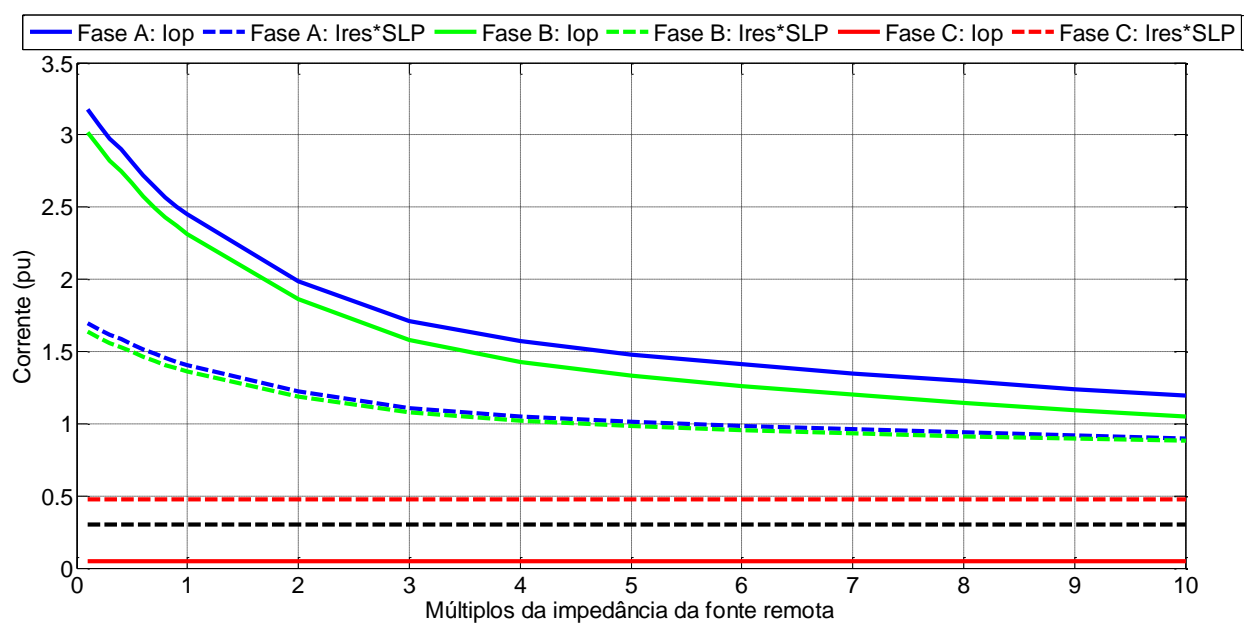

Figura 5.75 - Falta bifásica no circuito 1 com variação da força da fonte remota: Método da Memória de Corrente Capacitiva.

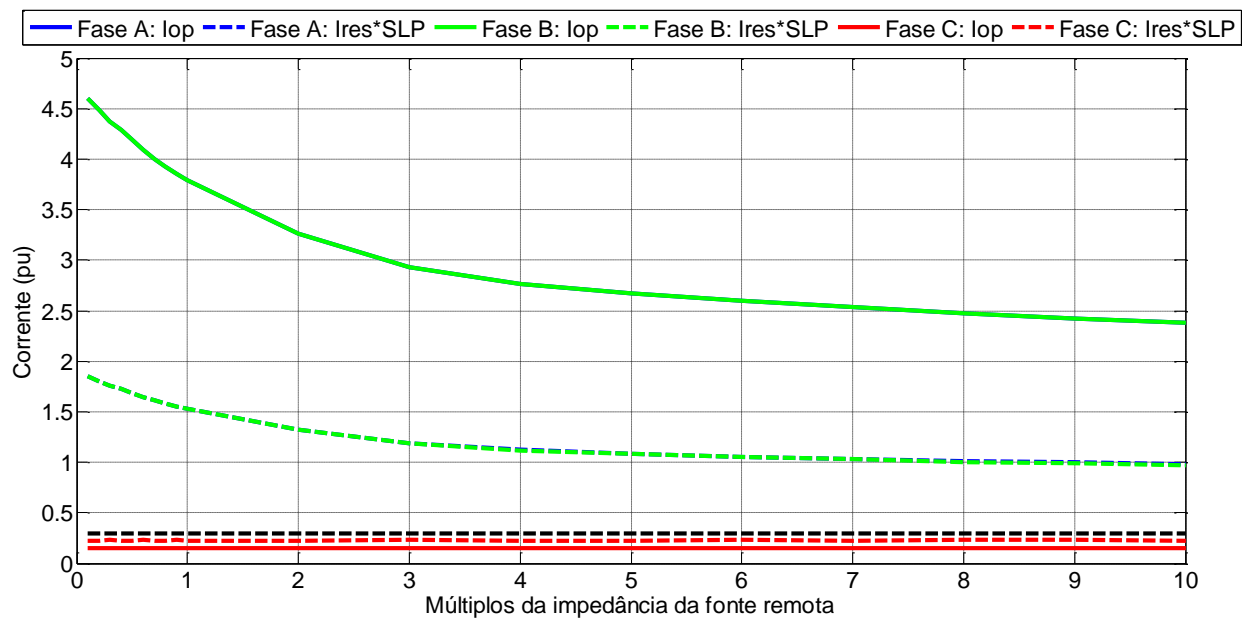

Figura 5.76 - Falta bifásica no circuito 1 com variação da força da fonte remota: Modelo $\pi$-Equivalente da linha.

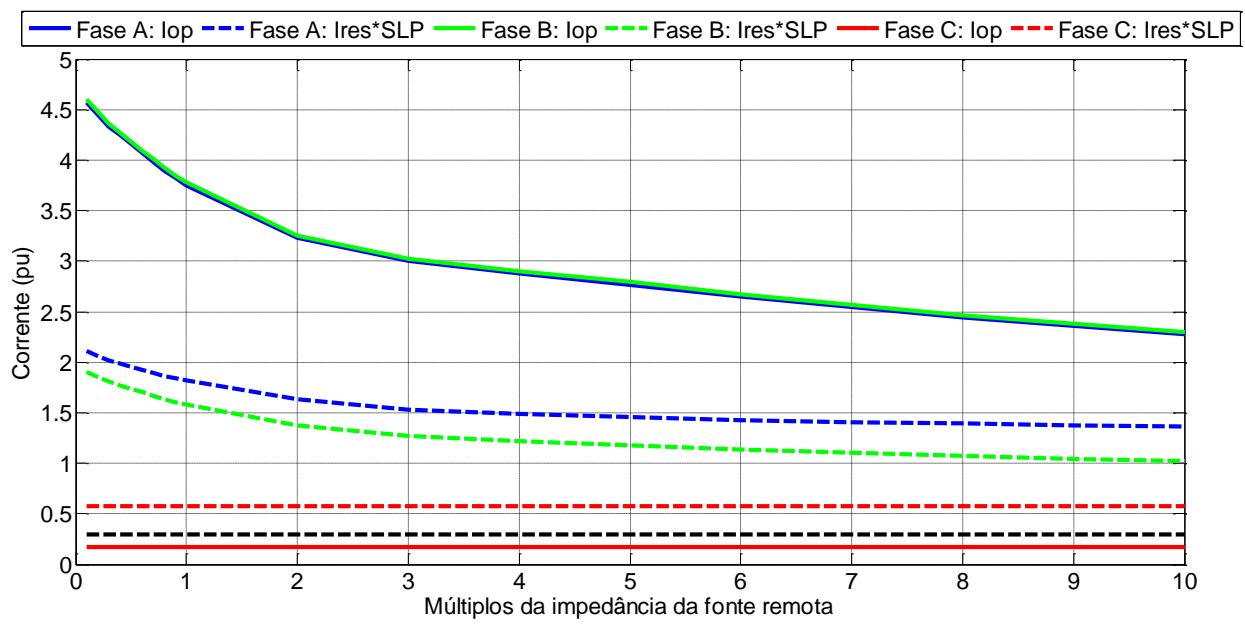

Figura 5.77 - Falta bifásica no circuito 1 com variação da força da fonte remota: Modelo de Bergeron da linha. 


\section{CAPÍTULO 6}

\section{CONCLUSÕES E PROPOSTAS PARA TRABALHOS FUTUROS}

Nesta dissertação foi apresentada a problemática do efeito da corrente capacitiva na atuação da proteção diferencial de linhas de transmissão de UAT e foi efetuada uma comparação detalhada de algumas das soluções propostas na literatura.

O sistema utilizado para dar suporte a esta discussão simula uma linha de transmissão de 1000 $\mathrm{kV}$ em operação no sistema elétrico interligado da China, interconectando os seus subsistemas Norte e Sul, partindo desde a SE Jindongnan e, finalizando na SE Jingmen (XU et al., 2007). Este sistema foi representado no software ATP, no qual foram realizadas todas as simulações apresentadas.

Uma vez que o objetivo deste trabalho é avaliar o desempenho de diferentes algoritmos de proteção diferencial aplicados às linhas de transmissão de UAT, optou-se pela utilização de uma única característica de restrição para todos os casos.

Para se verificar as respostas transitórias da proteção diferencial com a implementação dos diversos algoritmos, foram simulados casos pontuais dos diversos tipos de faltas dentro e fora da zona de proteção, bem como energização da linha, tanto em regime normal quanto em regime de curtocircuito. Os resultados mostraram a atuação de cada um dos métodos implementados, indicando que o Método da Memória da Corrente Capacitiva é o menos confiável visto que este superestima a corrente capacitiva para as fases afetadas pelo curto-circuito, acarretando em uma perda de sensibilidade da proteção diferencial.

Outro fato relevante observado através da análise da resposta transitória da proteção diferencial é que durante a energização de uma das linhas do circuito duplo em curto-circuito, verificase uma grande variação nos resultados dos métodos que utilizam o Modelo $\pi$ Equivalente e o Modelo de Bergeron da linha, bem como no Método das Capacitâncias Concentradas. Esta instabilidade não permite que a proteção diferencial identifique a fase defeituosa. Contudo, isto não impede uma correta atuação da proteção, visto que esta atua abrindo as três fases do sistema.

Com o intuito de avaliar mais profundamente a atuação dos métodos de remoção da corrente capacitiva, foram realizadas análises de sensibilidade paramétrica, variando parâmetros importantes do 
sistema, os quais interferem na atuação da proteção diferencial. Os parâmetros variados foram: localização da falta, resistência de falta, carregamento do sistema e força das fontes. Além disso, para cada variação desses parâmetros, foram simulados diversos tipos de curtos-circuitos.

Ao se variar a localização da falta, verificou-se que os métodos que utilizam o Modelo $\pi$ Equivalente e o Modelo de Bergeron da linha, não restringem corretamente as fases sãs para faltas ocorridas próximas as barras, pois não são capazes de remover totalmente a corrente capacitiva. Tal fato compromete a segurança de atuação desses métodos.

Por fim, a partir das análises realizadas pode-se constatar que o Método das Capacitâncias Concentradas se mostrou o mais eficiente e estável. De fato, este método apresentou uma correta atuação em praticamente todas as simulações realizadas, garantindo, assim, segurança e confiabilidade para o sistema. Este método só não apresentou uma atuação correta para o caso de carregamentos muito elevados, da ordem de $80^{\circ}$ de defasagem entre as barras. Contudo, na prática não são observados carregamentos tão elevados. Cabe ressaltar que este algoritmo faz uso tanto dos sinais de corrente quanto dos sinais de tensão dos terminais da linha, o que acarreta a necessidade de instalação de TPCs, agregando erros de medição inerentes a este equipamento.

Uma síntese dos resultados apresentados neste trabalho pode ser observada na Tabela 6.1, na qual as células em branco indicam que o método funcionou conforme o esperado.

A partir das constatações apresentadas neste trabalho, pode-se concluir que a proteção diferencial tal qual tem sido proposta poderá ser utilizada em linhas de transmissão de UAT, sendo capaz inclusive de eliminar adequadamente o efeito da corrente capacitiva da linha.

Como propostas de trabalhos futuros, deixam-se as seguintes sugestões:

- Realizar a análise do desempenho da proteção diferencial para linhas de transmissão de UAT com compensação série e shunt;

- Avaliar mais detalhadamente o efeito da corrente capacitiva no perfil de tensão da linha;

- Avaliar o desempenho dos algoritmos de proteção diferencial baseados no plano alfa de correntes;

- Avaliar a influência de modelos de TPC no Método das Capacitâncias Concentradas;

- Avaliar as técnicas considerando linhas de transmissão de circuito simples;

- Avaliar a influência do tipo de transposição na eliminação da corrente capacitiva. 
Tabela 6.1 - Síntese dos Resultados.

\begin{tabular}{|c|c|c|c|c|c|}
\hline Tipo de Análise & Tipo de Simulação & $\begin{array}{c}\text { Método das Cap. } \\
\text { Concentradas }\end{array}$ & Método da Memória & $\begin{array}{c}\text { Modelo } \pi \\
\text { Equivalente }\end{array}$ & Modelo de Bergeron \\
\hline \multirow{4}{*}{$\begin{array}{l}\text { Análise } \\
\text { Transitória }\end{array}$} & Curto Monofásico & - & Não atua & $\begin{array}{c}\text { Iminência de atuação } \\
\text { para as fases sãs }\end{array}$ & - \\
\hline & Curto Externo & - & - & - & - \\
\hline & Energização & - & Atua indevidamente & - & - \\
\hline & $\begin{array}{l}\text { Energização com } \\
\text { Curto }\end{array}$ & $\begin{array}{c}\text { Possui instabilidade, } \\
\text { atuando para todas } \\
\text { as fases }\end{array}$ & $\begin{array}{c}\text { Atua para todas as } \\
\text { fases }\end{array}$ & $\begin{array}{c}\text { Possui instabilidade, } \\
\text { atuando para todas } \\
\text { as fases }\end{array}$ & $\begin{array}{c}\text { Possui instabilidade, } \\
\text { atuando para todas } \\
\text { as fases }\end{array}$ \\
\hline \multirow{2}{*}{$\begin{array}{c}\text { Variação da } \\
\text { Localização da } \\
\text { Falta }\end{array}$} & Curto Monofásico & - & $\begin{array}{c}\text { Não atua para curtos } \\
\text { próximos a metade } \\
\text { da LT }\end{array}$ & $\begin{array}{l}\text { Atua indevidamente } \\
\text { para as fases sãs para } \\
\text { curtos próximos às } \\
\text { barras }\end{array}$ & $\begin{array}{c}\text { Atua indevidamente } \\
\text { para as fases sãs para } \\
\text { curtos próximos às } \\
\text { barras }\end{array}$ \\
\hline & Curto Bifásico & - & - & - & - \\
\hline \multirow{2}{*}{$\begin{array}{c}\text { Variação da } \\
\text { Resistência de } \\
\text { Falta }\end{array}$} & Curto Monofásico & - & $\begin{array}{l}\text { Não atua para } \\
\text { resistência de falta } \\
\text { superior a } 110 \Omega\end{array}$ & - & - \\
\hline & $\begin{array}{c}\text { Curto Bifásico- } \\
\text { Terra }\end{array}$ & - & - & - & - \\
\hline \multirow{3}{*}{$\begin{array}{l}\text { Variação do } \\
\text { Carregamento } \\
\text { do Sistema }\end{array}$} & Curto Monofásico & - & $\begin{array}{l}\text { Não atua para } \\
\text { nenhum } \\
\text { carregamento } \\
\text { simulado }\end{array}$ & - & - \\
\hline & Curto Bifásico & - & - & - & - \\
\hline & $\begin{array}{c}\text { Curto Bifásico- } \\
\text { Terra }\end{array}$ & - & - & - & - \\
\hline \multirow{2}{*}{$\begin{array}{c}\text { Variação da } \\
\text { Força da Fonte } \\
\text { Local }\end{array}$} & Curto Monofásico & - & $\begin{array}{c}\text { Não atua para } \\
\text { impedâncias } \\
\text { superiores a } 70 \% \text { do } \\
\text { valor nominal }\end{array}$ & - & - \\
\hline & Curto Bifásico & - & - & - & - \\
\hline \multirow{2}{*}{$\begin{array}{l}\text { Variação da } \\
\text { Força da Fonte } \\
\text { Remota }\end{array}$} & Curto Monofásico & - & $\begin{array}{c}\text { Não atua para } \\
\text { impedâncias } \\
\text { superiores a } 70 \% \text { do } \\
\text { valor nominal }\end{array}$ & - & - \\
\hline & Curto Bifásico & - & - & - & - \\
\hline
\end{tabular}




\section{REFERÊNCIAS BIBLIOGRÁFICAS}

ADAMIAK, M. G.; ALEXANDER, G. E.; PREMERLANI, W. A New Approach to Current Differential Protection for Transmission Lines, presented at the Electric Council of New England, Protective Relaying Committee Meeting, October 22-23, 1998, Portsmouth, NH.

ANDERSON, P.M. Power System Protection. Piscataway, New Jersey, EUA. John Wiley \& Sons, Inc., Publication, 1999.

AGÊNCIA NACIONAL DE ENERGIA ELÉTRICA (ANEEL). Chamada $n^{\circ}$ 005/2008 - Projeto Estratégico: Alternativas não convencionais para transmissão de energia elétrica em longas distâncias. Brasília, DF, 2008. Projeto de Pesquisa e Desenvolvimento Estratégico.

ARAÚJO, A. E. A.; NEVES, W. L. A.; Cálculo de Transitórios Eletromagnéticos em Sistemas de Energia, Universidade Federal de Minas Gerais, 2005.

BHALJA B.; MAHESHWARI R. P. Wavelet Transform Based Differential Protection Scheme for Tapped Transmission Line. Industrial Technology, 2006. ICIT 2006. IEEE International Conference, Mumbai 2006.

BHATTI, A. A. Performance Analysis of Microcomputer Based Differential Protection of UHV Lines Under Selective phase Switching, IEEE Transactions on Power Delivery, Vol. 5, No. 2 , pp 556-566, April 1990.

BI, T. S.; YU, Y. L.; HUANG, S. F.; YANG, Q. X. An Accurate Compensation Method of Distributed Capacitance Current in Differential Protection of UHV Transmission Line, 2005 IEEE PES General Meeting, Volume 1-3 pp: 770-774 Published: 2005.

BIN, L.; WENHUA, C.; JIALI, H.; ZHIQIAN, B. Special Problems in Current Differential Protection Based on Bergeron Model, 2009 Asia-Pacific Power and Energy Engineering Conference, March 2009.

DAHANE A. S.; DAMBHARE S. S. A Novel Algorithm for Differential Protection of Untransposed Transmission Line Using Synchronized Measurements. Developments in Power Systems Protection, 2012. DPSP 2012. 11th International Conference, Birmingham, UK, 2012.

DAMBHARE S.; SOMAN S. A.; CHANDORKAR M. C. Adaptive Current Differential Protection Schemes for Transmission-Line Protection. IEEE Transactions on Power Delivery, Vol. 24, No. 4, October 2000.

DAMBhare S.; SOMAN S. A.; CHANDORKAR M. C. Current Differential Protection of Transmission Line Using the Moving Window Averaging Technique. IEEE Transactions on Power Delivery, Vol. 25, No. 2, April 2010. 
EPE. Projeção da Demanda de Energia Elétrica. Rio de Janeiro, 2011.

ERNST L. J.; HINMAN W. L.; QUAM D. H.; THORP J. S. Charge Comparison Protection of Transmission Lines - Relaying Concepts. IEEE Transactions on Power Delivery, Vol. 7, No. 4, October 1992.

FLACK, E. Desempenho da Proteção Diferencial de Transformadores em Sistemas de Potência. Dissertação de Mestrado, Universidade Federal do Rio de Janeiro, Rio de Janeiro, Brasil, 2008. GAJIÉ, Z.; BRNĚIÉ, I.; RIOS, F. Multi-Terminal Line Differential Protection With Innovative Charging Current Compensation Algorithm. Developments in Power System Protection (DPSP), April 2010.

GONÇALVES, E.M. Metodologias para Validação de Proteções de Linhas de Transmissão. Dissertação de Mestrado, Universidade Federal de Minas Gerais, Belo Horizonte, Brasil, 2012.

HALL, I.; BEAUMONT, P.G.; SHUTO, I.; SAGA, M.; OKUNO, K.; BABER, G. P.; ITO, H. New Line Current Differential Relay Using GPS Synchronization. IEEE Bologna Power System Tech Conference. Bologna, Italy, 2003.

HART, D. G.; NOVOSEL, D.; SMITH, R. A. Modified Cosine Filters. Nov 2000. U.S. Patent $6,154,687$.

KASZTENNY, B.; BenMOUYAL G.; ALTUVE H. J.; FISCHER N. Tutorial on Operating Characteristics of Microprocessor-Based Multiterminal Line Current Differential Relays. Schweitzer Engineering Laboratories, Inc., 2011.

LEUVEN EMTP CENTER. ATP - Alternative Transient Program: Rule book. Herverlee, Belgium, 1987.

LI, C.; HE, J.; HU, J.; ZENG, R.; YUAN, J.; Switching Transient of 1000-kV System Considering Detailed Substation Structure, IEEE Trans. Power Del., vol. 27, no. 1, pp. 0885-0895, January 2012.

MCLAREN, P. G.; MCCONNACH, J. S. Sampling techniques applied to the derivation of impedance characteristics for use in power-system protection. Electronics Letters, p. 10-11, March 1965.

MANN, B. J.; MORRISON, I. F. Digital calculation of impedance for transmission line protection. IEEE Transactions on Power Apparatus and Systems, PAS 90, p. 270-278, Jan. 1971.

MILLER, H.; BURGER, J.; FISCHER, N.; KASZTENNY, B. Modern Line Current Differential Protection Solutions, proceedings at the 63rd Annual Conference for Protective Relay Engineers, March 2010. 
MOLAS, E. C.; SILVA, K.M. Modelagem e Simulação da Proteção Diferencial de Linhas de Transmissão no ATP. IV Simpósio Brasileiro de Sistemas Elétricos. Goiânia, Brasil, 2012.

MOLAS, E. C. Modelagem da Proteção Diferencial de Linhas de Transmissão com Análise no Plano Alfa Usando o Software ATP. Trabalho de Conclusão de Curso, Universidade de Brasília, Brasília, Brasil, 2012.

MOLAS, E. C.; ALVES, R. S. B.; SILVA, K. M. Análise da Influência da Corrente Capacitiva no Desempenho da Proteção Diferencial de Linhas de Transmissão de UAT. V Simpósio Brasileiro de Sistemas Elétricos. Foz do Iguaçu, Brasil, 2014.

MUNHOZ, C. D. Modelagem e Simulação da Proteção Diferencial de Linhas de Transmissão no Software ATP. Trabalho de Conclusão de Curso, Universidade de Brasília, Brasil, 2011.

NAVARRO, E. C.; ORDACGI, J. M.; COURY, D. V.; MENEZES, R. Proteção Diferencial de Linhas de Transmissão Análise no Plano $\alpha$. VII Seminário Técnico de Proteção e Controle (STPC), Rio de Janeiro, Brasil, 2003.

OPERADOR NACIONAL DO SISTEMA ELÉTRICO (ONS), Procedimentos de Rede - Submódulo 2.6: Requisitos Mínimos para os Sistemas de Proteção e Telecomunicações. Brasília, 2011. OPERADOR NACIONAL DO SISTEMA ELÉTRICO (ONS), Análise Estatística dos Desligamentos Forçados de Componentes do Sistema Elétrico Brasileiro Referente ao Ano de 2012. Brasil, 2013.

PAITHANKAR, Y.G. Transmission Network Protection: Theory and Pratice, Marcel Dekker INC., New York, 1998.

PAITHANKAR, Y.G.; BHIDE, S.R. Fundamentals of Power System Protection, Prentice-Hall, New Delhi, 2007.

PIRES, V. F.; GUERREIRO, M. A. A Current Differential Line Protection Using a Synchronous Reference Frame Approach. Developments in Power System Protection, Glasgow UK, 2008.

REBIZANT W.; SOLAK K. Transmission Line Differential Protection with Fuzzy Signal Processing Support. Electrical and Electronics Engineering (ELECO), 7th International Conference, Bursa 2011.

REN Y. L.; BO Z. Q.; HE J. H.; KLIMEK A. An Integrated Relay for Differential Protection of Transmission Lines. Power System Technology and IEEE Power India Conference, 2008. POWERCON 2008. Joint International Conference, New Delhi, 2008.

SAADAT, H. Power System Analysis. 3. Ed. USA: PSA Publishing, 2010.

SANAYE-PASAND M.; JAFARIAN P. Adaptive Protection of Parallel Transmission Lines Using Combined Cross-Differential and Impedance-Based Techniques. IEEE Transactions on Power Delivery, Vol. 26, No. 3, July 2011. 
SANTOS, L.F. Avaliação de Algoritmos Numéricos de Proteção para Linhas com Compensação Série. Dissertação de Mestrado, Universidade Federal de Itajubá, Itajubá, Brasil, 2006.

SEZI, T.; STRUECKER, O. L. A.; CHAGAS, M. Aspectos Práticos e Experiências de Campo no Uso de Relés Diferenciais de Linha Utilizando Sistemas Complexos de Telecomunicação e suas Influências. Seminário Técnico de Proteção e Controle (IX STPC), Belo Horizonte, Brasil 2008 .

SILVA, K. M. Estimação de Fasores Baseada na Transformada Wavelet para Uso na Proteção de Distância de Linhas de Transmissão. Tese de Doutorado, Universidade Federal de Campina Grande, Campina Grande, Brasil, 2009.

SUN, S. C.; RAY, R. E. A Current Differential Relay System Using Fiber Optics Communications. IEEE Transactions on Power Apparatus and Systems, Vol. PAS-102, No. 2, February 1983.

THOMPSON, M. J. Percentage restrained differential, percentage of what? Schweitzer Engineering Laboratories, 2011 64th Annual Conference for Protective Relay Engineers, College Station, TX, April 2011.

TZIOUVARAS, D. A.; AltUVE, H.; BenMOUYAL, G.; ROBERTS, J. Transmission Line Differential Protection with an Enhanced Characteristic. SEL, Dez. 2004.

VIANNA, P.L. Modelagem e Simulação da Proteção Diferencial de Baixa Impedância de Barramentos no Software ATP. Dissertação de Mestrado, Universidade de Brasília, Brasília, 2013.

WARD, S.; ERWIN, T. Current Differential Line Protection Setting Considerations. RFL Eletronics Inc. Boonton, New Jersey, 1993.

XU, Z. Y. ; DU, Z. Q.; RAN, L. ; WU, Y. K.; YANG, Q. X.; HE, J. L. A Current Differential Relay for a 1000-kV UHV Transmission Line, IEEE Trans. Power Del., vol. 22, no. 3, pp. 13921399, July 2007.

XUE, Y.; FINNEY, D.; LE, B. Charging Current in Long Lines ans High-Voltage Cables Protection Application Considerations. SEL, 2012.

ZHANG, J.; YUAN, Z.; GUO, Z. Study of the Entire Current Differential Protection of EHV Transmission Lines Based on Electronic Transducer. IEEE PES General Meeting, July 2008.

ZIEGLER, G. Numerical Distance Protection: Principles and Applications. 2. ed. Berlin, Germany: Siemens, AG, 2006.

ZIEGLER, G. Numerical Differential Protection: Principles and Applications. Siemens, Publicis Corporate Publishing, Germany, 2005. 


\section{APÊNDICE A}

\section{ENTRADA DA ROTINA LINE CONSTANTS DO ATP}

No quadro abaixo, é apresentado o cartão ATP que utiliza a rotina Line Constants para se obter os parâmetros da linha de transmissão em análise neste trabalho.

Quadro 8.1 - Cartão ATP da Rotina Line Constants

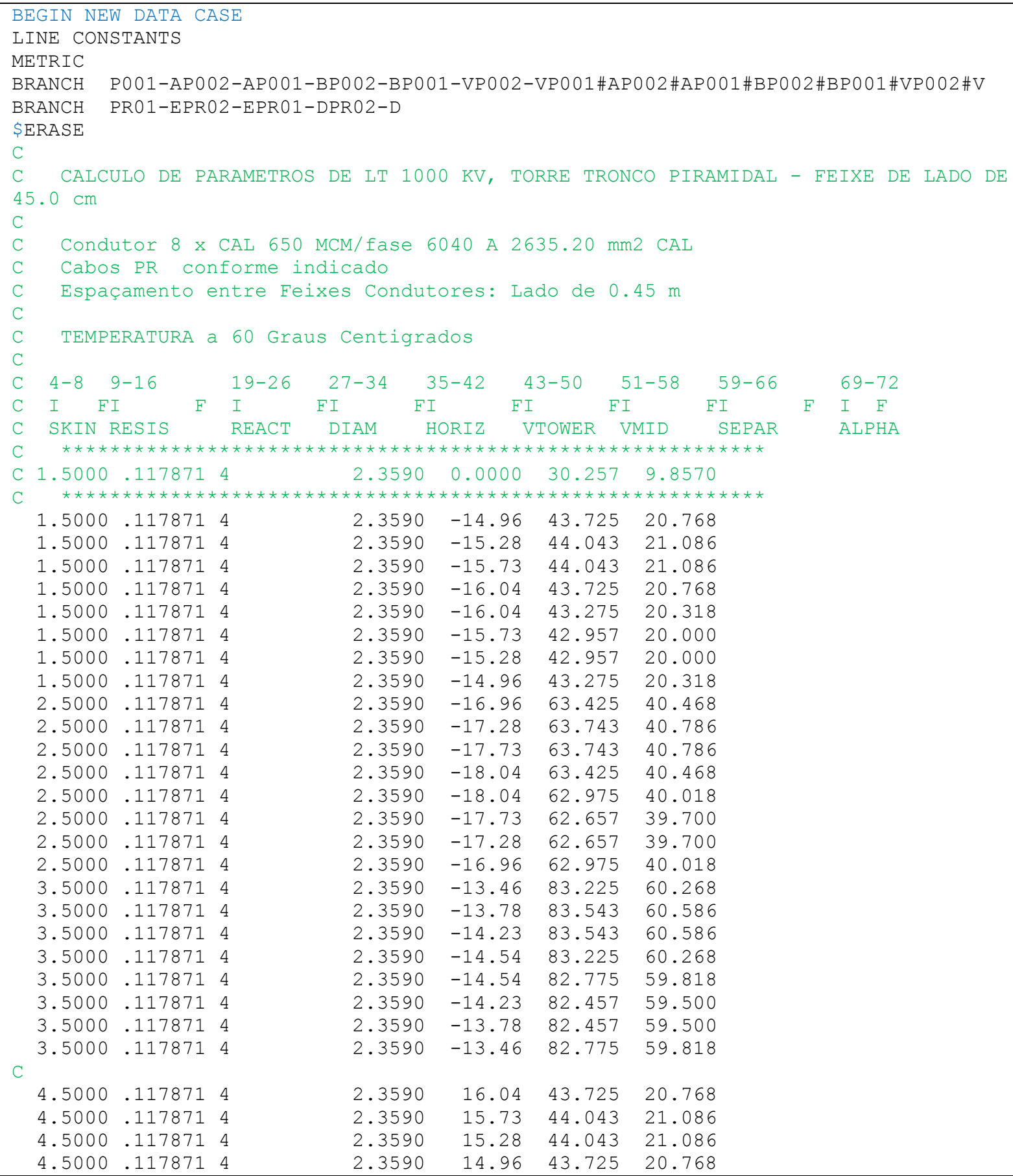




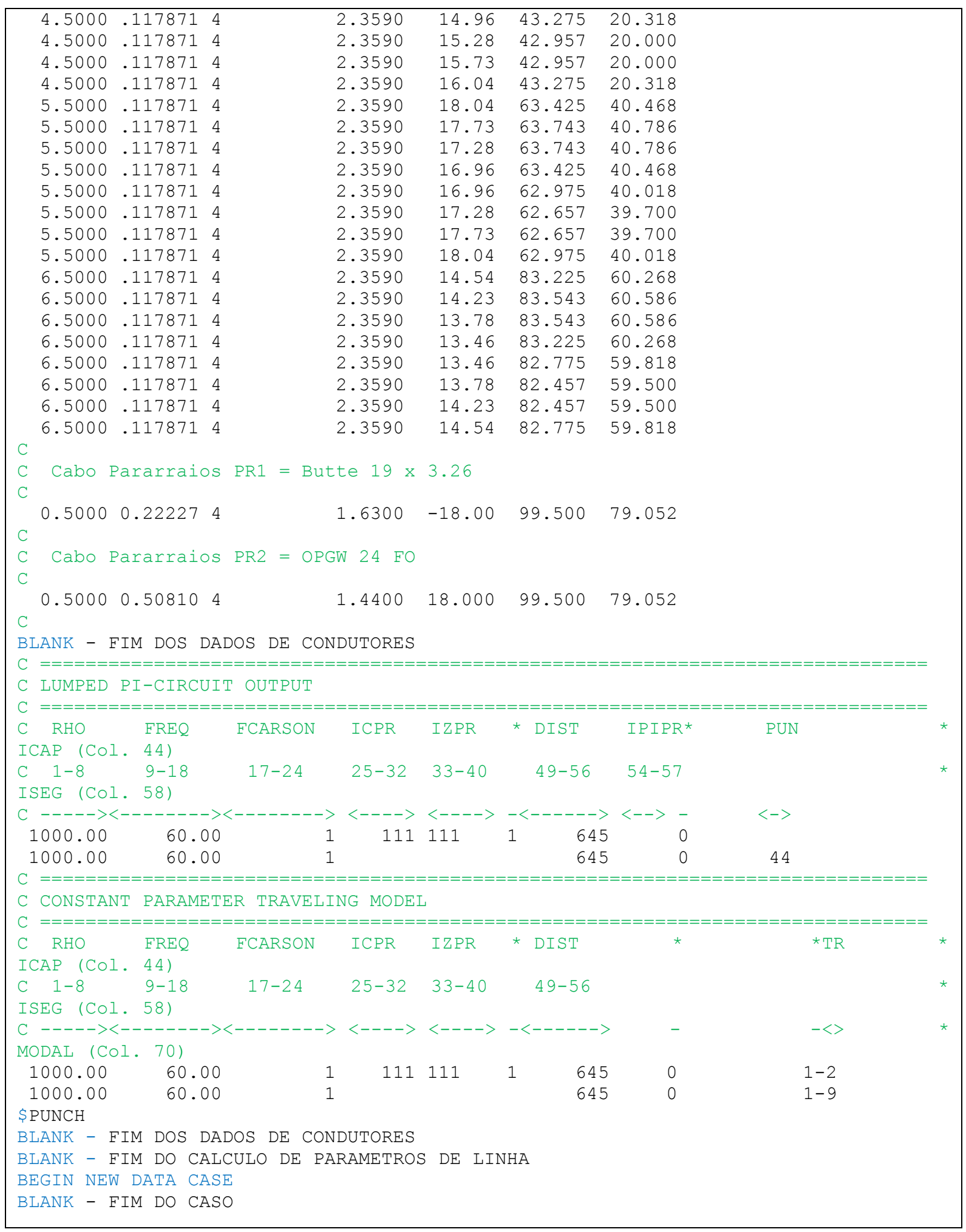




\section{APÊNDICE B}

\section{ARQUIVO ATP}

No quadro abaixo, é apresentado o cartão ATP utilizado na análise realizada neste trabalho.

Quadro 8.2 - Cartão ATP do Sistema Analisado

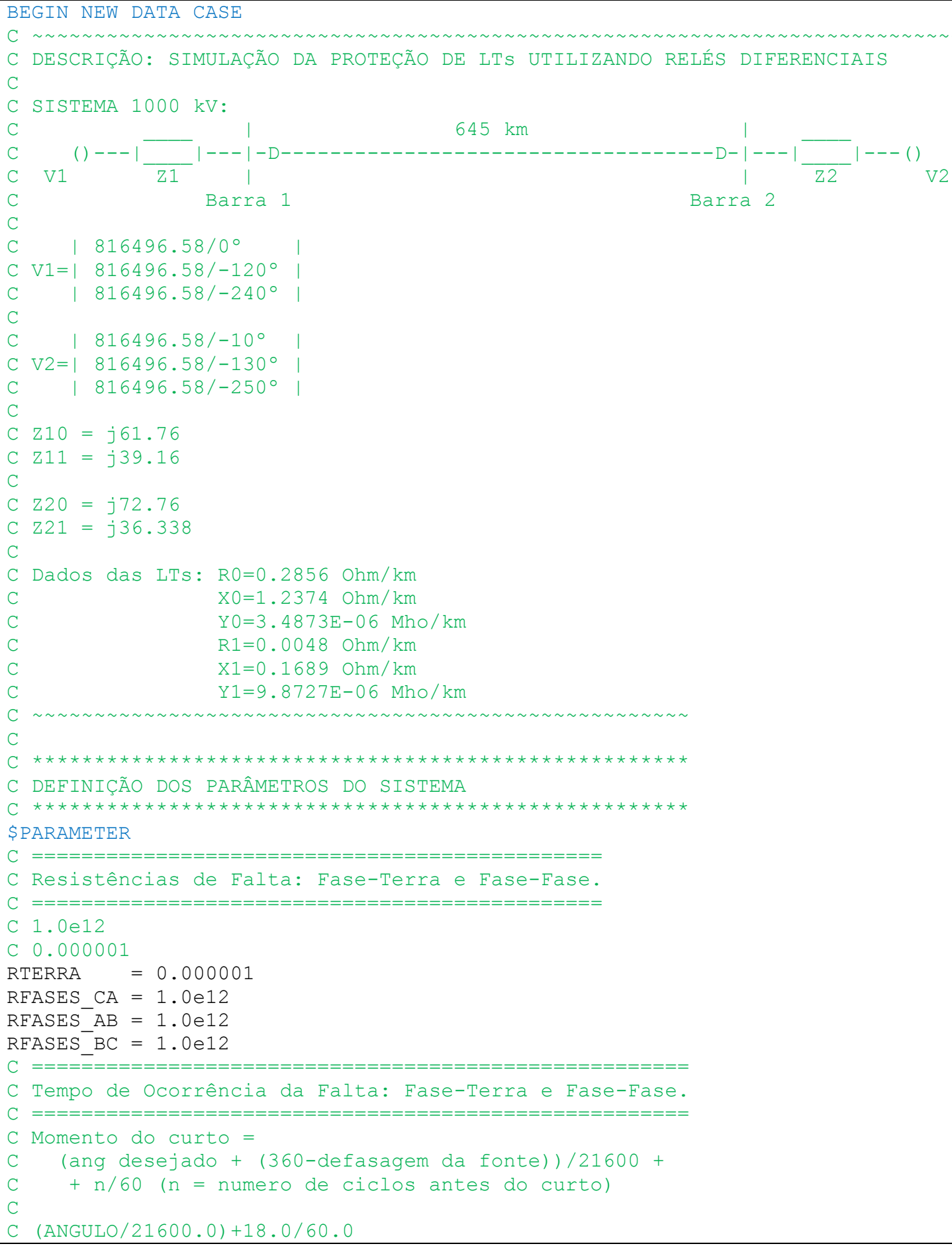




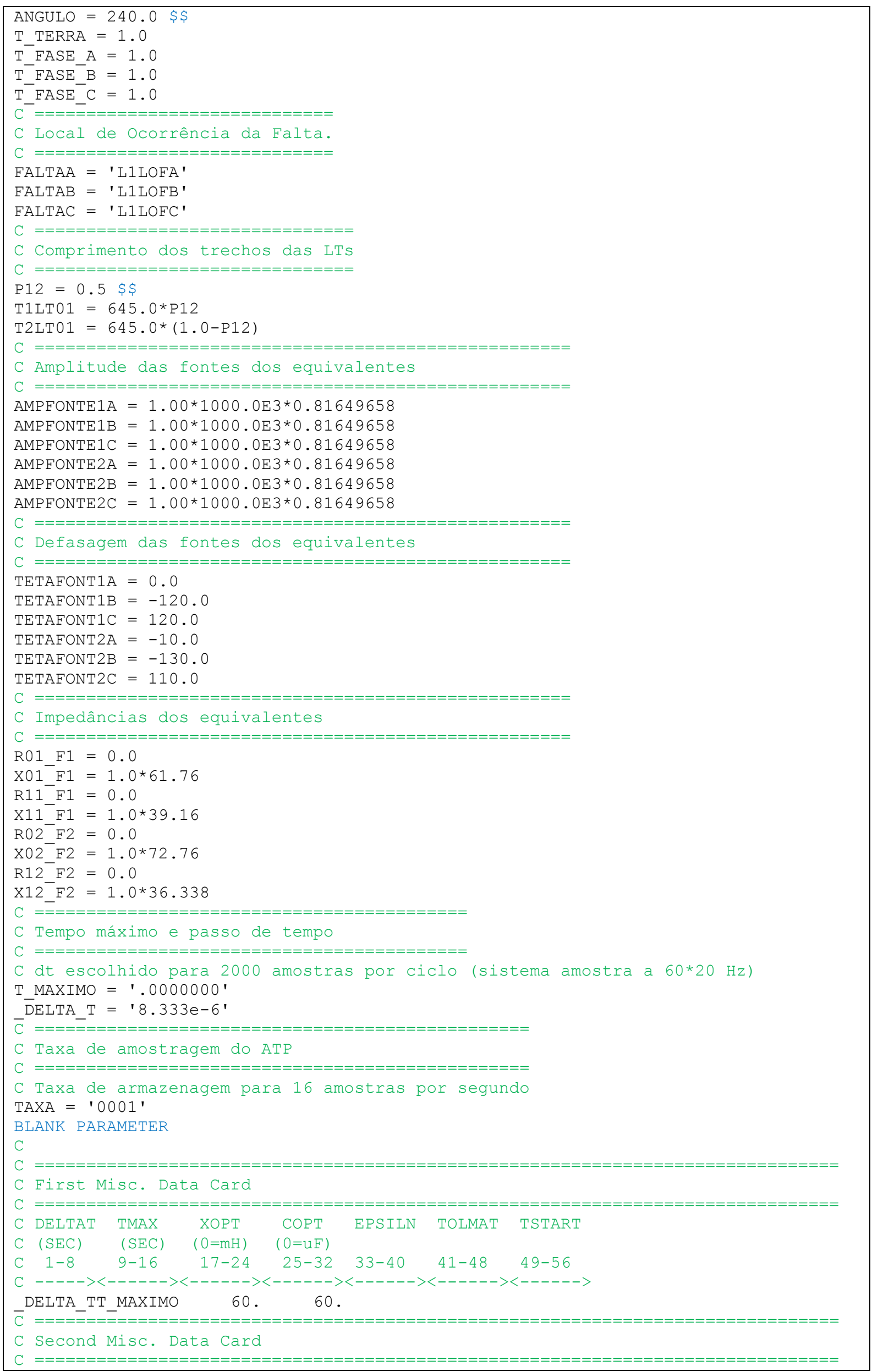




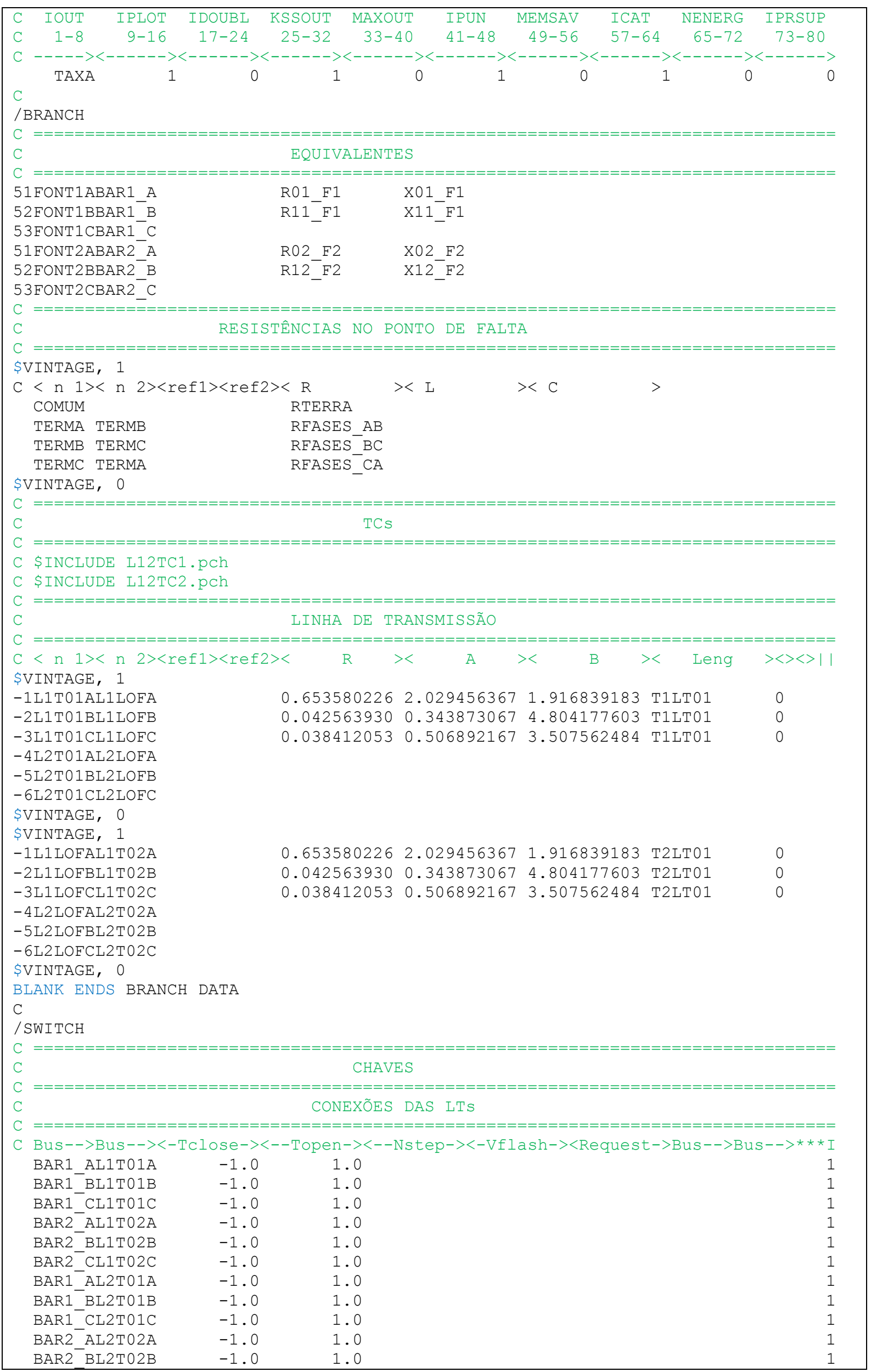




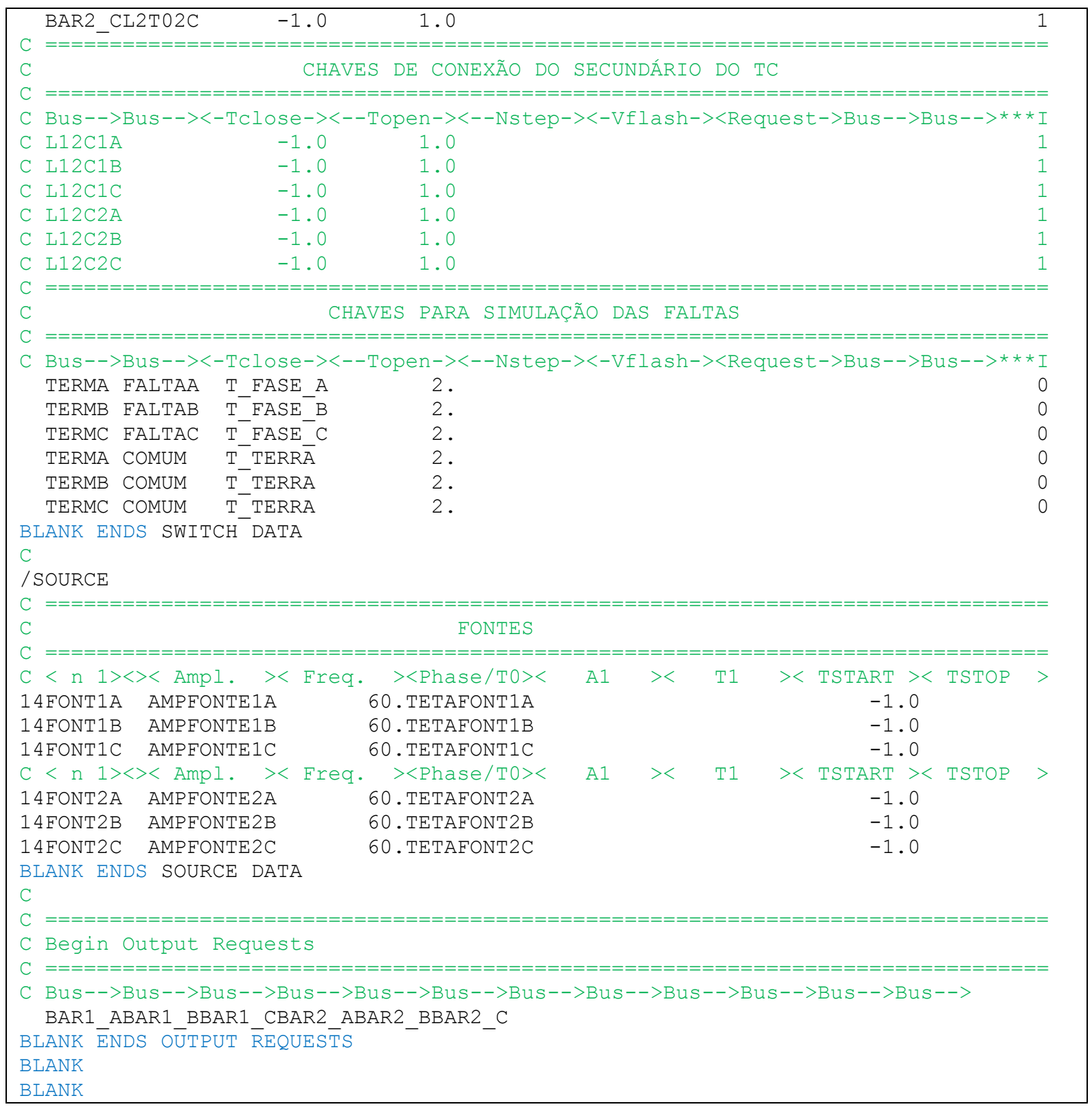

